\title{
A Critical Review of Ground Based Observations of Earthquake Precursors
}

\author{
Livio Conti ${ }^{1,2 * t}$, Piergiorgio Picozza ${ }^{1,2,3 t}$ and Alessandro Sotgiu ${ }^{2,3 t}$ \\ ${ }^{1}$ Uninettuno University, Rome, Italy, ${ }^{2}$ INFN - Sezione Roma Tor Vergata, Rome, Italy, ${ }^{3}$ Department of Physics, University of Rome \\ "Tor Vergata," Rome, Italy
}

OPEN ACCESS

Edited by:

Dimitar Ouzounov,

Chapman University, United States

Reviewed by:

Michel Parrot,

UMR7328 Laboratoire de Physique et Chimie de l'Environnement et de

l'Espace (LPC2E), France

Angelo De Santis,

University of Studies G. d'Annunzio

Chieti and Pescara, Italy

Sergey Alexander Pulinets,

Space Research Institute (RAS),

Russia

*Correspondence:

Livio Conti

livio.conti@uninettunouniversity.net

tThese authors have contributed equally to this work

Specialty section:

This article was submitted to

Geohazards and Georisks,

a section of the journal

Frontiers in Earth Science

Received: 08 March 2021 Accepted: 16 June 2021

Published: 06 July 2021

Citation:

Conti L, Picozza P and Sotgiu A (2021) A Critical Review of Ground Based

Observations of

Earthquake Precursors.

Front. Earth Sci. 9:676766.

doi: 10.3389/feart.2021.676766
We aim at giving a short review of the seismo-associated phenomena detected on ground that in recent years have been investigated as possible earthquake precursors. The paper comes together with a companion article-published on this same volume by Picozza et al., 2021-devoted to summarize the space-based observation of earthquake-precursors by satellites missions. In the present work, we give an overview of the observations carried out on ground in order to identify earthquake precursors by distinguishing them from the large background constituted by both natural non-seismic and artificial sources. We start discussing the measurements of mechanical parameters and variations of geochemical fluids detected before earthquakes; then we review thermal and atmospheric oscillations; finally, observations of electromagnetic and ionospheric parameters possibly related to the occurrence of impeding earthquakes are discussed. In order to introduce a so large field of research, we focus only on some main case studies and statistical analyses together with the main hypotheses and models proposed in literature in order to explain the observed phenomenology.

Keywords: earthquake precursors, LAIC mechanism, preseismic phenomena, radon, AGW-acoustic gravity waves, DEMETER, Swarm, CSES

\section{INTRODUCTION}

Earthquake prediction is the Saint Graal of seismology, but the study of possible earthquake precursors should be better regarded in the framework of fundamental geophysics more than in trying to guess the future (Ouzounov et al., 2018; Hough, 2020). Several authors have analyzed data and many papers have been published with claims ranging from (by chance) observations of spatial and temporal correlations - cautiously interpreted as possible earthquake precursors - up to the proposal of methods and procedures (never confirmed) aimed at forecasting earthquakes. The realm of studied earthquake precursors includes a variety of physical parameters ranging from mechanical deformation up to gas emissions; from variations of groundwater levels up to fluctuations of electromagnetic field (in a large spectrum of frequencies, possibly radiated, induced or generated as secondary effect of other primary perturbations); from variations of ground temperature up to fluctuations of ionospheric and magnetospheric parameters. The first reports about correlation between impending earthquakes and electromagnetic emissions date back to Varotsos (1981) (even though highly debated), Gokhberg et al. (1982) and Warwick et al. (1982). About 50 years ago, the successful short-term prevision of the strong Haicheng (China) earthquake (Lomnitz, 1994) as well as the failure in forecasting the event of Tangshan (China) (Lomnitz, 1994)-even though of comparable intensity - have started a swinging wave of hopes and delusions about the possibility that seismic events 
could be effectively forecasted (Turcotte, 1991; Uyeda et al., 2009b). Many measurements, claimed as earthquake precursors, have been carried out (occasionally or even by systematic observation campaigns) on single earthquakes (case studies). Unfortunately, only a few of them were repeated/reproduced in occasion of other seismic events (such as for example Hattori et al., 2013; Liu et al., 2010; Davidenko and Pulinets, 2019) so that the observations of these cases studies are in some aspect often "unique" and scattered in the panorama of earthquake precursor investigations. For example, some early observations have suggested that, before strong earthquakes, the focal area could generate and radiate detectable electromagnetic signals in a large range of frequency. Two hours before the $M=9.2$ Alaska earthquake of 1964 - one of the largest ever recorded seismic event in the era of regular seismological recording-Davies and Baker (1965) reported a strong ionospheric anomaly at about $4-5 \mathrm{MHz}$, recorded at Boulder, Colorado. Another "classical" case study was the measurement of fluctuations in magnetic field data (in ultra-low frequency range) carried out a couple of weeks (and then some hours) before the Loma Prieta earthquake (magnitude 7.1) on 1989 (Fraser-Smith et al., 1990). A less numerous type of analysis is constituted instead by statistical studies, performed by applying a given data analysis procedure to an ensemble (more or less statistically significant) of seismic events. In this framework, a systematic effort have been carried out by USGS along the San Andreas Fault at Parkfield, CA, by installing creep and strain meters, groundwater level detectors, magnetometers, etc. (Bakun and Lindh, 1985), but gathered data and results have not allowed to forecast any seismic event (Langbein et al., 2005). The most decidedly adverse perspective, mainly from the seismology and geodesy point of view, was summarized by Geller according to whom: $<<$ results in nonlinear dynamics are consistent with the idea that earthquakes are inherently (or actually) unpredictable because of the highly sensitive nonlinear dependence on initial conditions >> (Geller, 1997), while indirectly Uyeda replied that: $<<$ There are reasons for this pessimism because mere conventional seismological approach is not efficient for this aim. Overturning this situation is possible only through multidisciplinary science $>>$ (Uyeda et al., 2009b). This paper aims at presenting a critical overview of earthquake precursors observed on ground and the related analyses published in literature trying to point out their own characteristics (physical parameters, intensity, duration, background, etc.) and possible connection to the earthquake magnitude. We will also summarize some of the physical models proposed to reconcile the observed phenomenology with the physics of earthquake even though a scientific consensus of which could be preferable is still missing. We address the reader to the paper (Picozza et al., 2021) published in this same issue that provides a review of satellite-based observations and more in general of earthquake precursors in space.

\section{SUMMARY OF CLAIMED GROUND-BASED EARTHQUAKE PRECURSORS}

Even though our review does not pretend to be exhaustive of earthquake precursors on ground, we tried to select them between the most reliable ones published in literature. In the following, we will discuss several types of precursors that suggest an effective lithosphere-atmosphere-ionosphere-magnetosphere coupling, such as:

1) Seismicity that is the most extensively studied phenomenology before, during and after earthquakes (Mignan 2008; Hong et al., 2018; De Santis et al., 2019b). Also extreme low frequency acoustic emissions have been claimed (see for example Ihmlé and Jordan, 1994) to constitute earthquake precursors before the main rupture at a higher frequency.

2) Lithospheric mechanical deformations, such as those detectable with creep- and stain-meters (Niu et al., 2008; Langbein, 2015).

3) Variation of the groundwater level and composition, reported some weeks up to few hours before earthquakes (Hayakawa et al., 1997; Koizumi et al., 1999).

4) Gas exhalations, mainly (but not only) of radon or radioactive ions induced by gas-water release from earthquake preparation zone into the atmosphere (Khilyuk et al., 2000; Pulinets et al., 2003).

5) Fluctuations of temperature observed in temporal correlation with some earthquakes and possibly reconciled with variation of groundwater circulation and uplift or more recently with vapour condensation on surface (Tramutoli et al., 2005).

6) Propagation of acoustic gravity waves (AGW) (Molchanov and Hayakawa, 2008), A physical mechanism of seismoionospheric coupling including both $\mathrm{AGW}$ and radon exhalation has been recently suggested (Rapoport et al., 2020).

7) Fluctuation of electric and magnetic field components in a large range of frequencies [from ULF (Uyeda, et al., 2009b; Han et al. (2014)] to VHF (Sorokin et al., 2020). Many observations have been reported on ground and in space of (direct, induced and secondary) electromagnetic emissions localized on the earthquake area or measured along the related field line or spread around it.

8) Ground based observations of ionospheric parameters [such as Total Electron Content (TEC) (Liu et al., 2004; Liu, 2009), VLF reflection height (Hayakawa et al., 1996, 1997; Rodger et al., 1999), whistler dispersion (Hayakawa et al., 1993), critical frequency foF2 (Hobara and Parrot, 2005), etc.].

With the analysis of LEO satellite observations, the range of earthquake precursors investigations has been extended including measurements of disturbances of plasma parameters in the ionosphere-magnetosphere transition zone; thermal anomalies; AGW; precipitation of particles from the inner Van Allen belt (see Picozza et al., 2021 and references therein).

For each type of precursors listed above, we will try to discuss the main related information such as earthquake parameters (including time, location, magnitude and depth), time of the measured precursor, duration of the disturbance, amplitude, signal-to-noise ratio, distance from the epicentre, etc. Moreover, we have catalogued the physical models proposed in literature in order to verify which of them could better explain the phenomenology of the precursors and can reconcile the 
observed disturbances with the earthquake properties such as magnitude, momentum, focal mechanism, depth, etc.

\section{POSSIBLE MECHANICAL, GEOCHEMICAL AND THERMAL PRECURSORS OF EARTHQUAKES}

The earthquake precursors observed on ground can be generally categorized in two main groups: non-electromagnetic precursors and electromagnetic ones. In this section, we will review observations of the first type that includes mechanical, geochemical and thermal anomalies.

\section{Seismicity and Observation of Local Mechanical Deformations}

In the seismic sequence-often associated to large earthquakes-the main shock is frequently preceded by foreshocks of lower magnitude (Jones and Molnar, 1976; Reasenberg, 1999). Foreshocks occur within a variable time interval from the main earthquake (even though often with an increased frequency before the main shock) and spatially near to the epicentre of the main event (Sornette and Sornette, 1989; BenZion et al., 2003). Scholz (2019) suggested that foreshocks are part of the nucleation process resulting in the main seismic event and that, in some sequence, dilatancy could induce seismic energy release and explain short-term quiescence just prior to the main event (Press and Siever, 1982; Allegri et al., 1983; Lomnitz, 1994; Sgrigna and Malvezzi, 2003). A systematic worldwide study of foreshock catalogues for low magnitude earthquakes is a challenge due to the uneven threshold in seismic measurements around the world. It has been suggested that the foreshock occurrence and the claimed earthquake precursors (such as radon release, electromagnetic anomalies, groundwater level variations, etc.) could be correlated through some physical mechanism (De Santis 2014; Varotsos et al., 2019). After a strong earthquake, the aftershock sequence normally decays and the occurrence probability of a subsequent larger event is of a few per cent Gulia, and Wiemer (2019). Anyway, this probability is a function of the stress conditions due to previous earthquakes and long-term tectonic conditions. In this framework, foreshocks can give valuable information about the process in action (see Console et al., 1993; Avlonitis and Papadopoulos 2014; and references therein), but earthquake catalogues are still uncomplete and foreshock interpretation for earthquake forecasting is highly debated. Attempts to predict the next large earthquake, based on physical models and Coulomb stress transfer, have been unsuccessful due in part to incomplete knowledge of the location of faults Nanjo (2020). Gulia and Wiemer (2019) suggested that in some cases it would be possible to distinguish between decaying aftershock sequences and foreshocks preceding a large event. Gulia and Wiemer (2019) proposed that the probability of larger subsequent event is higher for seismic sequences diverting from the generally observed increase of $b$ value after a mainshock. Anyway, the authors consider preliminary their results due to the reduced number of events analyzed $(M>6$ with high dense seismic networks coverage). More recently, Trugman and Ross (2019) suggested that more than $70 \%$ of all mainshocks in Southern California was preceded by foreshocks, but van den Ende and Ampuero (2020) objected that only a percentage between 18 and $33 \%$ of mainshocks were preceded by significantly elevated seismicity rates. Several authors have reported surface deformations, such as tilt, strain, uplifts and downdrops, etc., measured before earthquakes of medium and high magnitude (Rikitake, 1987; Lomnitz, 1994). Some mechanical models Tse and Rice (1986) and Lorenzetti and Tullis (1989), etc. have been proposed in order to predict surface deformation possibly associated to the earthquake preparation phase. They need to describe the fault mechanical dynamics through constitutive relationships and to study the friction along the fault (Dieterich 1978; Dieterich, 1979; Ruina, 1983) in order to estimate if the induced strain rate, displacement, velocity, etc. are below the detectability threshold for the available instruments and experimental methodology. The results suggest that-due to signal-to-noise ratio, with respect to the intrinsic background-the strain rate is the most reliable observable. These investigations today can take advantage of temporal high-frequency sampling and spatial high-resolution measurements with GPS and SAR interferometry with satellites, in particular at low orbit. In the case of Amatrice earthquake, Panza et al. (2018) reported an increase of the deformation velocity for a transect ( $500 \mathrm{~km}$ wide) moving eastward, along the direction of tectonic extension (from Tyrrhenian to Adriatic coast). The velocity gradient has a peak localized in the Amatrice area (not observed for transects to the North and South). For further case studies see for example (Wright, 2016; Moro et al., 2017; Panza et al., 2018) and references therein. Even though the intensity of the measured deviations-carried out within some hundreds of kilometres from the epicentres-seems related with the earthquake magnitude, the claimed identification of these observations as earthquake precursors is not conclusive.

\section{Variation of Geochemical Fluids: Release of Gas and Groundwater Level Fluctuations}

Starting from the sixties, several reports have been published about a claimed increase of radon concentration before earthquakes (Lomnitz, 1994). The hypothesis is that an increase of compressional stresses could open and/or close micro-fractures and cracks facilitating radon exhalation of radon up to the surface together with the flow of groundwater carbon dioxide, methane, helium, etc. (Wakita et al., 1980; Teng et al., 1981; Biagi et al., 2001b). The ${ }^{222} \mathrm{Rn}$ is the most stable radon isotope, a noble radioactive gas generated by the alpha decay of Radium 226, with a half-life of about 3.8 days (Bé et al., 2011). ${ }^{222} \mathrm{Rn}$ is water soluble, with low concentration in surface water-due to the continuous release in the atmosphere- and higher concentration in deep groundwater. For this reason, the variation of concentration of ${ }^{222} \mathrm{Rn}$ has been studied as a marker of tectonic processes and proposed as a possible short-term precursor of seismic events (see for example Richon et al., 2003; Omori et al., 2007; Alam et al., 2020). 


\section{Physical Mechanisms for Correlating Gas Exhalation and Seismic Activity}

The variety of models suggested in order reconciling the observed radon exhalations with physical mechanisms driven by seismicity can be summarized into 1) releases induced by ultrasonic vibrations; 2) pressure-induced change of solubility; 3) collapses of pores; 4) development of new pores; and 5) fluid mixing in depth (Thomas, 1988).

1) According to the vibrational model, gas releases would be induced, or facilitated, by ultrasonic vibrations of rocks. Even though this mechanism has been tested in laboratory and during artificial explosions in seismic explorations, the power density of natural seismic spectra at high frequencies could not be enough for explaining the phenomenology of the seismo-associated exhalations. Moreover, releases induced by seismicity are more intense than the explosion induced ones, and these, besides, can follow (instead of precede) the rupture events.

2) It has been suggested that gases emissions could be induced by variations of solubility due to an increase of the fluids pressure during the earthquake preparation phase, but the mechanism would not be effective because the required increase seems too high to be transferred to the fluid phase (Cicerone et al., 2009).

3) The collapse of the pores volume due to the stress increase of the incoming earthquake region has been also claimed to induce gases release in groundwater. Even though observed in some laboratory tests, this mechanism is questionable because, generally, high stress values on porous rocks are effective in increasing the pores volume and the observed periodicity in the gas releases intensity is not easily reconcilable with the irreversible compression of pores.

4) A more effective role in gas exhalation could be played by the rocks dilatancy that can increase of tens and hundreds the rock porosity percentage (Brace, 1978; Bernabé et al., 2003; LongJohn et al., 2018): microfracturing both facilitates gas release from the rocks and increases the reaction ratio with ground waters through the growth of microscopic surfaces (Holub and Brady, 1981). On the other side, significant pores volume increases have been observed only near the rock failure strength, which would mean that the claimed mechanism could be effective only in the small volume of the seismic fault experiencing the rupture process, whereas gases releases have been observed even far from the epicentre (Pulinets and Ouzounov 2011).

5) The phenomenology of spread exhalations could be reconciled by invoking cracking due to corrosion and subs stage occurring at low stress with higher fluid content. Finally, it has been proposed that a mix of ground fluids and chemical elements between different aquifer systems could be the most effective mechanism for generating fluctuations (both positive and negative) of gas exhalation even because it explains also the temperature fluctuations some time measured together with radon exhalations (Byerlee, 1993). In this framework, the mechanism would have a role in the electrokinetic generation of low frequency electromagnetic emissions (Fenoglio et al., 1995) that will be discussed later.
All the physical models claimed to explain precursors share the hypothesis that fast and non-linear processes in the rocks along the seismic fault (such as deformation, dilatancy, fluids flow changes, pores volume variation, etc.) could originate the anomalous variations of observed parameters (Press and Siever, 1982; Lomnitz, 1994).

\section{Radon Exhalations}

The majority of the reports about significant variations of radon concentration was for moderate and strong magnitude seismic events (about $M \geq 4.0$ ), but fluctuations have been reported also for earthquakes of lower intensity. More than $80 \%$ of the measurements are constituted by increases of radon concentration with respect to the background reference value, with a distribution of the variations peaked between 50 and $100 \%$ and extending up to more than a thousand percent. The duration, as well as the beginning and ending time of the radon exaltation events, show a quite large variability-without a clear temporal distance with the claimed associated earthquake-that does not allow identifying time of radon exaltations as a sharp/reliable short-term earthquake precursor (Plastino and Bella 2001; Cicerone et al., 2009; Plastino et al., 2010; Sorokin et al., 2020). In fact, even though, in the majority of the cases, the anomalous fluctuations started within about one month before the earthquake and lasted less than about three months and a half, the statistics also includes radon exhalations ended before the earthquakes and/or continued after the seismic events (Pulinets and Ouzounov 2011). On the other side, Yasuoka et al. (2006) demonstrated that radon behaviour fits curve of the critical exponent (Sornette and Sammis, 1995).

The reported radon exhalations are more frequent near the epicentres, where also the highest variations have been measured. On the contrary, no significant correlation has been observed between the intensity and frequency of the gas exhalation from one side and the earthquake magnitude from the other one (Kissin and Grinevsky, 1990; Toutain and Baubron, 1999; Pulinets and Boyarchuk, 2005). That would suggest that, even though gas releases could be related to the seismic fault dynamics, their entity would not be correlated with the incoming earthquake intensity (Cicerone et al., 2009; Sorokin et al., 2020).

Both the advance in time of the radon exhalation (before the seismic event) and its duration are correlated with the earthquake magnitude, suggesting that bigger events are preceded by larger releases occurring more in advance (see for example the statistical study of Kissin and Grinevsky, 1990; Toutain and Baubron, 1999; as well as the most recent works Pulinets and Boyarchuk, 2005; Hartmann and Levy, 2005; Riggio and Santulin, 2015). This would furtherly support the Rikitake law of the empirical linearity between the logarithm of precursor time and the earthquake magnitude [see Figure 13 of Rikitake (1987)]. On the other side Pulinets and Ouzounov 2011 pointed out that the discrepancy between the claim that radon exhalations are a precursor to earthquakes (Toutain and Baubron, 1999; Omori et al., 2007; Pulinets, 2007) and the demonstration that radon releases are not a statistically reliable precursor (Geller, 1997) cannot be easily resolved with local measurement stations, due to 
the variety of measurement methods adopted worldwide and the uncertainty about the origin (crustal or mantle) of radon and the related transport models. Due to the difficulty of monitoring radon on the ground-with networks with high spatial resolution (Inan et al., 2008) over large areas (such as within and beyond the Dobrovolsky radius)-the authors suggested retrieving radon release (as well as methane, carbon dioxide and other geochemical fluids) indirectly, through remote sensing methods, from space-based observations of thermal infrared radiation, based on the LAIC model that correlates thermal anomalies with radon and other gas exhalations (Pulinets et al., 2006; Surkov, 2015; De Santis, et al., 2019b). However, the claim that closer to and on the eve of an earthquake a higher release should be observed is not yet confirmed and a statistical assessment of the true/false vs. positive/negative cases, through a reliable confusion-matrix based classification, is desirable. The recent statistical analysis of correlation between groundwater radon variations and seismo-tectonic activity of time series about the Wenchuan earthquake (Alam A. et al., 2020) would show a persistent trend with a notable upsurge just before and during the Wenchuan earthquake in the near stations not observed in the response of more distant monitoring stations.

\section{Measurements of Other Gas Emissions}

Radon is not the only gas studied looking for correlation between exhalations and earthquakes (Sugisaki, 1978; Chung, 1984; Sato et al., 1986; Claesson et al., 2004). The intensity of the exhalations strongly varies for different species such as methane, argon, carbon monoxide and di-oxide, helium, etc. (Kawabe, 1984; Satake et al., 1984; Varshal et al., 1984; Huixin and Zuhuang, 1986). Even though fewer and scattered (Tsunogai and Wakita, 1995; Toutain et al., 1997; Sugisaki et al., 1996; Amonte et al., 2021 and therein references), the measurements of other gases show statistical distributions and a functional dependences - from the (postulated) associated earthquake events - similar to those pointed out for the radon observations (Reimer, 1980; Reimer, 1990; O’Neil and King, 1980; Craig, 1980; Sugisaki and Sugiura, 1985; Sugisaki and Sugiura, 1986; Nagamine and Sugisaki, 1991). On the other side, whereas some gasses (such as hydrogen, helium to argon ratio and chlorine) show an increase, other ones (including helium, methane to argon ratio and nitrogen to argon ratio) decrease before earthquakes (Bella et al., 1995a; Bella et al., 1995b; Virk et al., 2001).

Based on the literature, at present, a quantitative estimation of the intensity of the correlation mechanism, as well as of the temporal and spatial distance between claimed anomalous gas releases and the occurrence of seismic events are still missing. Therefore, no firm conclusions can be drawn about the reliability of the hypothesis.

\section{Aerosols and Bubbles Exhalations}

Aerosol measurements showed anomalous variations before and after the Gujarat M 7.7 event on January 26th, 2001 (Okada et al., 2004)-that was also preceded by the anomalous disturbances of TEC, ions and electron density, electron temperature and VLF electric field- and before the Chile M 8.8 earthquake on February 27th, 2010 (Akhoondzadeh, 2015). By analysing data of Aerosol
Optical Depth (AOD) (measured through absorption of light at $550 \mathrm{~nm}$ by MODIS of Terra and Aqua satellites) Qin et al. (2014) have shown a significant fluctuation along the active Longmenshan faults, seven days before the Wenchuan earthquake (May 12th, 2008) before whom several have been the detections of anomalous variations of electromagnetic, atmospheric and ionospheric parameters including air temperature, outgoing longwave radiation, relative humidity, etc. Similarly, Akhoondzadeh and Jahani Chehrebargh (2016) reported anomalies in the AOD detected by MODIS before 16 high magnitude earthquakes; Boyarchuk (1997) shown exhalation of metallic aerosols $(\mathrm{Cu}, \mathrm{Fe}$, $\mathrm{Ni}, \mathrm{Zn}, \mathrm{Pb}, \mathrm{Co}, \mathrm{Cr}$ and radon); King (1986) reported emissions of $\mathrm{Rn}, \mathrm{He}, \mathrm{H}, \mathrm{Co}_{2}$ up to $500 \mathrm{~km}$ far from the epicentre (from few weeks to hours) before the seismic event; several analyses (Alekseev and Alekseeva, 1992; Heinicke et al., 1995; Pulinets et al., 1997; Biagi, 2009) claimed an increase of up two orders of magnitude of the charged aerosols density and an enhancement of the local radioactivity from weeks to days before earthquakes (correlated with possible exhalations of radon and other radioactive species).

Increased gas release in seismic regions during the earthquake preparation phase has been observed not only on land near faults (King, 1986), but also near submarine faults (McCartney and Bary, 1965; Lyon, 1974) with an intense rise of gas bubbles (including vapour, $\mathrm{CO}_{2}, \mathrm{He}$, methane, etc.) due to volcanic activity (Marty et al., 1993; Nikolaeva et al., 2009). The bubbles of gas under the sea can carry small electric charge $\left(10^{-14}-10^{-13}\right) \mathrm{C}(\mathrm{Gak} 2013)$ that can originate electric field in the atmosphere (Harper 1957; Blanchard, 1963). Even though the detailed balance of air-sea fluxes is still not completely known (Zavarsky et al., 2018), marine spray aerosol strongly contributes to an increase in aerosol optical depth (Revell et al., 2019) and winds spread aerosols into the atmosphere both over the land and over the sea. Based on that Sorokin et al. (2020) advanced the hypothesis that the electromagnetic environment on the lands and over the sea could be similarly affected by aerosol releases, as would be confirmed by the analyses of electric field perturbations detected by satellite, that don't show a significant difference for seismic events on land and at sea.

\section{Groundwater Level and Vapour Variations}

Studies about level variation of ground waters in occurrence with seismic events have been carried since long time ago and are particularly numerous (Hamilton, 1975; Kovach et al., 1975; Raleigh et al., 1977; Cai and Shi, 1980,; Merifield and Lamar 1981; Golenetskii et al., 1982; Wakita et al., 1985; Asteriadis and Livieratos, 1989; Liu et al., 2006). Between the end of last century and the begin of the current, the investigations extended including test campaigns in other countries (Kissin and Grinevsky, 1990; Igarashi et al., 1992; Igarashi et al., 1995; Roeloffs and Quilty, 1997; Koizumi et al., 1999; King, 1986; Chadha et al., 2003; Koizumi et al., 2004). In many cases, the reports about level variation of ground waters in occurrence with seismic events are not systematic and "scattered", making difficult comparisons and a statistical analysis. Nevertheless, the trend of the main characteristics (such as distribution, spatial and temporal distance, intensity, etc.) seems qualitatively similar in the gas releases and ground water level measurements suggesting 
a common driver in the earthquake preparation phase that, anyway, asks for further confirmations. In order to point out the correlation between variation of ground water level and seismic events it is needed to reject the background effect (Roeloffs, 1988) due to not seismic processes such as tidal effects (Bredehoeft, 1967); rainfalls, pressure variations and seasonal contributions (Rice and Cleary, 1976; Roeloffs and Quilty, 1997), oil and gas extractions, etc. Even though measurements of water level fluctuations are spread up to values of some meters, the most frequently absolute variations are within $1 \mathrm{~m}$ with a large majority of decreases before the earthquake. The statistical distribution of advance time between ground water level variation and seismic events ranges between less than one day up to years with a peak at about one month and half, while the largest anomalies would occur nearer to the earthquake time. In addition, the largest variations have been observed nearer the epicentre (with the majority within $200 \mathrm{~km}$ ), but there is not a clear evidence of a correlation between the entity of the variation and the earthquake magnitude. More recent observations (see for example Plastino, 2006; De Luca et al., 2018) have confirmed the general picture of the impact of seismic activity on the groundwater level fluctuation. Inan et al. (2010) reported hydro-geochemical anomalies lasting for more than a month before an earthquake magnitude 4.8 , in Western Turkey, detected within few tens of kilometers from the epicenter. A longer preparation phase seems confirmed also by the analysis of De Santis et al. (2020) of a precursory anomaly lasting almost a year (from September 2018 to July 2019) of ground water level data from a borehole located about $200 \mathrm{~km}$ from the epicenter of the July 6, 2019, M7.1 Ridgecrest earthquake and six USGS groundwater-monitoring sites.

\section{Thermal Anomalies Possibly Associated With Seismic Events}

In the framework of earthquake precursor's research, several analyses have investigated the existence of anomalous temperature variations before earthquakes (Tronin 1996; Carreno et al., 2001; Tronin et al., 2002b; Jing et al., 2013; Ouzounov and Freund 2004; Saraf and Choudhury 2005; Choudhury et al., 2006; Ouzounov et al., 2007; Panda et al., 2007; Bi et al., 2009; Saraf et al., 2009; Qin et al., 2013; Lu et al., 2016). Relatively few are the reports about such anomalies detected on ground before earthquakes, the reason being the reduced number of test campaigns devoted to such a measurements and the complexity of the study aimed at discriminating positive effects from those not related to earthquakes. Now day, the satellite remote sensing has extended the available dataset as well as the capability of detection.

\section{How Earthquakes Could Generate Thermal Anomalies}

The first hypothesis advanced in order to reconcile the possible appearance of a thermal anomaly in conjunction with earthquakes has been that such an anomaly would originate in depth during the seismic preparation phase (for example by frictional heating on fault surfaces) and would propagate up to the surface. Due to the low thermal conductivity of the rocks, the direct diffusion of an anomalous thermal fluctuation is quite inefficient in reaching the surface asking for some years even for diffusing of few meters. An alternative idea was that thermal fluctuations could be generated by fluids flow variation in depth-such as uplift or interruption of the hot geothermal groundwater circulation in volcanic regions and/or due to the volumetric variation of porous rocks due to dilatancy that facilitates fluids and gases flow-and then transported to the surface by the groundwater motion. The speed of the flow, the volume of groundwater involved as well as the depth variation would drive the temperature fluctuation intensity and temporal trend. Being the geothermal gradient of about $1.5-3.5^{\circ} \mathrm{C}$ per $100 \mathrm{~m}$ (but even higher for volcanic regions), a temperature variation of several degrees can be generated by the circulation trough rocks at some hundreds of meters. The hypothesis of a fluid driven propagation would explain why the majority of the claimed observations observed on ground has been carried out near thermal sources (in Greece and Japan, where significant subductions and geochemical activity take place) (Zheng et al., 2020); within few tens of kilometres from the epicentre; with a peak of the intensity distribution at less than one degree; before and during the seismic events. Anyway, it must be noticed that no such geothermal anomalous fluctuation have been reported along the Saint Andreas fault (Lachenbruch and Sass, 1992). Moreover, because thermal anomalies have observed both on ground and over the sea surface, Pulinets and Ouzounov (2011) ruled out thermal waters as a source to explain observed anomalies.

A further hypothesis has been advanced for the generation mechanism according to which the variation of tidal force could trigger shallow thrust fault earthquakes (Cochran et al., 2004). In fact, Tanaka et al. (2002) have found a correlation between temporal trend of tidal force and seismic events. It appears reasonable that the tectonic stress due to tidal force can contribute to reach the rock critical failure point (Heaton, 1975; McNutt and Beavan, 1981; Kilston and Knopoff, 1983) and then could be correlated with the earthquake nucleation (Weiyu et al., 2018). In this framework, it has been claimed that tidal force could generate some seismo-associated thermal anomalies (Ma et al., 2012; Ma et al., 2015; Yan Z. et al., 2017; Weiyu et al., 2018; Zhang et al., 2018). However, even this generation mechanism does not overcome the limits due to the inefficient propagation process up to the surface.

An interesting link could exist between thermal anomalies and radon exhalation. Even though Toutain and Baubron (1999) (see also references therein) have shown some systematic correlation between radon exaltation and seismic events, further investigations (for example İnan et al., 2008) have not confirmed previous results and other scientists (such as for example Geller, 1997) have demonstrated that the claim of using radon as earthquake precursor could be illusory. Pulinets and Ouzounov (2011) and Sorokin et al. (2020) proposed that the discrepancies between data, models and statistical accuracy could be due to the variety of instruments and methodology adopted for the measurements campaigns as well as to the mosaic-like distribution of radon exhalations that could appear randomly scattered in space and time. By assuming 
that radon exhalations would result into local increase of temperature, Pulinets and Ouzounov (2011) claim that the remote sensing of thermal anomalies (propagated from ground to upper atmosphere) would solve the difficulties of point like observations of radon on ground (Pulinets, 2007).

\section{Detections of Thermal Anomalies}

The prospective of investigating seismo-associated thermal anomalies has strongly changed with space-based observations. The Earth's surface naturally emits thermal radiation that is routinely measured by satellite sensors in the $(8-14 \mu \mathrm{m})$ spectral range (Pergola et al., 2004; Genzano et al., 2007). Several different methods have been applied to identify thermal fluctuations. Tramutoli et al. (2001) suggested the RST (Robust Satellite Techniques) procedure; Ouzounov and Freund (2004) analyzed LST (land surface temperature) data; Bryant and Nathan (2003) suggested the NTG (Nighttime Thermal Gradient) method and finally Zhang et al. (2010) applied wavelet transformation to infrared data. On the other side, various thermal parameters and datasets, collected on ground and trough remote sensing have been studied (Heaton, 1975; Tanaka et al., 2002; Blackett et al., 2011). Several studies have analyzed TIR (Thermal InfraRed spectral radiations) measurements acquired by infrared sensors on board of several satellite missions such as MODIS (on Terra and Aqua), FY Chinese satellite, MSG-41 SEVIRI on MeteoSat missions, AVHRR on NOAA satellites, etc. (Weiyu, et al., 2018; Yan R. et al., 2017; Zhang and Meng, 2019; Zhang et al., 2021). A common feature of the cited processing methods is to statistically process long temporal series of remote sensing data in order to extract possible anomalies (Lisi, et al., 2010; Sannazzaro, et al., 2014). Even though this approach provides a better statistical robustness, on the other side it could prevent from detecting small but significant thermal anomalies (Weiyu et al., 2018). One of the last research paper on the geochemical and thermal seismo-associated anomalies by Martinelli et al. (2020a) provides also an interesting summary and further references on this subject.

\section{Acoustic Gravity Waves}

At the begin of 2000 several authors (Gokhberg and Shalimov, 2000; Molchanov et al., 2004; Korepanov, et al., 2009) suggested that the earthquake precursor's phenomenology could be explained by the emission of AGW oscillations in a range of 6-60 min generated by lithospheric oscillations or gas exhalations and amplified in their propagation from the Earth surface through the atmosphere up to the ionosphere. The model of Molchanov et al. (2004) is based on the emission of charged aerosol (including an increase of groundwater, stable/radioactive gases and heat flows) in the earthquake preparation phase that would generate local disturbances in the conductivity in the atmosphere-ionosphere circuit. The advantage of this approach would be its capability to explain the large variety of observed disturbance taking in to account anomalous electromagnetic ULF/ELF measurements on ground (Schekotov et al., 2006) and in space (Rozhnoi et al., 2004), small scale plasma irregularities (Molchanov, 2009) in the geomagnetic flux tubes possibly reconciled with earthquakes occurrence, thermal fluctuations (Molchanov et al., 2004) as well as the claimed preearthquake character of VHF measurements (Devi et al., 2012). The analyses of ultra-low frequency electric and magnetic field before earthquakes shown electromagnetic perturbations associated with growth of plasma density structures (with scales between 10 and $40 \mathrm{~km}$ ) several days before earthquake in the magnetic tubes with the footprint over the epicentre (Zhang et al., 2009; Akhoondzadeh 2013) similarly to what occurs over tropical cyclones (Isaev et al., 2002; Sorokin et al., 2005). It has been suggested (Akhoondzadeh, 2013) that these seismo-associated plasma fluctuations would be generated by quasi-static electric field amplification due to AGWs instability for value of critical field greater than about $10 \mathrm{mV} / \mathrm{m}$ (Chmyrev et al., 1997; Sorokin et al., 1998, 2005). The plasma irregularities along the magnetic tube show variations of tens of percent and dimensions from few hundreds of meters to tens kilometres (Chmyrev et al., 2008) while amplitude of magnetic field fluctuation are of few nT and with frequencies from fraction of $\mathrm{Hz}$ up to few $\mathrm{Hz}$ (Chakraborty et al., 2018 and references therein). Beyond several advantages (Lizunov, et al., 2020), the models based on AGW and internal gravity waves suffer of the difficulty in explaining local disturbances (such as electromagnetic and plasma fluctuation over the epicentral zone) because the directional propagation of such a waves would shift the interaction zone with the ionosphere of a thousand of kilometres far from the epicentre (Hayakawa et al., 2011; Yang et al., 2019; Sorokin et al., 2020).

\section{SEISMO-ELECTROMAGNETIC PERTURBATIONS DETECTED ON GROUND}

As mentioned above, beyond the mechanical oscillations (of the ground surface or of the atmospheric layers), the geochemical fluids variations and the thermal anomalies, the list of proposed earthquake-precursors on ground includes many observations of electromagnetic disturbances. We will concentrate only on measurements on ground, addressing to the companion article by Picozza et al. (2021) on the same volume for a review of the space born detection of possible seismo-electromagnetic precursors.

One of the most cited, and now "classical", case study is the observation of the increase of the ULF $(0.5-2.0 \mathrm{~Hz})$ magnetic field amplitude stated one month before of the Loma Prieta (California) earthquake of October 17th, 1989 (Ms 7.1) registered $7 \mathrm{~km}$ far from the epicentre. The amplitude of the horizontal component intensified a couple of weeks before and then further strongly increased in the $0.01-0.5 \mathrm{~Hz}$ range some hours before the shock, when power was lost, (Fraser-Smith et al., 1990). Nevertheless, a detector operating $50 \mathrm{~km}$ far did not measure any anomalous signal in the same period. The hypothesis that the anomalous observations could have been originated by atmospheric natural background has been rejected, but on 2009 Campbell (2009)-by comparing geomagnetic indices trend with a portion of the magnetic 
measurements by Fraser-Smith et al. (1990)-claimed that, despite their large amplitudes and other unusual characteristics, the observations of Fraser-Smith et al. (1990) would merely represent natural magnetic disturbance fields. Instead, after a critical and careful reanalysis, (Fraser-Smith et al., 2011), confirmed that the large-amplitude fields observed before the Loma Prieta earthquake are fundamentally different from "natural magnetic disturbance fields" and that they may well have been precursor fields to the earthquake.

\section{Looking for ULF and Higher Frequency Electromagnetic Precursors}

On ground, Fraser-Smith et al. (1990), reported a SNR in the ULF frequency range up to 60 . Instead, the SNR reported for satellite observations by Larkina et al. (1989), Serebryakova et al. (1992) and Parrot (1994) was limited to 10. Nevertheless, this value is significantly higher than the background noise suggesting the possibility to detect seismo-electromagnetic precursors also from space at least in some case of strong earthquakes. The alleged preearthquake magnetic ULF (lower than several $\mathrm{Hz}$ ) signals have a skin depth (tens of kilometres for $1 \mathrm{~Hz}$ ) larger than that at higher frequencies (hundreds of meters for $10 \mathrm{kHz}$ ); moreover, low frequency magnetic signals suffer of a reduced attenuation, which allows long-range detection. These are some of the reasons that have drawn much attention to low-frequency magnetic field anomalies as important earthquake precursors. In addition to the Loma Prieta observations, early studies of ULF precursors were done also on the 1988 Spitak M 6.9 earthquake (Kopytenko et al., 1993), 1993 Guam M8.0 (Hayakawa et al., 1996), 1996 Hetian M7.1 event (Du et al., 2002), 1997 Kagoshima M 6.5 earthquake (Hattori et al., 2002), etc. In order to take into account the dependence of the ULF magnetic anomalies from the magnitude and the hypocentre distance earthquake from the observation site (Hattori 2004; Schekotov et al., 2006), Hattori et al. (2006) and Hattori et al. (2013) suggested to consider the cumulative (daily sum) of the local energy of the earthquakes weighted by the squared distance from the measurement station. This method have been adopted also by Han et al. (2014), that have carried an interesting statistical study - based on a superposed epoch approach for a long time period (2001-2010)-by analysing data at $0.01 \mathrm{~Hz}$ measured nighttime (LT 2:30-4:00 am) at the Kakioka (Japan) geomagnetic station and compared with Kanoya observatory, as a reference, in order to reduce background of artificial noises and global geomagnetic perturbations. The authors report an increased probability of ULF magnetic anomalies 1-2 weeks before medium and strong shallow earthquakes [confirming previous results by Hattori et al. (2013)] and pointed out that perturbations are more relevant for stronger and closer events. More recently, Han et al. (2016) have reported statistical significant anomalies in the geomagnetic diurnal variation (GDV) of the vertical component in a long-term observations from 17 Japanese stations about 2 months before the 2011 Tohoku earthquake (Mw 9.0) confirming results of Xu et al. (2013) and Han et al. (2015) on the same event. Liu et al. (2020) extended the study of the geomagnetic solar quiet daily (Sq) for the same Tohoku event: by analysing data from 20 geomagnetic observatories in the period 2009-2012 pointing out a relevant perturbation about one month and half before the earthquake.

In the same years, several studies have been carried out looking for possible precursors on ground. in frequency bands higher than ULF, in particular investigating the variability of well know and highly stable radio signals used for communication and geolocalization networks. By studying the attenuation of radio LF and VLF point-to-point transmissions over long distances, several authors (see for example Hayakawa, et al., 1996; Bella et al., 1998; Biagi et al., 2001a; Biagi et al., 2004) have reported cases of attenuation of broadcasted signal some days before seismic events occurred near the radio propagation path and suggested that preseismic ionospheric disturbances could have affected the conditions of transmission/reflection in the Earthionosphere waveguide. More recent investigations have claimed similar effects (Rozhnoi et al., 2009; Fidani, 2010; Biagi et al., 2011; Zhang et al., 2019).

One of the most controversial aspect of seismo-associated electromagnetic precursors is the large variety of observations even for the measurements possibly associated to the strongest events. For example, electromagnetic precursors have been detected, or claimed, only in some specific frequency bands and the spread in latitude and in longitude is different (or even opposite with a claimed clustering) in some analyses. We believe that, at present, many aspects of the seismoelectromagnetic phenomena must still be understood. Nevertheless, the studies seem to support the hypothesis that seismo-electromagnetic precursors can be observed several hours before medium and strong earthquakes and that their intensity seems higher near the epicentre.

\section{The Turn of the Century}

For an extended review of early observations and models, we must cite the precious works of Park et al. (1993) and Johnston (1997). Between the end of the last century and the beginning of the 2000s, we can register an increased interest in the investigation of seismo-electromagnetic precursors (see for example Jianguo et al., 2000; Nikiforova and Michnowski, 1995; Hao et al., 2000, Hattori et al., 2002; Liu et al., 2001; Liu et al., 2002; Liu et al., 2004; Korepanov et al., 2009; Sgrigna et al., 2004; Sgrigna and Conti, 2010; Ouzounov et al., 2006; Dudkin et al., 2010; Ramírez-Rojas and Flores-M árquez, 2013). In occasion of 1995 Kobe earthquake, seismo-electromagnetic emissions in ULF, ELF and VLF frequency ranges have been registered by Nagao et al. (2002), while Zafrir et al. (2003) reported measurements of radon and ULF emissions. Several research groups were active in Greece (Thanassoulas and Tselentis, 1993; Eftaxias et al., 2003; Hristopulos and Mouslopoulou, 2013) where (Varotsos et al., 2002; Varotsos et al., 2003a; Varotsos et al., 2003b; Varotsos et al., 2008) proposed the highly controversial VAN method (se also Uyeda et al., 2009b). Between the other national communities of scientists that set the standard at the beginning of this century we can cite: Italy (Biagi et al., 2001a, Tramutoli et al., 2005; Sgrigna et al., 2007; Sgrigna and Conti, 2012); France (Zlotnicki and Cornet, 1986; Parrot et al., 1993, Parrot, 995); Japan (Hattori, 
2004, Hattori et al., 2006; Uyeda et al., 2009a; Uyeda et al., 2009b); URSS-Russia (Chirkov, 2004; Kotsarenko et al., 2005; Morozov, 2006; Namgaladze et al., 2009) with several observations have been carried out for example in Kamchatka area (Vershinin et al., 1999); etc. In this framework, several space projects have been proposed and developed such as DEMETER (Parrot, 2002), QuakeSat (Flagg et al., 2004), ESPERIA (Sgrigna et al., 2008a; Sgrigna et al., 2008b), VULKAN (Kuznetsov et al., 2011), CSES (Shen et al., 2018; Lin et al., 2018; Yan et al., 2018; Li et al., 2020; Sotgiu et al., 2021) and FORMOSAT-7/COSMIC-2 (Lin et al., 2020). The Earth remote sensing is the new frontier of seismoelectromagnetic investigation because it allows monitoring several regions worldwide that is a key ingredient for statistical studies including several seismic events occurring in different tectonic systems and geomagnetic conditions. If the space-based investigation will provide solid results, we will need of satellite constellations that can ensure a global coverage with enough spatial and temporal resolution (Sgrigna et al., 2004). For the reader interested in an in-depth study, we refer to Tanimoto et al. (2015) and Ouzounov et al. (2018) that provide an updated and extended summary of research in the field.

\section{How Seismo-Associated Electromagnetic Disturbances Could be Generated}

Several models have been proposed in literature in order to explain the observed phenomenology of seismoelectromagnetic field precursors. We can divide them in two main categories depending on whether they could explain the lower frequency precursors (ULF) (Uyeda, et al., 2009b) or generate the disturbances at higher frequency (mainly ELF/ VLF but also higher bands up to HF).

\section{Generation of Low Frequency Magnetic Fields}

In order to explain the ULF precursory fluctuations, three main effects have been suggested such as 1) the magnetohydrodynamic (MHD) effect (Draganov et al., 1991); 2) the piezomagnetic effect (Sasai, 2001) (Parrot, 1995) and 3) the electrokinetic effect (Nourbehecht, 1936-1963; Fitterman, 1979).

1) In the MHD effect, a conducting fluid moving in a magnetic field generates a secondary induced field. We can define a magnetic Reynold number Rm such as the ratio between the convective term (due to the resistance to flux change of magnetic field) and the diffusive one (due to Ohmic dissipation) in the MHD equation. From the formula $R_{m}=$ $\mu_{0} \sigma \mathrm{vL}$ (where $\sigma$ is the conductivity, $\mathrm{v}$ the velocity of the fluid and $L$ is the characteristic length scale of the source) the induced field $B_{i}$ can be estimated as a function of the external one: $B_{i}=R_{m} B$.

2) In the piezomagnetic mechanism, the applied stress would change the magnetization $M$ of the ferromagnetic rocks inducing a secondary magnetic field. By solving the differential equation, that, in an isotropic material, we can write as $\Delta \mathrm{M}_{\mathrm{i}}=\beta \mathrm{T}_{\mathrm{ij}} \mathrm{M}_{\mathrm{j}}$-where $\beta$ is the sensitivity to the stress and $\mathrm{T}_{\mathrm{ij}}$ is a function of the stress tensor, of the displacement vector and of the material's parameters-it is possible to estimate the magnetic field at the surface due to piezomagnetic mechanism.

3) Finally, in the electrokinetic effect an electric current is generated not by an electric field gradient, but by a pressure gradient at the electrified interface of a solidliquid boundary. The electrokinetic current would be responsible of an induced magnetic field according to the Biot-Savart law.

Draganov et al. (1991) reconciled the (Fraser-Smith et al., 1990) observations with an origin in the MHD effect. Nevertheless, this conclusion was obtained by using values of permeability and lithostatic pressure of about two orders of magnitude higher than that at the Loma Prieta hypocentre depth (Fenoglio et al., 1995). On the contrary, it can be argued that, due to the strong attenuation of the magnetic field intensity, which decreases as the third power of the distance, MHD effect would give a negligible contribution to the magnetic signal detected on ground. Even the contribution of the piezoelectric effect could be negligible (Fenoglio et al., 1995), being of about $10^{-2} \mathrm{nT}$, i.e. two order of magnitude less than the two or about $7 \mathrm{nT}$ reported by (Fraser-Smith et al., 1990). Whereas the electrokinetic effect could be able to generate a signal of 5-10 nT of the same order of magnitude of the signals measured before the Loma Prieta earthquake (Fenoglio et al., 1995). Interesting is also the research activity that tries to apply/ extend the lesson learned in laboratory to research on field (see for example Vallianatos and Tzanis, 1999; Tzanis and Vallianatos, 2002; Vallianatos et al., 2004).

\section{Electromagnetic Emissions at Higher Frequency}

In order to explain the generation of electromagnetic emissions detected before some earthquakes (mainly in the ELF/VLF range but also up to HF) several physical models have been proposed that can be summarized in 4 main typologies such as: contact electrification, separation electrification, piezo-electrification (Ogawa et al., 1985; Zlotnicki and Cornet 1986) and atmospheric electricity generated by radon exhalation (Pierce, 1976). The electric field emissions generated in granite samples under bending or impact/shock have been studied by Ogawa et al. (1985) that has reconciled the observed phenomenology with the electric dipole momentum due to contact/separation electrification or piezo-electrification that would induce a charge separation. At a distance $r$ from the dipole momentum (p), the near-, induced- and radiated-field (associated with increasing frequency range) are proportional to $\mathrm{p} / \mathrm{r}^{3}, \mathrm{dp} / \mathrm{dt} / \mathrm{cr}^{2}$ and $\mathrm{d}^{2} \mathrm{p} / \mathrm{dt}^{2} / \mathrm{c}^{2} \mathrm{r}$ respectively.

\section{Most Recent Hypotheses on the Generation of Electromagnetic Fields}

Some authors such as Liperovsky et al. (2008a) suggested that the variety of variables and coupling mechanisms involved in generating precursors and the large phenomenology of observed anomalies could be reconciled claiming that different physical mechanisms can explain quite the same precursors. It is not necessary to quote Occam's razor to argue that the simplest 
explanation, with fewer parameters, is usually the correct one. However, a consistent unified model would certainly be preferable for more stringent checks of the variables involved. By summarizing results from literature (including cited works and also Kondo, 1968; Vershinin et al., 1999; Hao et al., 2000) the amplitude of on ground preseismic quasi-static electric field disturbances-detected on long spatial (hundreds of kilometers) and temporal scales (from 10 days up to few hours)-can be estimated never exceeding $100 \mathrm{~V} / \mathrm{m}$ (even though sudden and more intense increases fluctuations have been reported on shorter distances). In space, these values reduce to about $10 \mathrm{mV} / \mathrm{m}$ (Zhang et al., 2014). The proposed hypotheses of an electrostatic origin of the lithosphere-atmosphere ionosphere coupling mechanism, through a direct propagation, have been ruled out by several authors such as Sorokin et al. (2020). Moreover, Denisenko (2015) and Denisenko et al. (2018) have demonstrated that the penetrations of both a lithospheric electric field and a current in the ionosphere is negligible. In order to explain preseismic electric field anomalies (Freund, 2010) proposed that they could be originated by tectonic stress applied to lithospheric rocks. In fact, laboratory experiments have pointed out that igneous rocks under stress are able to generate currents carried by both electrons and positive holes that can cause positive electric potential, ionization of air molecules and corona discharge on the rocks surface. This model has been criticized for two different points of view. The anomalies registered in space (of for example ionospheric plasma parameters, electromagnetic values, etc.) consist of both increase and decrease of the studied variable: some time the same variable can show an increase or a drop along the temporal series about a given seismic event. According with Pulinets and Ouzounov (2011) the "unipolar character" electric field suggested by Freund (2010) would be in contradiction with the experimental results of bidirectional behaviour of ionospheric preseismic effects and could be applicable only to earthquakes occurring on ground because the release of charges in atmosphere would need of solid rocks on the surface. Moreover, even though the mechanism proposed by Freund (2010) could contribute to explain short time electric field fluctuations (on the scale of about $10 \mathrm{~min}$ ), Sorokin et al. (2020) argued that it would not be able to explain quasi-static electric field in space on a longer temporal scale.

Pulinets and Ouzounov (2011) proposed the so-called LAIC model that can be summarized as follows. Radioactive gases (mainly radon) exhalations would be responsible of the preseismic chain. In the first step, the higher radon concentration (through alpha decay) would increase the local ionization in lower atmosphere and consequently the attachment centers for water vapor condensation causing a higher release of latent heat (Garavaglia et al., 2000; Dey and Singh, 2003; Silva and Claro, 2005). The resulting anomalies in the gradient of temperature would: 1) propagate from ground up to the high atmosphere (as detected by the OLR measurements), and 2) generate a flow of clusters/condensation nuclei (Svensmark and Friis-Christensen, 1997; Svensmark et al., 2007) that will affect the clouds formation rate and morphology (Ondoh, 2004). Simultaneously, the conductivity of atmospheric layers would change affecting the Global Electric Circuit inducing fluctuations in the ionospheric parameters such as: height scale, temperature and density of electron and ions, ion composition, etc. According with the authors, the model results into: the formation of ionospheric irregularities, electromagnetic disturbances, and the precipitation of charged trapped magnetospheric particles. Finally, the model forecast a feedback process when precipitating electrons would increase the $\mathrm{D}$ layer ionization affecting: VLF reflection height, whistler dispersion and more in general the e. $\mathrm{m}$. propagation conditions in the Earth-ionosphere. The "bipolar character" of Pulinets and Ouzounov (2011) model aims at reconciling in a consistent scheme the extended phenomenology of the preseismic observations: the positive or negative direction of anomalous electric field on the ground can induce both positive and negative variations observed for several physical parameters (such as the electric air conductivity over the earthquake, the ionospheric parameters, the cloud formation, etc.).

More recently, Sorokin and Hayakawa (2014) proposed that preseismic processes would originate a current source near to ground that modify the lower atmosphere properties by generating an EMF (electro-motive force) that will cause ionospheric electromagnetic and plasma disturbances. The model would allow explaining several aspects of the phenomenology such as: the existence of quasi-static electric field on ground and in space over the seismic regions, the increase of conductivity with altitude and a mechanism for limiting the vertical component of the electric field on ground. Associated with EMF enhancement, ionospheric instability can generate AGW, field-aligned currents and plasma irregularities along the magnetic tubes, spectral broadening of VLF transmitter signals, enhancement in space of ELF (due to scattering of with conductivity irregularities) and changes in Schuman resonance harmonics.

A common feature to the models [such as Pulinets and Ouzounov (2011) and Sorokin et al. (2020)] based on radon release is that they could be applicable both for in land and undersea earthquakes and potentially independently from the seismo-tectonic characteristics of the involved faults, as long as a sufficient radon exhalation takes place.

\section{Ionospheric Disturbances}

The ionosphere is a highly dynamic environment characterized by global structures (evolving under the solar periodic and irregular activity) as well as by local irregularities on different scales and times. The list of ionospheric parameters routinely monitored by ionosondes and GPS that have been studied in correlation with seismic activity includes total electron content (TEC); F2-layer critical frequency (foF2); electron temperature at F2-layer heights; LF radio signals etc. Some references can be for example: (Strakhov and Liperovsky, 1999; Ondoh, 2003; Ondoh, 2009; Trigunait et al., 2004; Hobara and Parrot, 2005; Liu et al., 2006; Maekawa et al., 2006; Ondoh and Hayakawa, 2006; Dabas et al., 2007; Chum et al., 2016).

Hayakawa et al. (2011) reported an increase of the amplitude and frequency shift of the fourth Schuman resonance before seismic events and proposed that this could be due to changes in the height of reflection and absorption of electromagnetic waves induced by variation of the ionization degree in the $\mathrm{D}$ layer. 
Ondoh (2003) reported that changes in the altitudinal profile of ionospheric plasma density over a seismically active region could be accompanied by the formation of sporadic layers in the lower ionosphere. In addition, Pfaff et al. (2005) tried to reconcile the occurrence of sporadic E layer with seismic events, proposing that this would be induced by differential charging of top and bottom sides of clouds due to the migration of radon. Silina et al. (2001), Ondoh (2004), Ondoh and Hayakawa (2006) and Korsunova and Khegai (2006) and Korsunova and Khegai (2008) have identified ionospheric earthquake precursors by using sporadic Es layer. The method applied to ionosonde data has shown an increase of Es occurrence in conjunction with strong earthquakes $(M>7)$ in Japan and moderate earthquakes (with $5.5 \leq \mathrm{M}$ ) in Italy (Perrone et al., 2010). Similarly, Perrone et al. (2018) have identified anomalous variations of the sporadic E-layer parameters $\left(h^{\prime} E s\right.$, foEs) and foF2 in occasion of earthquakes with magnitude $M \geq$ 6.0 in Greece during the 2003-2015 period. By studying the foF2 variations, through ionosondes measurements, Hobara and Parrot (2005) have detected a decrease near the epicenter of the Hachinohe earthquake (magnitude 8.3) of 1968. A decrease of foF2 (greater than 25\%) has been reported also by Liu et al. (2006) within 5 days before of more than 150 seismic events (of magnitude greater or equal than 5) occurred in a period of 5 years. The authors pointed out a correlation between the entity of the decrease and the earthquake magnitude, whereas the effect decreases far from the epicenter and is not more evident more than $150 \mathrm{~km}$ from the epicenter. In addition, Kandalyan and Alquran (2010) have investigated the existence of a possible correlation between the occurrence of strong earthquakes and ionospheric scintillations. Even though, many TEC anomalies, detected by GPS networks, have been correlated to seismic events (see also Tsai et al., 2006; Singh et al., 2009; Jhuang et al., 2010; Hasbi et al., 2011; Kon et al., 2011; Ma and Wu, 2012; Contadakis et al., 2012 and references therein) nevertheless, the debate is still intense because some authors (e.g., Rishbeth, 2006) highlighted that generally TEC perturbations could be caused by the natural ionospheric and geomagnetic variability and that the precursors analyses are generally carried out after the earthquake occurrence (e.g., Mulargia and Geller, 2003; Afraimovich and Astafyeva, 2008). For this reason, statistical analyses on long time series are particularly valuable. By analyzing changes in total electron content from the global ionosphere map (GIM) within $2.5^{\circ}$ latitude and $5.0^{\circ}$ longitude around the earthquake epicenter, Thomas et al. (2017) found no statistically significant TEC changes before the $1279 \mathrm{M} \geq 6.0$ earthquakes for the period 2000-2014 (after declustering for aftershocks). The Wenchuan earthquake on May 12th, 2008, 14:28 LT, occurred in the eastern edge of the Tibetian plateau, is remembered not only for its devastating consequences-with tens of thousands of death and the large-scale disruptions in the western Sichuan-but also for having given a further input to Chinese scientific community, involved in studying earthquake precursors, to develop the satellite CSES mission designed for remote sensing the Earth electromagnetic environment. Zhao et al. (2008) have studied TEC data from 58 GPS receivers installed nearby the epicenter of the Wenchuan earthquake. Whereas the enhancement observed on May 3rd have been mainly reconciled with geomagnetic storm occurred in the 00:00-10:00 UTC, the analysis has pointed out a TEC anomalous disturbances detected on May 9th over the southern China and its conjugate point in the southern hemisphere could be related to the Wenchuan earthquake. For specific techniques that allow discriminating between real seismo-ionospheric anomalies and artifacts see also ( $\mathrm{He}$ et al., 2014). By analyzing VTEC measurements, during all of the $20 \mathrm{M}$ $\geq 6.0$ earthquakes in the Taiwan area from September 1999 to December 2002, Liu et al. (2004) reported preseismic ionospheric anomalies (with respect a 15-days running average) before of the $80 \%$ of the analyzed earthquakes. More precisely, for the seismic events in the Taiwan, ionospheric VTEC remarkably decreased during 18:00-22:00 LT within 1-5 days before the earthquakes. Observations are in agreement with the $93 \%$ reported by Liu et al. (2000). In occasion of the Chi-Chi earthquake Liu et al. (2010) reported that the correlations between the co-located NmF2 and VTEC about one week before the event was extremely high (about 0.95 ) suggesting that TEC measurements via GPS receiver would allow monitoring preseismic ionospheric anomalies. Liu et al. (2004) suggested that the anomalies appear first near the Earth's surface and then extend to higher altitudes through an unknown mechanism such as diffusion, atmospheric gravity waves or due to some vertical preseismic electric field. Since a large amount of contribution comes from higher altitudes, the appearance of the diurnal VTEC features may be somewhat later than that of the NmF2 (or foF2).

By investigating TEC spatial distribution, Liu J. Y. (2009) and Zakharenkova et al. (2008) reported that preseismic TEC fluctuations seems accompanied by simultaneous changes of the electric field in the ionosphere [of the order of $1-10 \mathrm{mV} /$ $\mathrm{m}$, also in agreement with Klimenko et al. (2012)], but without variations on ground; the authors also estimated that an increase of several times of the aerosols concentration on ground could cause TEC variations of several tens of percent (see also Ruzhin et al., 2014).

According with Freund (2010), the rocks under stress would constitute a dynamo able to generate preseismic currents of electrons and positive holes. The author of Kuo et al. (2011) estimated that current density of about $\left(10^{-7}-10^{-6}\right) \mathrm{A} / \mathrm{m}^{2}$ would be able to generate a daytime TEC variations from $2 \%$ up to $25 \%$. On the contrary, Sorokin et al. (2020) highlighted that this hypothesis would be incompatible with the measurements because: 1) the duration of the Freund currents (only several minutes) doesn't match with that of the TEC variations; for achieving the claimed current intensity it would be needed a vertical electric field of about $\left(10^{7}-10^{8}\right) \mathrm{V} / \mathrm{m}$ that is higher than the values observed on ground in the seismic areas.

The investigation of seismo associated disturbances on a long temporal scale can be carried out by the study of the variations of amplitude and phase of VLF signals (between ground based transmitters and receivers) traveling over the preparation zone of seismic events (Biagi et al., 2004; Rozhnoi et al., 2004; Hayakawa et al., 2011). Amplitude and phase of such signals generally very stable as a function of time-have shown variations of the scale of tens of minutes possibly induced by variations the height of the Earth-ionosphere waveguide due to local ionization or secondary effects induced by seismic sequence. 


\section{Multi-Parametric Analyses Looking for Earthquake Precursors}

The common feature of the most recent models for investigating earthquake precursors is to assume a multi-parameter coupling mechanism (which also includes several feedback processes, see for example İnan et al., 2010; Pulinets and Ouzounov 2011; Freund 2013; Hayakawa et al., 2018; Ouzounov et al., 2018) according to which the exchange of energy and particles between the lithosphere and the lower and upper atmospheric layers of the ionosphere, during the earthquake preparation phase, causes a variety of precursor phenomena that should be considered as a whole [in the so called holistic approach of De Santis et al. (2019b)]. Therefore, one of the updated trends in precursor research is the simultaneous measurement of several physical variables [such as radon and other gas release, air temperature and humidity (e.g., Akhoondzadeh et al., 2018), thermal infrared emissions (e.g., Natarajan and Philipoff, 2018), electromagnetic fields and ionospheric parameters, including electron density (e.g., Zhang et al., 2011; De Santis et al., 2015) etc.] for a joint analysis of such complex and interrelated system (Ouzounov et al., 2018). Because data needed for these investigations are collected both on ground and by satellite, we address the reader to the companion article Picozza et al. (2021) and to therein references, where this topic is further discussed for space-based observations of precursors. The possible correlation between seismic events and fluctuation of water column content has been studied for example by Dey et al. (2004) for the 2001 M7.8 Gujarat earthquake; by Ma et al. (2010) for the Hengchun (Taiwan) M 7.2 event of 2006 and by Wu et al. (2016) for the 2009 M6.2 L'Aquila earthquake. Anomalies of ozone have been investigated for example by Akselevich and Tertyshnikov (1995) and by Tronin (2002a). In this framework, Piscini et al. (2017) proposed the CAPRI (Climatological Analysis for seismic PRecursor Identification) algorithm searching for anomalies of the time series of climatological parameters. The authors analyzed skin temperature, total water vapor column, and total ozone column for the period from two months prior to the entire Amatrice-Norcia seismic sequence (central Italy)-which began on August 24, 2016 with an M6 earthquake and included two other large quakes (i.e., an M5.9 earthquake on October 26 and then an M6.5 on October 30)-comparing the measurements with time series of data from the previous 37 years in order to remove the possible effect of global warming. The method was also extended to analyze the M 6.2 L'Aquila (2009) earthquake. Piscini et al. (2017) reported persistent anomalies that emerged simultaneously in all parameters analyzed, conclusions that would be confirmed by comparing the data with those of the same months in other seismically quiet years. On the other hand, the authors have commendably pointed out that a single anomaly, if present, of an individual climatological parameter would have low statistical significance as it could be caused by several sources unrelated to the earthquake. Moreover, weather phenomena could move and mix the substances released from underground into the atmosphere could mask precursors, if any, lowering their signal-tonoise ratio and shortening their persistence in the atmosphere (Marchetti et al., 2019). Similar results have been obtained by De Santis et al. (2020) that have applied a multi-parametric study to the 2019 M7.1 Ridgecrest earthquake, by analysing furthermore methane exhalations [as suggested by Cui et al. (2019)], electron density fluctuations, and magnetic field measurements from Swarm satellites (Friis-Christensen et al., 2006; Zhu et al., 2019). The results can be summarized as follows: 1) precursor times would be much longer than those identified by other papers (especially about ionospheric precursors which seem to occur only a few hours to days before large seismic events) (see for example Heki, 2011; He and Heki, 2017; Yan R. et al., 2017); 2) the preparation phase would be much longer than few days [as also suggested by Liu et al. (2020), Marchetti et al. (2019), Marchetti et al. (2020), Sugan et al. (2014), Giovambattista and Tyupkin (2004)]; claimed precursors would follow the empirical Rikitake (1987) law, recently confirmed for ionospheric precursors from the satellite by De Santis et al. (2019a). In any case, it is a complex task to monitor several or all atmospheric effects due to the LAIC mechanism that also include linear cloud structures (the "earthquake clouds" that would repeat the shape of the tectonic structure in the sky (Jones and Stewart, 1997; Nissen et al., 2012); OLR [Ongoing Longwave Radiation-infrared emission at 10-13 $\mu \mathrm{m}$ recorded above the clouds (Ouzounov et al., 2007)]; jet streams ( $\mathrm{Wu}, 2007)$; etc. Even in a multi-parametric approach, the benefit of analysing the OLR-measured in the upper atmosphere - is that the OLR can take into account the cumulative effect of all thermal contributions possibly due to the earthquake, between the ground surface and the tropopause, according with the so-called "synergy of precursors" (Pulinets, 2011). Moreover, thanks to the long time series of data collected by the NASA Aqua and NOAA/AVHRR satellites, it is possible to compare the local and temporal variations of the OLR with a wellestimated reference background that would improve the statistical significance and reliability of pre-earthquake fluctuations of this parameter. Ouzounov et al. (2007) reported that a few days before the M 9.1 Sumatra earthquake of December 26, 2004, the OLR value was above $80 \mathrm{~W} / \mathrm{m}^{2}$ compatible with the estimate given by Kafatos et al. (2007). In general, the results of the multi-parameter analyses-also made possible by recent big data analysis techniques and large computational capacity-reinforce the idea of considering such an integrated anomaly recognition system as an effective tool for systematically finding earthquake precursors.

\section{POSSIBLE APPROACHES FOR RECOGNIZING NATURAL AND ARTIFICIAL ELECTROMAGNETIC BACKGROUND}

In order to identify electromagnetic earthquake precursors it is essential to reject carefully the background due to natural nonseismic sources and industrial electromagnetic noise. Although, the main driver of the electromagnetic Earth environment is the solar wind that shapes the magnetosphere and affects its dynamics, several other natural and artificial sources of electromagnetic emissions take place in the geomagnetic cavity. The terrestrial electromagnetic background noise of not-ionizing radiations (distributed-although not uniformly-in a broad range of power levels and frequencies from about $\mathrm{mHz}$ up 
to $300 \mathrm{GHz}$ ), is generated by a wide variety of natural (atmospheric thunderstorms (e.g., Neubert et al., 2008) or cosmic rays) and man-made (power line harmonic radiation, industrial and communications equipment, etc.) sources (Hayakawa, 1994). These emissions constitute a significant background with the respect to the elusive electromagnetic emissions and related ionospheric disturbances possibly caused by natural geophysical activities, such as earthquakes and volcanic eruptions (Hayakawa, et al., 2011).

\section{Natural Non-Earthquake Electromagnetic Noise on Ground and in the Near Terrestrial Environment}

Depending on the frequency, the natural electromagnetic noise in the magnetosphere arises from wave-particle interaction phenomena, while within the ionosphere originates from atmospheric electric discharges through several propagation mechanisms Simões et al. (2012). On ground, in some areas, the artificial noise generated by technological devices exceeded the natural one, while in the VLF-HF range, the atmospheric electromagnetic emissions exceed the artificial ones in rural areas (in the order of some tens of $\mathrm{dB}$ ) and are comparable to them in industrialized zones. At higher frequencies, the electromagnetic noise induced by thunderstorms becomes less important, and that of cosmic origin (up to millimeter wavelength) prevails (Bianchi and Meloni 2007).

In the ULF band (from $1 \mathrm{mHz}$ up to $1 \mathrm{~Hz}$, i.e., from the lowest frequency that the magnetospheric cavity can support, up to the ions gyro-frequencies) are observed the geomagnetic pulsations and the "incoherent noise" (Lanzerotti et al., 1990; Jacobs et al., 1964). The low-frequency pulsations are generally originated by the Kelvin-Helmholtz instability in the magnetopause, through to the interaction of the solar wind with the magnetosphere, or by the waves "upstream" in the "foreshock" region. Wave-particle interactions in the magnetosphere give rise to the so-called "chorus" and "hiss" phenomena. The chorus are among the most intense electromagnetic emissions generated in the external magnetosphere and propagating up to the Earth surface where are observed at intermediate latitudes. The spectral characteristics of the chorus (from about $500 \mathrm{~Hz}$ to about $1.2 \mathrm{kHz}$ ) consist in a succession of tones predominantly growing-that resemble to the birds chirping, that constitutes the origin of their name. Hiss are intense electromagnetic emissions, occurring mainly in the auroral zone, in a broad frequency band (from a few hundreds of $\mathrm{Hz}$ up to several tens of $\mathrm{kHz}$ ). The most important electromagnetic phenomenon in the ELF band is the Schumann resonance, at about $7 \mathrm{~Hz}$ and higher harmonics, arising at the proper oscillation frequencies of the natural Earth-ionosphere waveguide (Polk, 1983). The tropospheric layers (with variable electrical conductivity) between the Earth crust and the ionosphere (both of them schematized as perfectly conductors) constitute an electromagnetic cavity in which electromagnetic radiation is trapped and waves can propagate. Waves constructive interference can excite resonances in the frequency band of about $6 \div 60 \mathrm{~Hz}$ in the above-mentioned Earth-ionosphere waveguide. Lightning are the main source of electromagnetic noise background in the ionosphere, where they generate emissions from ELF (about few $\mathrm{Hz}$ ) up to VHF (about hundreds of $\mathrm{MHz}$ ) although most of the energy is concentrated in the VLF band (from 0.1 to $10 \mathrm{kHz}$ ) with a typical power spectrum slope. Some thousands of storms are estimated to occur daily on the Earth (Shvets and Hayakawa, 2011), generating about 100 lightning per second, with discharges up to $10 \mathrm{kA}$ per each and releasing an amount of energy from a few units up to a few tents of GJ, i.e., powers of the order of $0.1 \div$ $1 \mathrm{TW}$, for a total of $10^{19} \mathrm{~J}$ released yearly around the world. The natural electromagnetic phenomena relevant in the ELF-VLF frequency bands are the so-called sferics, tweeks and whistlers, generated by lighting electromagnetic pulsed signals (of a few $\mathrm{ms}$ ), that travel with a low attenuation in the Earth-ionosphere waveguide for thousands of kilometres (Helliwell, 1965; Hitchcock and Patterson 1995). The propagation of the spherical waves is determined by the variable ionospheric conditions and the sferics can be observed with directional antennas and AM receivers as typical disordered sounds called "statics". The tweeks (generally detected in the evening after the sunset) are sferics showing a spectral dispersion during their propagation and that, in acoustic spectra, sounds similar to birds singing with frequencies of about $1 \div 7 \mathrm{kHz}$. The higher harmonics penetrate in the ionosphere more in depth than the lower components that, being less attenuated, cover longer distances. Different paths imply different arrival times and the spectrograms show descending tones with a duration from about $25 \mathrm{~ms}$ up to about $150 \mathrm{~ms}$. The whistlers are intense circularpolarized electromagnetic waves propagating at a frequency below the plasma frequency (from about $6 \mathrm{kHz}$ up to a few hundred $\mathrm{Hz}$ ), generated by lightning and perceived in radio receivers as characteristic decreasing tones. Whistler waves rotate clockwise propagating along the geomagnetic field lines through the ionosphere up to the magnetosphere, bouncing back and forth, and showing a significant spectral dispersion as function of the path length and the characteristics of the crossed medium. Also in the LF/MF/HF bands, up to the plasma frequency, the natural electromagnetic noise is mainly generated by atmospheric phenomena (with an amplitude decreasing at higher frequencies) and its propagation is affected by local ionospheric conditions and geometry of the paths. For frequencies higher than $15 \div 30 \mathrm{MHz}$ the cosmic noise of astrophysical origin appears (Kraus, 1988; Erickson, 1990).

\section{Anthropogenic Sources of Electromagnetic Emissions in the Near-Earth Space}

The natural electromagnetic background is accompanied by the emissions due to human activities. The artificial noise originated by industrial technologies (power lines, radio and TV broadcasting stations, communications facilities, etc.) strongly depends on the distance from the sources, can vary also by many orders of magnitude, frequency and power, and show distinctive features such as continuous or impulsive regime, modulation and polarization. In the ELF band, the most powerful source of artificial noise (except Antarctica where the natural ELF 
emissions can be detected with few anthropogenic interference) is represented by power lines harmonic radiation (PLHR) which ideally operate at a single frequency of $50 \mathrm{~Hz}(60 \mathrm{~Hz}$ in the U.S.). At these frequencies, the electric and magnetic fields are virtually disconnected and (due to the multipolar configuration of the electric lines) decrease dramatically by increasing distance from the lines. Satellite observations show that PLHR can contribute-through non-linear interactions-to precipitation of Van Allen particles from the slot region in the radiation belts. The principal part of the PLHR energy dissipates in the lower ionosphere modifying ionospheric currents. Ground-based radio-navigation and communications VLF transmitters in the $10 \div 20 \mathrm{kHz}$ frequency band can trigger new waves, ionospheric heating, wave-electron interactions, and particle precipitation via the cyclotron resonance. The wave and the particles interact when the Doppler-shifted wave frequency seen by the particles is close to the electron gyro-frequency. The trajectory of particles follows the magnetic field lines but the ray path of the injected waves is only field aligned if the wave is propagating in a whistler mode duct. The strongest interaction region is around the geomagnetic equator. Triggered emissions by coherent waves are related with non-linear wave growth caused by resonant particle trapping in a non-uniform magnetic field. At HF frequencies, powerful broadcasting stations can provoke ionospheric Joule heating by changing plasma temperature and density Erickson (1990). The dissipation in the ionosphere of the above-mentioned waves may contribute to the global warming of the Earth, since the change in global temperature increases the number of natural lightning discharges in the atmosphere and this produce more magnetospheric whistlers that may provoke heating and ionization in the lower ionosphere. This is a feedback mechanism since lightning are sources of NOx that influence the ozone concentration in the atmosphere contributing to the greenhouse effect. Moreover, precipitation of energetic electrons by anthropogenic waves may trigger other lightning discharges. This explains the importance in studying such anthropogenic electromagnetic emissions. For VHF or higher frequencies, that are relevant for radio astronomy observations Erickson (1990), the anthropogenic electromagnetic emissions are due to radio and television broadcasting stations, mobile communications, car ignition systems and industrial equipment, while radar and satellite devices, as well as highly directional SHF/EHF emitters, do not give a significant contribution to the electromagnetic noise background.

\section{Rejecting Non-Earthquake Associated Effects From Data Analysis}

The described features could allow distinguishing the effects of natural non-seismic, seismic and man-made electromagnetic emissions. In some frequency range (i.e., at 50 or $60 \mathrm{~Hz}$ or for signals from radio transmitters), it is easier to reject man-made electromagnetic emissions. On the other hand, in many cases, it is not straight to remove the background emissions due to magnetospheric disturbances and tropospheric sources aimed at identifying seismo-electromagnetic disturbances. This is particularly true for example in the statistical analyses (such as those based on the epochs overlap method) where data from different geographic regions (naturally exposed to different geomagnetic processes) are grouped and studied together.

In this framework, the analyses published in literature have adopted different strategies. Unfortunately, in many cases, the studies have not carefully excluded data collected in geomagnetically disturbed periods. A reduction of the background can be achieved by using magnetospheric and ionospheric indices. Some examples are the well-assessed (global or aerial) indices $\mathrm{Kp}, \mathrm{Ap}, \mathrm{AE}$, Dst, etc. released with relatively low time resolution (hour or multi-hour scale). Other ones are the more detailed indices able to describe the geomagnetic perturbations at mid-latitudes as a function of longitudinally asymmetric (ASY) and symmetric (SYM) disturbances for both $\mathrm{H}$ and $\mathrm{D}$ components (respectively parallel and perpendicular to the geomagnetic dipole axis). A further filtering, more difficult to be applied but that can be investigated, is to take care of the metrological conditions and of the lightning activity in the area of the earthquake and in the conjugated one. Frequencies range around the band of the known VLF transmitters should be also rejected in the analyses of seismo-associated disturbance because the power of the artificial signals can overwhelm the natural and faint emissions possibly associated to earthquakes. On the other side the high stability in power and frequency of these transmitters, as well as of the radio broadcasting stations, have been and are investigated in order to point out fluctuation in the transmission parameters possibly due to seismo-electromagnetic disturbances occurred along the transmission path from the transmitter and a fixed receiver station. In addition, the polarization of eventually directional signals can give hints on the internal or external origin of detected measurements candidates to be associated to lithospheric processes. In general, a strong interdisciplinary approach, between different research fields, is mandatory to clean data, to reject background and to better distinguish such complex phenomena.

Hattori (2004) applied the principal component analysis (PCA) for decomposing and filtering time-domain series of observations in order to identify background signals (generated by DC noise, natural emitters and man-made devices) that could be removed in order to point out earthquake related anomalies (if any). The authors have applied the procedure to ground measurements of magnetic field (also including data gathered during strong geomagnetic disturbances) and reported that the first two principal components would be correlated to geomagnetic variation and anthropogenic sources, respectively, while the third component has been investigated in order to point out seismo-associated disturbances. By applying principal component analysis to magnetic data from six observatories (4 near Napa, California, together with two remote reference stations), Kappler et al. (2017) were able to identify and distinguish global geomagnetic signals (such as solar-generated noise) and anthropogenic signals.

Recently some authors have explored the application of machine learning methods for automatically classifying and recognizing earthquake precursors on ground and in space (see for example Rouet-Leduc et al., 2017; Li et al., 2018; 
Akyol et al., 2020; Johnson et al., 2021; Xiong et al., 2020; Xiong et al., 2021). The field of research is very interesting, but asks for some caution. Even though the amount of available observations is huge, the supervised methods could suffer the difficulty of learning from a limited number of tagged measurement: because even for scientists the signature of possible precursors is still unclear, it is hard to define a clear "learning path" for an automatic recognition. On the other side, the unsupervised methods could help in extracting/clarifying the signature of precursors, but the artificial intelligence systems should be trained also in distinguishing spurious phenomena for the needed background rejection.

\section{REPORTS OF EARTHQUAKE LIGHTS FROM WITNESSES AND ANOMALIES IN ANIMAL BEHAVIOUR}

One of the most controversial debates about earthquake precursors is the presumed correlation between the occurrence of seismic events and: 1) observations of earthquake lights; 2) reports of anomalous animal behaviour. We highlight that these two groups of alleged precursors are significantly inhomogeneous and very different from each other. Nevertheless, we present them in the same paragraph not with the purpose of mixing such a broad phenomenology, but because they often share a noninstrumental method of observation (with some recent, but still rare and unclear exceptions of photo/video recording) and suffer from the high variability of sensory perceptions by biological organisms with the consequent inherent difficulty of assessing the statistical significance of the reports.

\section{Reports on Earthquake Lights}

Pre- and co-seismic visible luminescence phenomena (so-called earthquake lights, EQLs for short) have been reported by several authors such as Galli (1910), Terada (1930), Richter (1958) and Yasui (1968) that published the first photograph of EQL; Derr (1973), Derr (1986), Tsukuda (1997) for the Kobe earthquake; Papadopoulos (1999), Stothers (2004), St-Laurent (2000) and Omori et al. (2007). The reports refer primarily to shallow earthquakes of high magnitude, but in some cases, observations have also been collected on medium events with deeper epicentres. EQLs have been reported from a few up to several kilometers from the epicenter, across the visible spectrum, with durations ranging from a fraction of a second to several seconds. EQLs have been sighted both before (from several weeks to a few seconds, near the epicenter) and during earthquakes (even far from the epicentre). More recently, in his valuable catalog of evidence of eyewitnesses - ranging from 9 months before up to five months after the main shock of the 2009 L'Aquila earthquake-Fidani (2010) compiled a careful classification (and an attempt to locate) observations of lights, flames and other bright observations-reported in a wide area up to $50 \mathrm{~km}$ far the city of L'Aquila and along the Aterno valley-looking for a correlation with the occurrence of the earthquakes of the L'Aquila seismic sequence. Heraud and Lira (2011) reported some EQLs that would have occurred during the
2007 Pisco earthquake-also supported by a video recording, and apparently not induced by thunderstorms or electrical faults-suggesting that they would have been generated by some electrical phenomena not yet understood in the atmosphere above the epicentral area. In general, some of the EQLs reported in the literature seem less convincing, however, some characteristics of the EQLs (shapes, colours, flames, etc.) are recurrent in the evidences (such as in the L'Aquila, Saguenay, and Pisco events) and the quantity of observations ask for a careful consideration of this phenomenon. Persinger, (1983) suggested that co-seismic EQLs would be related to energy release during fracturing of rocks; (Brady and Rowell, 1986; Kato et al., 2010; Martinelli et al., 2020b) and other authors showed that under high-stress conditions rocks could emit electromagnetic radiation prior to fracture. Additional hypotheses have been proposed in order to explain the origin of EQLs (Mizutani et al., 1976; StLaurent et al., 2006), including a generation due to gas and aerosol exhalation Liperovsky et al. (2005) and a high-frequency electromagnetic origin Liperovsky et al. (2008b). Analysing the observation of claimed EQLs potentially associated to about 65 earthquakes (38 from Europe and 27 from the Americas) in different geotectonic settings, Thériault et al. (2014) proposed an updated model for the origin of EQLs associated with both intraplate and interplate earthquakes, which is based on the generation of electron charge carriers under high-voltage conditions (see also Freund et al., 2009; Freund 2010). Their thesis is that EQLs may be predominantly associated with intraplaque earthquakes within or nearby rift-related structures. EQLs do not always appear to occur before all strong earthquakes, and they vary in rate. Freund et al. (2021) suggested a solid-state physics mechanism that could take into account the variety of phenomenology. The peroxy defects in igneous rocks-mainly in gabbroic rocks that fill the sub vertical dykes and would be preferentially located along boundaries or between adjacent mineral grains-would make them highly susceptible to ever so slight displacements of mineral grains. The propagation of seismic waves would activate peroxy bonds generating charges displacement. The co-seismic EQL would be caused by the rupture of peroxy bonds, a discharge from the top of the dyke, removing some of the charge carriers. Less evident is how the other processes (corona discharges, thermal infrared emissions, air ionization as well as ion and electron fluctuation in the ionosphere, and electro-magnetic anomalies) would be generated by such mechanism before the propagation of seismic mechanical waves. Within the already highly debated topic of earthquake precursors Hough (2016), the complexity of the observations of pre- and co-earthquake EQLs is even more controversial because analysing eyewitness observations is much more difficult than studying instrumental measurements. Moreover, the possibility of misinterpretations is not negligible, also because the survey of witnesses is generally based on questionnaires filled out and collected after tragic events in very difficult and stressful environmental conditions. Therefore, the statistical completeness of anecdotic or sparse datasets could strongly influence the interpretation of the collected data, the over- or under-estimation of outliers and the rejection of spurious cases. In addition, at least in some 
cases, data are collected and analysed much later than the seismic events, when eyewitness accounts may no longer be independent. Photographic and video evidences are certainly a valuable tool to support the reliability and objectivity of claimed observations, but published testimonies leave room for uncertainty and interpretation. Despite the large amount of testimony collected in published about EQLs (see also Lockner et al., 1983; Johnston, 1991; Whitehead and Ulusoy, 2015 and reference therein), it appears that the rate of observation by witnesses for EQLs is significantly lower than even the most conservative estimates of hallucination prevalence in the normative population. This consideration is neither a bias due to the authors' skepticism nor a preclusion against the investigation and existence of EQLs, but something that should be cautiously taken into account when assessing the reliability of this intriguing phenomenon. Indeed, it is worth noting that the prevalence of hallucinations is by no means negligible even in the general population (which may include psychotics, whether they know they are psychotic or not. Some estimates of prevalence in nonclinical samples are about 10\% (Sidgwick, 1891; West, 1948; Posey and Losch, 1983; Asaad and Shapiro, 1986; Sidgwick et al., 1994). Tien (1991) suggested 10-30 cases per 1,000 people per year while for Ohayon (2000) (although the methodology adopted is open to criticism) up to $40 \%$ of the 13,000 subjects included in the study would have experienced daytime hallucinations, demonstrating how hallucinations can occur sporadically even in healthy subjects in normative populations (including all possible types of dis- or mis-perception). More recently, Temmingh et al. (2011) suggest a lifetime prevalence of $10-15 \%$ for vivid sensory hallucinations. Because of the difficult conditions of a post-earthquake survey, reports published in EQLs include limited information on some key witness parameters (such as education, occupation, alcohol and drug use, and cognitive status) that play a role in estimating the status of participants in psychological studies (e.g., Badcock et al., 2017; Eaton and Kessler, 1985), and that should, at least, not be ignored when collecting and evaluating data from witnesses of earthquake observations. Memories of witnesses and therefore a precise time location of the observations are key points in distinguishing EQL occurred during main shocks or before them (but possibly during foreshocks). If the co-seismic intense flashes of light bursting out of the ground could be "more easily" reconciled with the propagation of seismic waves (Freund, 2019), the preseismic luminous events are more debated, even though the supporters of EQLs claim a common origin of pre- and co-earthquake visible emissions. Therefore, filtering psychological uncertainty and the future instrumental proofs could help in cross-checking eyewitness testimonials and clarifying EQLs existence and origin. The need to consider all possible biases, including possible "human illusions," in the difficult task of distinguishing EQLs from background noise is relevant not only to reject spurious events, but also to estimate the possible rate of EQLs. According to Papadopoulos (1999), De Ballore (1913) and Mallet (1855) and Thériault et al. (2014), EQLs would occur in about $10 \%$ of earthquakes (5-6\% at night, while they would be hardly visible during the day) but for Persenger and Derr (1984) this percentage would represent a lower limit because many observed EQLs would never be reported and published in the scientific literature, or are interpreted as unidentified flying objects (UFOs) (Devereux et al., 1983). All these aspects should be carefully evaluated in surveys (including those aimed at estimating EQLs) in populations exposed to long and highly stressful conditions-such as the seismic sequence that often precedes main earthquakes-which obviously have an impact on the psychological and psychiatric response to environmental stimuli (individual and social) possibly varying the threshold of reaction as well as the sensitivity of witnesses, even if sincere and in good faith!

\section{Can Anomalies in Animal Behaviour be Reliably Correlated With Impending Earthquakes?}

In the letter of 1949, recently published Dyer et al. (2021), in reference to the work of Karl von Frisch (Nobel Prize in Physiology in 1973) and the sensory perception of animals, A. Einstein wrote "It is conceivable that the investigation of the behaviour of migratory birds and homing pigeons may one day lead to the understanding of some physical process that is not yet known". A few words that show an insight into animal ethology and physiology that preceded by more than half a century the investigations and discoveries of our years about some animals capabilities (Wu and Dickman, 2012; Lambert et al., 2013; Mouritsen, 2018). But, can birds be sensitive to earthquakes as Yosef (1997) has suggested? It is well know that birds can use the Sun, stars, and magnetic field to orient themselves; young and adult turtles as well as salmon navigate using the geomagnetic field as a reference system (Lohmann, 2007; Lohmann and Lohmann, 2019); glass eels would have a magnetic compass linked to the tidal cycle (Cresci et al., 2017); cellular autofluorescence is sensitive to the magnetic field (Ikeya and Woodward, 2021); etc. Although, such research could also shed new light on the long-standing claim that animals are sensitive to earthquake precursors (see for example Ikeya, 2004; Freund and Stolc, 2013; Yamauchi et al., 2014; Grant et al., 2015 and therein references) however, this topic is highly debated to the point of overt skepticism even within the most open and convinced scientific community to investigate precursors. In their famous paper, Woith et al. (2018) analysed more than 700 reports of claimed correlation between earthquakes and "anomalies" in animal behaviour. Observations have been claimed for organisms belonging to more than one hundred different species-ranging from deep-sea fish (Orihara et al., 2019) to catfish (Musha, 1957), from mice (Ikeya et al., 1996) to elephants (Garstang, 2009), from pets to snakes (Tributsch, 1982), from cows (Fidani et al., 2014; Yamauchi et al., 2017) to mouse (Yokoi et al., 2003), etc.-published in nearly 200 papers. Hypotheses advanced to explain the claimed anomalous animal behaviours range from a high sensitivity (postulated but not demonstrated) of animals to earthquakerelated mechanical oscillations to their claimed ability to sense magnetic field fluctuations of a few nanotesla (Li et al., 2009) (which should be cautiously verified, pre-earthquake magnetic anomalies being detected even below this threshold). The claimed observation distance varies from a few up to 
hundreds of kilometers, but most of them were observed within $100 \mathrm{~km}$ of the epicentre and about $70 \%$ within $50 \mathrm{~km}$. Although the advance in time varies from a few minutes to months before the earthquake, the number of claimed observations increases close to the seismic event and almost $60 \%$ of the cases fall in the last $5 \mathrm{~min}$. Observations of claimed abnormal animal behaviour have been reported for several earthquakes worldwide, but more than $50 \%$ of the reports relate to only 3 earthquakes out of the 160 analysed by Woith et al. (2018). Beyond the specific reports, the objective difficulties in analysing data (and screening publications) on putative earthquake precursors based on animal behaviour can be summarized as follows: 1) the common bias of categorizing animal behavior as anomalous events only ex post seismic events; 2) the often unclear distinction of normal/anomalous behavior when a threshold and quantitative criteria are missing (preventing a clear definition of the signal-to-noise ratio); 3) the frequent cases of (too) short or partially published time series [focusing only on the "relevant" (claimed) portion of the "anomalous" data]; 4) the partial or missing monitoring of environmental variables (such as meteorological parameters, moon phase illumination, ethological constraints/variabilities, human or predatory conditioning, animal health conditions, etc.) that may influence animal behavior even under normal conditions; 5) statistical uncertainty in looking for recurrence/exceptionality when comparing too short time series of biological cycles with external sporadic events. Some attempts have been made in the past to evaluate (systematically and independently) the reliability of some earthquake prediction approaches and methods, such as the IASPEI initiative (Wyss, 1997; Wyss and Dmowska, 1997), or the international Collaboratory for the Study of Earthquake Predictability (CSEP) (Jordan, 2006; Michael and Werner 2018), etc. However, regardless of the initiatives, these approaches cannot be fruitfully applied to control animal observations because of the incomplete description of the original observations, the lack of data, and the difficulty of repeating observations under similar and controlled seismic and environmental conditions (Fidani, 2013; Fidani et al., 2014). The combined effect of too short time series, the periodicity of biological cycles, phase shifts, and the temporal distribution of earthquakes in long seismic sequences (with the difficulty of distinguishing foreshocks and aftershocks) can lead to misinterpreting random coincidences for positive correlations. Indeed, for example, the $80 \%$ success rate of catfish in alerting for an incoming earthquake claimed by Hatai and Abe (1932) should be interpreted more carefully because on $85 \%$ of the observation days an earthquake occurred by chance. Similarly, the claimed anomalies in toad behaviour (Grant and Halliday, 2010) were observed in too short a time period compared to the overlap between their life cycle and the long sequence of the L'Aquila earthquake. The correlation between earthquake and anomalies in ant behavior suggested by Berberich et al. (2013) was not confirmed in the longer study, up to two years, by Apostol et al. (2014). And the list could be longer. Furthermore, modeling the reasons that might have driven the emergence of animal sensitivity to earthquake precursors is even more complex because it is unclear what ethological stressor might have driven the natural selection of individuals capable of recognizing earthquake-related phenomena. Even less clear is why and how this sensitivity appeared in many species (of different phylum, class, order, genus, and species) and living in such diverse environments (on land, in the sea, and in the air). Indeed, although earthquakes are disruptive to human constructions, their occurrence is relatively infrequent (even in the zone of maximum seismicity) and generally safe for animals, so it is difficult to justify that mechanical effects in the destruction of burrows or eggs can explain an adaptive response and (generalized) modification of the genome and/or ethology of animals. The hypotheses advanced can be summarized into two main groups. Adaptive evolution may have developed/increased the animals' sensitivity to early mechanical oscillations of P- and S-waves (Wikelski et al., 2020). This hypothesis has the advantage that the presumed increased ability would not necessarily be a specific response to seismic stimuli, but could simply be an increased sensitivity to noise and infrasonic waves, naturally evolved as a reaction to predator pressure (Kirschvink, 2000). On the other hand, it has been suggested that animals would be highly sensitive to fluctuations in earthquake-related parameters [such as magnetic field, humidity (Tichy and Loftus, 1996), temperature, etc.]. Although, by altering the magnetic field it has been experimentally demonstrated that it is possible to change the direction of flight of birds within a Faraday cage, it is not correct to infer the statement that all birds or animals in all circumstances are equally sensitive to the magnetic field (Kirschvink, et al., 2010). For example, even in the pigeon-which is not a migratory bird but tends to return to the dovecote-the orientation system is more complex and not yet fully understood. Mora et al. (2004) suggested that iron-rich cells in the beaks of pigeons were nerve cells containing magnetite and thus able to aid navigation through the Earth's magnetic field. However, Treiber et al. (2012) and Treiber et al. (2013) realized that the iron-rich cells are actually immune system cells (macrophages) and not neurons. Magrophages could probably have a function in orientation toward the dove, but not in orientation with respect to the magnetic field. Furthermore, while sensitivity to the quasi-static geomagnetic field, which allows animals to map and recognize their environment, may support orientation as well as migration, the postulated sensitivity of animals to even the highest frequency content of electromagnetic spectra (which could be relevant to earthquakes) is less convincing. More recently, some complex scenarios have been suggested about a putative mechanism of magnetoreception by electromagnetic induction in the inner ear of some birds (Nimpf et al., 2019). From this perspective, nonstatic magnetic field sensitivity would not be an evolutionary capacity driven by seismic events, but a collateral/derived capacity consisting of a lowered response threshold. To explain the biological effects of weak magnetic fields, some molecular transduction mechanisms have been proposed (Binhi and Prato 2018; Bialas et al., 2019). While for animal navigation/orientation, the main hypothesis is a specialized magnetic sense associated with pairs of radicals located in the 
retina of the eye, nonspecific effects could occur due to the interaction of magnetic fields with the magnetic moments of rotating molecules dispersed in the organism. Indeed, Binhi and Prato (2018) have shown that the precession of the magnetic moments of these rotating molecules can be slowed due to a mixing of the quantum levels of magnetic moments (LMMs) inducing a magnetic field dependence that is in good agreement with experiments in which biological effects arise in response to the reversal of magnetic field orientation. Although these studies would suggest a (potentially "common") sensitivity of biological organisms to the magnetic field, even under non-static conditions, nevertheless, at present, the purported response of animals to earthquake precursors seems a bit of a blanket statement. Indeed, such sensitivity-even greater than the instrumental sensitivity of measurements made in various test campaigns to study earthquake precursors-would cut across so many different species that they do not share other important sensory characteristics. Systematic monitoring campaigns with continuous bio-logging of animal collectives, including movements and physiological parameters - such as the experiments about ultra-sensitive measurement of micromovement of cows in the stable and on pasture (see Brown et al., 2013; Wikelski, et al., 2020), and therein references-could yield valuable insights on this topic.

\section{CONCLUSION}

The hypothesis that before earthquake it could be possible to detect surface deformations is supported by the observation of dilatancy effects in labs experiments before rocks rupture. GPS and satellitebased SAR interferometry have given powerful tools for such a worldwide investigation both on local scale and on the continental one through the measurements carried out along the plate boundary. However the growth of the observed effects that would prelude to the earthquakes would not allow defining time and place of the occurrence.

All the physical models claimed to explain precursors share the hypothesis that fast and non-linear processes in the rocks along the seismic fault (such as deformation, dilatancy, fluids flow changes, pores volume variation, etc.) could originate the anomalous variations of observed parameters. Even though experiments and theoretical models give some hints about the possibility to reconcile the observed phenomenology with physical mechanisms operative in the active faults-and nonlinear effects have been detected in laboratory tests-the scalability of results obtained in small-size labs experiments up to the large scale of real seismic fault dynamics is highly debated mainly for the large uncertainty about the values of many key parameters that are still barely known in the depth conditions of the faults.

The proposed models of a direct propagation of an electrostatic disturbance from ground to the upper atmosphere and then in the ionosphere have been ruled out by theoretical calculations and simulations. In this framework, it has been suggested that the lithosphere-atmosphere-ionosphere coupling could be due to atmospheric processes including acoustic gravity waves. It worth noting that the complexity of the observed phenomenology-and mainly the high variability of the spatial and temporal scales of the ionospheric preseismic fluctuations-could be hardly reconciled with only one single coupling mechanism prevailing over all the other proposed models. On this basis, the hypothesis that the lithosphereatmosphere-ionosphere coupling is implemented by multiple physical mechanisms together seems reasonable. For example, the variation of geochemical species (mainly radon exhalations) proposed in order to explain atmospheric thermal anomalies could also generate atmospheric oscillations that can trigger AGW.

Even though the spatial distribution of preseismic geochemical fluids variations (groundwater level, vapour emissions, gases releases and radioactivity fluctuations) would be correlated with the geographical system of seismic faults, the timing of the anomalies could still be basically random as well as the earthquakes themselves and their foreshocks, generating a $<<$ mosaic of precursors $>>$ (Sorokin et al., 2020) function of depth and magnitude.

Up to now, in several proposed models, a key role seems played by radon emission that would vary atmospheric parameters (such as conductivity) inducing a reaction in the global electric circuits. From one side, this prospective avoids the difficulties of a direct propagation of electromagnetic signal. However, from another side, probably, these hypotheses, if confirmed, expose the research of earthquake precursors to further conceptual and practical difficulties due such as: the complexity of transport and diffusion processes; the effect of convection and turbulence in the atmosphere; the difficulty in distinguishing seismo-associated signals from the large electromagnetic noise due to thunderstorm electricity, artificial signals and geomagnetic activity. However, achieving a better understanding of the physics of earthquakes (before, during, and after the seismic event) deserves the efforts being made by the involved scientific community worldwide.

\section{AUTHOR CONTRIBUTIONS}

All authors listed have made a substantial, direct, and intellectual contribution to the work and approved it for publication.

\section{ACKNOWLEDGEMENT}

This work was supported by the Italian Space Agency in the framework of the "Accordo Attuativo 2020-32.HH.0 Limadou Scienza+” (CUP F19C20000110005). 


\section{REFERENCES}

Afraimovich, E. L., and Astafyeva, E. I. (2008). TEC Anomalies-Local TEC Changes Prior to Earthquakes or TEC Response to Solar and Geomagnetic Activity Changes? Earth Planet. Sp. 60 (9), 961-966. doi:10.1186/BF03352851

Akhoondzadeh, M. (2015). Ant Colony Optimization Detects Anomalous Aerosol Variations Associated with the Chile Earthquake of 27 February 2010. Adv. Space Res. 55 (7), 1754-1763. doi:10.1016/j.asr.2015.01.016

Akhoondzadeh, M., De Santis, A., Marchetti, D., Piscini, A., and Cianchini, G. (2018). Multi Precursors Analysis Associated with the Powerful Ecuador $(\mathrm{MW}=7.8)$ Earthquake of 16 April 2016 Using Swarm Satellites Data in Conjunction with Other Multi-Platform Satellite and Ground Data. Adv. Space Res. 61 (1), 248-263. doi:10.1016/j.asr.2017.07.014

Akhoondzadeh, M., and Jahani Chehrebargh, F. (2016). Feasibility of Anomaly Occurrence in Aerosols Time Series Obtained from MODIS Satellite Images during Hazardous Earthquakes. Adv. Space Res. 58 (6), 890-896. doi:10.1016/ j.asr.2016.05.046

Akhoondzadeh, M. (2013). Novelty Detection in Time Series of ULF Magnetic and Electric Components Obtained from DEMETER Satellite Experiments above Samoa (29 September 2009) Earthquake Region. Nat. Hazards Earth Syst. Sci. 13 (1), 15-25. doi:10.5194/nhess-13-15-2013

Akselevich, V. I., and Tertyshnikov, A. V. (1995). METHODOLOGY OF ECOLOGICAL MONITORING DATA APPLICATION TO SEISMIC FORECASTING. Atmos. Oceanic Opt. 8 (7), 567-569.

Akyol, A. A., Arikan, O., and Arikan, F. (2020). A Machine Learning-Based Detection of Earthquake Precursors Using Ionospheric Data. Radio Sci. 55 (11), e2019RS006931. doi:10.1029/2019RS006931

Alam, A., Wang, N., Zhao, G., and Barkat, A. (2020). Implication of Radon Monitoring for Earthquake Surveillance Using Statistical Techniques: A Case Study of Wenchuan Earthquake. Geofluids., 2020, 1-14. doi:10.1155/2020/ 2429165

Alekseev, V. A., and Alekseeva, N. G. (1992). Investigation of Metal Transfer in the Biosphere during Gaseous Emission in Zones of Tectonic Activity Using Methods of Nuclear-Physics. Nucl. Geophys. 6 (1), 99-110.

Allegri, L., Bella, F., Della Monica, G., Ermini, A., Improta, S., Sgrigna, V., et al. (1983). Radon and Rilt Anomalies Detected before the Irpinia (South Italy) Earthquake of November 23, 1980 at Great Distances from the Epicenter. Geophys. Res. Lett. 10 (4), 269-272. doi:10.1029/GL010i004p00269

Amonte, C., Asensio-Ramos, M., Melián, G. V., Pérez, N. M., Padrón, E., Hernández, P. A., et al. (2021). Hydrogeochemical Temporal Variations Related to Changes of Seismic Activity at Tenerife, Canary Islands. Bull. Volcanol. 83, 24. doi:10.1007/s00445-021-01445-4

Apostol, A., Moldovan, I.-A., Constantin, A. P., and Toader, V. E. (2014). “Are Red wood Ants Earthquake Predictors," in Proceedings of Second European Conference on Earthquake Engineering and Seismology 2nd ECEES), Istanbul, 1-3. http://www.eaee.org/Media/Default/2ECCES/2ecces_esc/2298.pdf.

Asaad, G., and Shapiro, B. (1986). Hallucinations: Theoretical and Clinical Overview. Am. J. Psychiatry 143 (Issue 9), 1088-1097. doi:10.1176/ ajp.143.9.1088

Asteriadis, G., and Livieratos, E. (1989). Pre-seismic Responses of Underground Water Level and Temperature Concerning a 4.8 Magnitude Earthquake in Greece on October 20, 1988. Tectonophysics 170 (1-2), 165-169. doi:10.1016/ 0040-1951(89)90111-X

Avlonitis, M., and Papadopoulos, G. A. (2014). Foreshocks and B Value: Bridging Macroscopic Observations to Source Mechanical Considerations. Pure Appl. Geophys. 171 (10), 2569-2580. doi:10.1007/s00024-014-0799-6

Badcock, J. C., Dehon, H., and Larøi, F. (2017). Hallucinations in Healthy Older Adults: An Overview of the Literature and Perspectives for Future Research. Front. Psychol. 8 (JUL), 1134. doi:10.3389/fpsyg.2017.01134

Bakun, W. H., and Lindh, A. G. (1985). The Parkfield, California, Earthquake Prediction experiment. Science 229 (4714), 619-624. doi:10.1126/ science.229.4714.619

Bé, M.-M., Coursol, N., Duchemin, B., Lagoutine, F., and Legrand, J. (2011). Note Technique LNHB 2011/53, Gif-sur-Yvette: CEA Saclay.

Bella, F., Biagi, P. F., Caputo, M., Cozzi, E., Della Monica, G., Ermini, A., et al. (1998). Field Strength Variations of LF Radio Waves Prior to Earthquakes in central Italy. Phys. Earth Planet. Interiors 105 (3-4), 279-286. doi:10.1016/ S0031-9201(97)00097-6

Bella, F., Biagi, P. F., Caputo, M., Cozzi, E., Monica, G. D., Ermini, A., et al. (1995a). Helium Content in thermal Waters in the Caucasus from 1985 to 1991 and Correlations with the Seismic Activity. Tectonophysics 246 (4), 263-278. doi:10.1016/0040-1951(94)00260-G

Bella, F., Biagi, P. F., Caputo, M., Monica, G. D., Ermini, A., Manjgaladze, P. V., et al. (1995b). Possible Creep-Related Tilt Precursors Obtained in the Central Apennines (Italy) and in the Southern Caucasus (Georgia). Pageoph 144 (2), 277-300. doi:10.1007/bf00878635

Ben-Zion, Y., Eneva, M., and Liu, Y. (2003). Large Earthquake Cycles and Intermittent Criticality on Heterogeneous Faults Due to Evolving Stress and Seismicity. J. Geophys. Res. 108 (B6), 2307. doi:10.1029/2002jb002121

Berberich, G., Berberich, M., Grumpe, A., Wöhler, C., and Schreiber, U. (2013). Early Results of Three-Year Monitoring of Red Wood Ants' Behavioral Changes and Their Possible Correlation with Earthquake Events. Animals 3 (1), 63-84. doi:10.3390/ani3010063

Bernabé, Y., Mok, U., and Evans, B. (2003). Permeability-porosity Relationships in Rocks Subjected to Various Evolution Processes. Pure Appl. Geophys. 160 (5-6), 937-960. doi:10.1007/PL00012574

Bi, Y., Wu, S., Xiong, P., and Shen, X. (2009). A Comparative Analysis for Detecting Seismic Anomalies in Data Sequences of Outgoing Longwave Radiation. Lecture Notes in Computer Science (Including Subseries Lecture Notes in Artificial Intelligence and Lecture Notes in Bioinformatics), Berlin: Springer, 5914, 285-296. doi:10.1007/978-3-642-10488-6_29

Biagi, P. F., Ermini, A., and Kingsley, S. P. (2001b). Disturbances in LF Radio Signals and the Umbria-Marche (Italy) Seismic Sequence in 1997-1998. Phys. Chem. Earth, C: Solar, Terrestrial Planet. Sci. 26 (10-12), 755-759. doi:10.1016/ S1464-1917(01)95021-4

Biagi, P. F., Ermini, A., Kingsley, S. P., Khatkevich, Y. M., and Gordeev, E. I. (2001a). Difficulties with Interpreting Changes in Groundwater Gas Content as Earthquake Precursors in Kamchatka, Russia. J. Seismology 5 (4), 487-497. doi:10.1023/A:1012015317086

Biagi, P. F., Maggipinto, T., Righetti, F., Loiacono, D., Schiavulli, L., Ligonzo, T., et al. (2011). The European VLF/LF Radio Network to Search for Earthquake Precursors: Setting up and Natural/man-Made Disturbances. Nat. Hazards Earth Syst. Sci. 11 (2), 333-341. doi:10.5194/nhess-11-333-2011

Biagi, P. F., Piccolo, R., Castellana, L., Maggipinto, T., Ermini, A., Martellucci, S., et al. (2004). VLF-LF Radio Signals Collected at Bari (South Italy): A Preliminary Analysis on Signal Anomalies Associated with Earthquakes. Nat. Hazards Earth Syst. Sci. 4 (5-6), 685-689. doi:10.5194/nhess-4-685-2004

Biagi, P. F. (2009). "Pre and Post Seismic Disturbances Revealed on the Geochemical Data Collected in Kamchatka (Russia) during the Last 30 Years," in Electromagnetic Phenomena Associated with Earthquakes. Editor M. Hayakawa (Kerala: Transworld Research Network), 97-117.

Bialas, C., Barnard, D. T., Auman, D. B., McBride, R. A., Jarocha, L. E., Hore, P. J., et al. (2019). Ultrafast Flavin/tryptophan Radical Pair Kinetics in a Magnetically Sensitive Artificial Protein. Phys. Chem. Chem. Phys. 21 (25), 13453-13461. doi:10.1039/c9cp01916b

Bianchi, C., and Meloni, A. (2007). Natural and Man-Made Terrestrial Electromagnetic Noise: An Outlook. Ann. Geophys. 50 (3), 435-445. doi:10.4401/ag-4425

Binhi, V. N., and Prato, F. S. (2018). Rotations of Macromolecules Affect Nonspecific Biological Responses to Magnetic fields. Sci. Rep. 8 (1), 13495. doi:10.1038/s41598-018-31847-y

Blackett, M., Wooster, M. J., and Malamud, B. D. (2011). Exploring Land Surface Temperature Earthquake Precursors: A Focus on the Gujarat (India) Earthquake of 2001. Geophys. Res. Lett. 38 (15), 15303. doi:10.1029/ 2011 GL048282

Blanchard, D. C. (1963). The Electrification of the Atmosphere by Particles from Bubbles in the Sea. Prog. Oceanography 1 (C), 73-202. doi:10.1016/00796611(63)90004-1

Boyarchuk, K. A. (1997). Kinetics of Elementary Ions in the Lower Atmosphere Acted upon by Ionizing Radiation. Izvestiya. Atmos. Oceanic Phys. 33 (2), 214-217.

Brace, W. F. (1978). Volume Changes during Fracture and Frictional Sliding: A Review. Pure and Applied Geophysics PAGEOPH, 116, 603-614. doi:10.1007/ BF00876527 
Brady, B. T., and Rowell, G. A. (1986). Laboratory Investigation of the Electrodynamics of Rock Fracture. Nature 321 (6069), 488-492. doi:10.1038/ 321488a0

Bredehoeft, J. D. (1967). Response of Well-Aquifer Systems to Earth Tides. J. Geophys. Res. 72 (12), 3075-3087. doi:10.1029/jz072i012p03075

Brown, D. D., Kays, R., Wikelski, M., Wilson, R., and Klimley, A. (2013). Observing the Unwatchable through Acceleration Logging of Animal Behavior. Anim. Biotelemetry 1 (1), 20. doi:10.1186/2050-3385-1-20

Bryant, N. A., and Nathan, R. B. (2003). "Observed Weather Satellite Thermal Responses Prior to and after Earthquakes," in AGU 2003 Fall Meeting, T52D04, San Francisco, CA, (. AGU).

Byerlee, J. (1993). Model for Episodic Flow of High-Pressure Water in Fault Zones before Earthquakes. Geology 21 (4), 303. doi:10.1130/0091-7613(1993) $021<0303$ :mfefoh>2.3.co;2

Cai, Z., and Shi, H. X. (1980). An Introduction to Seismological Fluid Geology. Beijing: Seismological Press.

Campbell, W. H. (2009). Natural Magnetic Disturbance fields, Not Precursors, Preceding the Loma Prieta Earthquake. J. Geophys. Res. Space Phys. 114 (A5), n/a. doi:10.1029/2008ja013932

Carreno, E., Capote, R., Yague, A., Tordesillas, J. M., Lopez, M. M., Ardizone, J., et al. (2001). "Observations of thermal Anomaly Associated to Seismic Activity from Remote Sensing." in General Assembly of European Seismology Commission, Portugal, Lisbon, Portugal, 265-269.

Chadha, R. K., Pandey, A. P., and Kuempel, H. J. (2003). Search for Earthquake Precursors in Well Water Levels in a Localized Seismically Active Area of Reservoir Triggered Earthquakes in India. Geophys. Res. Lett. 30 (7), 1416. doi:10.1029/2002GL016694

Chakraborty, S., Sasmal, S., Chakrabarti, S. K., and Bhattacharya, A. (2018). Observational Signatures of Unusual Outgoing Longwave Radiation (OLR) and Atmospheric Gravity Waves (AGW) as Precursory Effects of May 2015 Nepal Earthquakes. J. Geodynamics 113, 43-51. doi:10.1016/j.jog.2017.11.009

Chirkov, Y. B. (2004). The Study of Local Sources of ULF Geoelectric Signals with Steep Fronts. Ann. Geophys. 47 (1), 213-227. doi:10.4401/ag-3273

Chmyrev, V. M., Isaev, N. V., Serebryakova, O. N., Sorokin, V. M., and Sobolev, Y. P. (1997). Small-scale Plasma Inhomogeneities and Correlated ELF Emissions in the Ionosphere over an Earthquake Region. J. Atmos. Solar-Terrestrial Phys. 59 (9), 967-974. doi:10.1016/S1364-6826(96)00110-1

Chmyrev, V. M., Sorokin, V. M., and Shklyar, D. R. (2008). VLF Transmitter Signals as a Possible Tool for Detection of Seismic Effects on the Ionosphere. J. Atmos. Solar-Terrestrial Phys. 70 (16), 2053-2060. doi:10.1016/ j.jastp.2008.09.005

Choudhury, S., Dasgupta, S., Saraf, A. K., and Panda, S. (2006). Remote Sensing Observations of Pre-earthquake thermal Anomalies in Iran. Int. J. Remote Sensing 27 (20), 4381-4396. doi:10.1080/01431160600851827

Chum, J., Liu, J.-Y., Laštovička, J., Fišer, J., Mošna, Z., Baše, J., et al. (2016). Ionospheric Signatures of the April 25, 2015 Nepal Earthquake and the Relative Role of Compression and Advection for Doppler Sounding of Infrasound in the Ionosphere. Earth Planets Space 68 (1), 1-12. doi:10.1186/s40623-016-0401-9

Chung, Y. (1985). Radon Variations at Arrowhead and murrieta Springs: Continuous and Discrete Measurements. Pageoph 122 (2-4), 294-308. doi:10.1007/BF00874600

Cicerone, R. D., Ebel, J. E., and Britton, J. (2009). A systematic compilation of earthquake precursors. Tectonophy. 476 (3-4), 371-396. doi:10.1016/ j.tecto.2009.06.008

Claesson, L., Skelton, A., Graham, C., Dietl, C., Mörth, M., Torssander, P., et al. (2004). Hydrogeochemical Changes before and after a Major Earthquake. Geol 32 (8), 641. doi:10.1130/G20542.1

Cochran, E. S., Vidale, J. E., and Tanaka, S. (2004). Earth Tides Can Trigger Shallow Thrust Fault Earthquakes. Science 306 (5699), 1164-1166. doi:10.1126/ science. 1103961

Console, R., Murru, M., and Alessandrini, B. (1993). Foreshock Statistics and Their Possible Relationship to Earthquake Prediction in the Italian Region. Bull. Seismological Soc. America 83 (4), 1248-1263.

Contadakis, M. E., Arabelos, D. N., Pikridas, C., and Spatalas, S. D. (2012). Total Electron Content Variations over Southern Europe before and during the M 6.3 Abruzzo Earthquake of April 6, 2009. Ann. Geophys. 55 (1), 83-93. doi:10.4401/ ag-5322
Craig, H., Chung, Y., Poreda, J., Lupton, J., and Damascene, S. (1980). Fluid-phase earthquake precursor studies in southern California. Eos, Transactions, American Geophysical Union 61 (1035), 1035.

Cresci, A., Paris, C. B., Durif, C. M. F., Shema, S., Bjelland, R. M., Skiftesvik, A. B., et al. (2017). Glass Eels (Anguilla anguilla) Have a Magnetic Compass Linked to the Tidal Cycle. Sci. Adv. 3 (6), e1602007. doi:10.1126/sciadv.1602007

Cui, J., Shen, X., Zhang, J., Ma, W., and Chu, W. (2019). Analysis of Spatiotemporal Variations in Middle-Tropospheric to UpperTropospheric Methane during the Wenchuan Ms = 8.0 Earthquake by Three Indices. Nat. Hazards Earth Syst. Sci. 19 (12), 2841-2854. doi:10.5194/nhess-19-2841-2019

Dabas, R. S., Das, R. M., Sharma, K., and Pillai, K. G. M. (2007). Ionospheric Precursors Observed over Low Latitudes during Some of the Recent Major Earthquakes. J. Atmos. Solar-Terrestrial Phys. 69 (15), 1813-1824. doi:10.1016/j.jastp.2007.09.005

Davidenko, D. V., and Pulinets, S. A. (2019). Deterministic Variability of the Ionosphere on the Eve of Strong $(M \geq 6)$ Earthquakes in the Regions of Greece and Italy According to Long-Term Measurements Data. Geomagn. Aeron. 59 (4), 493-508. doi:10.1134/S001679321904008X

Davies, K., and Baker, D. M. (1965). Ionospheric Effects Observed Around the Time of the Alaskan Earthquake of March 28, 1964. J. Geophys. Res. 70 (9), 2251-2253. doi:10.1029/jz070i009p02251

De Luca, G., Di Carlo, G., and Tallini, M. (2018). A Record of Changes in the Gran Sasso Groundwater before, during and after the 2016 Amatrice Earthquake, central Italy. Sci. Rep. 8 (1), 1-16. doi:10.1038/s41598-018-34444-1

De Santis, A., Abbattista, C., Alfonsi, L., Amoruso, L., Campuzano, S. A., Carbone, M., et al. (2019b). Geosystemics View of Earthquakes. Entropy 21 (4), 412. doi:10.3390/e21040412

De Santis, A., Cianchini, G., Marchetti, D., Piscini, A., Sabbagh, D., Perrone, L., et al. (2020). A Multiparametric Approach to Study the Preparation Phase of the 2019 M7.1 Ridgecrest (California, United States) Earthquake. Front. Earth Sci. 8, 478. doi:10.3389/feart.2020.540398

De Santis, A., De Franceschi, G., Spogli, L., Perrone, L., Alfonsi, L., Qamili, E., et al. (2015). Geospace Perturbations Induced by the Earth: The State of the Art and Future Trends. Physics and Chemistry of the Earth, Parts A/B/C, 85-86, 17-33. doi:10.1016/j.pce.2015.05.004

De Santis, A. (2014). Geosystemics, Entropy and Criticality of Earthquakes: A Vision of Our Planet and a Key of Access. Nonlinear Phenomena in Complex Systems: From Nano to Macro Scale. Dordrecht: Springer, 3-20. doi:10.1007/ 978-94-017-8704-8 1

De Santis, A., Marchetti, D., Pavón-Carrasco, F. J., Cianchini, G., Perrone, L., Abbattista, C., et al. (2019a). Precursory Worldwide Signatures of Earthquake Occurrences on Swarm Satellite Data. Sci. Rep. 9 (1), 1-13. doi:10.1038/s41598019-56599-1

Denisenko, V. V., Boudjada, M. Y., and Lammer, H. (2018). Propagation of Seismogenic Electric Currents through the Earth's Atmosphere. J. Geophys. Res. Space Phys. 123 (5), 4290-4297. doi:10.1029/2018JA025228

Denisenko, V. V. (2015). Estimate for the Strength of the Electric Field Penetrating from the Earth's Surface to the Ionosphere. Russ. J. Phys. Chem. B 9 (5), 789-795. doi:10.1134/S199079311505019X

Derr, J. S. (1973). Earthquake Lights: a Review of Observations and Present Theories. Bull. Seismological Soc. America 63 (6-1), 2177-2187.

Derr, J. S. (1986). Rock Mechanics: Luminous Phenomena and Their Relationship to Rock Fracture. Nature 321 (6069), 470-471. doi:10.1038/321470a0

Deverux, P., McCartney, P., and Robins, D. (1983). Bringing UFOSs Down to Earth: many Reports of UFO Sightings Come from Areas Close to Geological Faults. Far from Being Spaceships from Other Worlds, Could the Explanation of UFOs Be Much More Earthbound? New Scientist 99 (1373), 627-630.

Devi, M., Barbara, A. K., Ruzhin, Y. Y., and Hayakawa, M. (2012). Over-theHorizon Anomalous VHF Propagation and Earthquake Precursors. Surv. Geophys. 33 (5), 1081-1106. doi:10.1007/s10712-012-9185-z

Dey, S., Sarkar, S., and Singh, R. P. (2004). Anomalous Changes in Column Water Vapor after Gujarat Earthquake. Adv. Space Res. 33 (3), 274-278. doi:10.1016/ S0273-1177(03)00475-7

Dey, S., and Singh, R. P. (2003). Surface Latent Heat Flux as an Earthquake Precursor. Nat. Hazards Earth Syst. Sci. 3 (6), 749-755. doi:10.5194/nhess-3749-2003 
Dieterich, J. H. (1979). Modeling of Rock Friction: 1. Experimental Results and Constitutive Equations. J. Geophys. Res. 84 (B5), 2161-2168. doi:10.1029/ JB084iB05p02161

Dieterich, J. H. (1978). "Time-Dependent Friction and the Mechanics of Stick-Slip" in Rock Friction and Earthquake Prediction. Editors J. D. Byerlee and M. Wyss, Basel: Birkhäuser Verlag, 790-806. doi:10.1007/978-3-0348-7182-2_15

Draganov, A. B., Inan, U. S., and Taranenko, Y. N. (1991). ULF Magnetic Signatures at The Earth Surface Due to Ground Water Flow: A Possible Precursor to Earthquakes. Geophy. Res. Letters 18 (6), 1127-1130. doi:10.1029/91GL01000

Du, A., Huang, Q., and Yang, S. (2002). Epicenter Location by Abnormal ULF Electromagnetic Emissions. Geophys. Res. Lett. 29 (10), 94-1-94-3. doi:10.1029/ $2001 \mathrm{gl} 013616$

Dudkin, F., Arora, B. R., Korepanov, V., Leontyeva, O., Sharma, A. K., and Sharma, A. K. (2010). Application of Polarization Ellipse Technique for Analysis of ULF Magnetic fields from Two Distant Stations in Koyna-Warna Seismoactive Region, West India. Nat. Hazards Earth Syst. Sci. 10 (7), 1513-1522. doi:10.5194/nhess-10-1513-2010

Dyer, A. G., Greentree, A. D., Garcia, J. E., Dyer, E. L., Howard, S. R., and Barth, F. G. (2021). Einstein, von Frisch and the honeybee: a historical letter comes to light. J. Comp. Physiol. A Neuroethol. Sens. Neural. Behav. Physiol., 1-8. doi:10.1007/s00359-021-01490-6

Eaton, W. W., and Kessler, L. G. (1985). Epidemiologic Field Methods in Psychiatry. Epidemiologic Field Methods in Psychiatry: The NIMH Epidemiologic Catchment Area Program. Elsevier, 1-379. doi:10.1016/C20090-02951-1

Eftaxias, K., Kapiris, P., Polygiannakis, J., Peratzakis, A., Kopanas, J., Antonopoulos, G., et al. (2003). Experience of Short Term Earthquake Precursors with VLF-VHF Electromagnetic Emissions. Nat. Hazards Earth Syst. Sci. 3 (3/4), 217-228. doi:10.5194/nhess-3-217-2003

Erickson, W. C. (1990). "Radio noise near the Earth in the $1 \hat{a} € 30 \mathrm{MHz}$ frequency range" in Low frequency Astrophysics from Space. Springer, 57-69.

Fenoglio, M. A., Johnston, M. J. S., and Byerlee, J. D. (1995). Magnetic and Electric fields Associated with Changes in High Pore Pressure in Fault Zones: Application to the Loma Prieta ULF Emissions. J. Geophys. Res. 100 (B7), 12951-12958. doi:10.1029/95jb00076

Fidani, C. (2013). Biological Anomalies Around the 2009 L'Aquila Earthquake. Animals 3 (3), 693-721. doi:10.3390/ani3030693

Fidani, C., Freund, F., and Grant, R. (2014). Cows Come Down from the Mountains before the $(\mathrm{Mw}=6.1)$ Earthquake Colfiorito in September 1997; a Single Case Study. Animals 4 (2), 292-312. doi:10.3390/ani4020292

Fidani, C. (2010). The Earthquake Lights (EQL) of the 6 April 2009 Aquila Earthquake, in Central Italy. Nat. Hazards Earth Syst. Sci. 10 (5), 967-978. doi:10.5194/nhess-10-967-2010

Fitterman, D. V. (1979). Theory of Electrokinetic-Magnetic Anomalies in a Faulted Half-Space. J. Geophys. Res. 84 (B11), 6031-6040. doi:10.1029/ JB084iB11p06031

Flagg, S., Bleier, T., Dunson, C., Doering, J., DeMartini, L., Clarke, P., et al. (2004). Using Nanosats as a Proof of Concept for Space Science Missions: QuakeSat as an Operational Example. 18th Annual AIAA/USU Conference on Small Satellites, SSC04-IX-4), Logan, 1-12. Available at: https://digitalcommons.usu. $\mathrm{edu} / \mathrm{cgi} / \mathrm{view}$ content.cgi?article $=1728$ andcontext $=$ smallsat.

Fraser-Smith, A. C., Bernardi, A., McGill, P. R., Ladd, M. E., Helliwell, R. A., and Villard, O. G. (1990). Low-frequency Magnetic Field Measurements Near the Epicenter of the Ms7.1 Loma Prieta Earthquake. Geophys. Res. Lett. 17 (9), 1465-1468. doi:10.1029/GL017i009p01465

Fraser-Smith, A. C., McGill, P. R., and Bernardi, A. (2011). Comment on "Natural Magnetic Disturbance fields, Not Precursors, Preceding the Loma Prieta Earthquake" by Wallace H. Campbell. J. Geophys. Res. Space Phys. 116 (A8), n/a-n/a. doi:10.1029/2010ja016379

Freund, F. (2019). Co-seismic Earthquake Lights: The Underlying Mechanism. Pure Appl. Geophys. 176 (8), 3439-3450. doi:10.1007/s00024-019-02142-2

Freund, F. (2013). Earthquake Forewarning - A Multidisciplinary challenge from the Ground up to Space. Acta Geophys. 61 (4), 775-807. doi:10.2478/s11600013-0130-4

Freund, F., Ouillon, G., Scoville, J., and Sornette, D. (2021). Earthquake Precursors in the Light of Peroxy Defects Theory: Critical Review of Systematic
Observations. Eur. Phys. J. Spec. Top. 230 (1), 7-46. doi:10.1140/epjst/e2020000243-x

Freund, F., and Stolc, V. (2013). Nature of Pre-earthquake Phenomena and Their Effects on Living Organisms. Animals 3 (2), 513-531. doi:10.3390/ani3020513

Freund, F. T., Kulahci, I. G., Cyr, G., Ling, J., Winnick, M., Tregloan-Reed, J., et al. (2009). Air Ionization at Rock Surfaces and Pre-earthquake Signals. J. Atmos. Solar-Terrestrial Phys. 71 (17-18), 1824-1834. doi:10.1016/j.jastp.2009.07.013

Freund, F. (2010). Toward a Unified Solid State Theory for Pre-earthquake Signals. Acta Geophys. 58 (5), 719-766. doi:10.2478/s11600-009-0066-x

Friis-Christensen, E., Lühr, H., and Hulot, G. (2006). Swarm: A Constellation to Study the Earth's Magnetic Field. Earth Planet. Sp 58 (4), 351-358. doi:10.1186/ BF03351933

Galli, I. (1910). Raccolta e classificazione di fenomeni luminosi osservati nei terremoti. Boll. Soc. Sismol. Ital. XIV, 221-448.

Garavaglia, M., Dal Moro, G., and Zadro, M. (2000). Radon and Tilt Measurements in a Seismic Area: Temperature Effects. Phys. Chem. Earth, A: Solid Earth Geodesy 25 (3), 233-237. doi:10.1016/S1464-1895(00)00038-7

Garstang, M. (2009). Precursor Tsunami Signals Detected by Elephants. Open Conservat. Biol. J., 3, 1-3.

Geller, R. J. (1997). Earthquake Prediction: a Critical Review. Geophys. J. Int. 131 (3), 425-450. doi:10.1111/j.1365-246X.1997.tb06588.x

Genzano, N., Aliano, C., Filizzola, C., Pergola, N., and Tramutoli, V. (2007). A Robust Satellite Technique for Monitoring Seismically Active Areas: The Case of Bhuj-Gujarat Earthquake. Tectonophysics 431 (1-4), 197-210. doi:10.1016/ j.tecto.2006.04.024

Giovambattista, R. D., and Tyupkin, Y. S. (2004). Seismicity Patterns before the $\mathrm{M}=5.8$ 2002, Palermo (Italy) Earthquake: Seismic Quiescence and Accelerating Seismicity. Tectonophysics 384 (1-4), 243-255. doi:10.1016/ j.tecto.2004.04.001

Gokhberg, M. B., Morgounov, V. A., Yoshino, T., and Tomizawa, I. (1982). Experimental Measurement of Electromagnetic Emissions Possibly Related to Earthquakes in Japan. J. Geophys. Res. 87 (B9), 7824-7828. doi:10.1029/ JB087iB09p07824

Gokhberg, M. B., and Shalimov, S. L. (2000). Lithosphere--ionosphere Relation and its Modeling. Russ. J. Earth Sci. 2 (2), 95-108. doi:10.2205/2000ES000032

Golenetskii, S. I., Dem'yanovitch, M. G., Semenov, R. M., Vas' ko, V. G., Avdeev, V. A., Kashkin, V. F., et al. (1982). Seismicity of the Regions of the Orongoi Basins and the Earthquake of 2 October 1980 in Western Transbaikal. Sov. Geol. Geophys. 23, 39-46.

Grant, R. A., and Halliday, T. (2010). Predicting the Unpredictable; Evidence of Pre-seismic Anticipatory Behaviour in the Common Toad. J. Zoolog. 281 (4), no. doi:10.1111/j.1469-7998.2010.00700.x

Grant, R. A., Raulin, J. P., and Freund, F. T. (2015). Changes in Animal Activity Prior to a Major $(\mathrm{M}=7)$ Earthquake in the Peruvian Andes. Phys. Chem. Earth, Parts A/B/C 85-86 (86), 69-77. doi:10.1016/j.pce.2015.02.012

Gulia, L., and Wiemer, S. (2019). Real-time Discrimination of Earthquake Foreshocks and Aftershocks. Nature 574 (7777), 193-199. doi:10.1038/ s41586-019-1606-4

Hamilton, R. M. (1975). Earthquake Studies in China: A Massive Earthquake Prediction Effort Is Underway. Earthquake Inf. Bull. (Usgs) 7 (6), 3-8. Available at: http://pubs.er.usgs.gov/publication/70178910.

Han, P., Hattori, K., Hirokawa, M., Zhuang, J., Chen, C.-H., Febriani, F., et al. (2014). Statistical Analysis of ULF Seismomagnetic Phenomena at Kakioka, Japan, during 2001-2010. J. Geophys. Res. Space Phys. 119 (6), 4998-5011. doi:10.1002/2014JA019789

Han, P., Hattori, K., Huang, Q., Hirooka, S., and Yoshino, C. (2016). Spatiotemporal Characteristics of the Geomagnetic Diurnal Variation Anomalies Prior to the 2011 Tohoku Earthquake (Mw 9.0) and the Possible Coupling of Multiple Pre-earthquake Phenomena. J. Asian Earth Sci. 129, 13-21. doi:10.1016/j.jseaes.2016.07.011

Han, P., Hattori, K., Xu, G., Ashida, R., Chen, C.-H., Febriani, F., et al. (2015). Further Investigations of Geomagnetic Diurnal Variations Associated with the 2011 off the Pacific Coast of Tohoku Earthquake (Mw 9.0). J. Asian Earth Sci. 114, 321-326. doi:10.1016/j.jseaes.2015.02.022

Hao, J., Tang, T., and Li, D. (2000). Progress in the Research on Atmospheric Electric Field Anomaly as an index for Short-Impending Prediction of Earthquakes. J. Earthquake Prediction Res. 8 (3), 241-255. 
Harper, W. R. (1957). The Generation of Static Charge. Adv. Phys. 6 (24), 365-417. doi:10.1080/00018735700101396

Hartmann, J., and Levy, J. K. (2005). Hydrogeological and Gasgeochemical Earthquake Precursors ? A Review for Application. Nat. Hazards 34 (3), 279-304. Springer. doi:10.1007/s11069-004-2072-2

Hasbi, A. M., Mohd Ali, M. A., and Misran, N. (2011). Ionospheric Variations before Some Large Earthquakes over Sumatra. Nat. Hazards Earth Syst. Sci. 11 (2), 597-611. doi:10.5194/nhess-11-597-2011

Hatai, S., and Abe, N. (1932). The Responses of the Catfish, Parasilurus Asotus, to Earthquakes. Proc. Imperial Acad. 8 (8), 375-378. doi:10.2183/pjab1912.8.375

Hattori, K., Akinaga, Y., Hayakawa, M., Yumoto, K., Nagao, T., and Uyeda, S. (2002). "ULF Magnetic Anomaly Preceding the 1997 Kagoshima Earthquakes," in Seismo Electromagnetics: Lithosphere-Atmosphere-Ionosphere Coupling. Editors M. Hayakawa and O. A. Molchanov (Terra Scientific Pub. Comp), $19-28$.

Hattori, K., Han, P., Yoshino, C., Febriani, F., Yamaguchi, H., and Chen, C.-H. (2013). Investigation of ULF Seismo-Magnetic Phenomena in Kanto, Japan during 2000-2010: Case Studies and Statistical Studies. Surveys in Geophysics. 34 (3), 293-316. doi:10.1007/s10712-012-9215-x

Hattori, K., Serita, A., Yoshino, C., Hayakawa, M., and Isezaki, N. (2006). Singular Spectral Analysis and Principal Component Analysis for Signal Discrimination of ULF Geomagnetic Data Associated with 2000 Izu Island Earthquake Swarm. Phys. Chem. Earth, Parts A/B/C 31 (4-9), 281-291. doi:10.1016/j.pce.2006.02.034

Hattori, K. (2004). ULF Geomagnetic Changes Associated with Large Earthquakes. Terr. Atmos. Ocean. Sci. 15 (3), 329-360. doi:10.3319/ tao.2004.15.3.329(ep)

Hayakawa, M., Asano, T., Rozhnoi, A., and Solovieva, M. (2018). "Very-low- and Low-Frequency Sounding of Ionospheric Perturbations and Possible Association with Earthquakes," in Pre-Earthquake Processes: A Multidisciplinary Approach to Earthquake Prediction Studies. Editors D. Ouzounov, S. Pulinets, K. Hattori, and P. Taylor (Hoboken: Wiley Online Library), 277-304.

Hayakawa, M., Hobara, Y., Ohta, K., and Hattori, K. (2011). The Ultra-lowfrequency Magnetic Disturbances Associated with Earthquakes. Earthq Sci. 24 (6), 523-534. doi:10.1007/s11589-011-0814-2

Hayakawa, M., Kawate, R., Molchanov, O. A., and Yumoto, K. (1996). Results of Ultra-low-frequency Magnetic Field Measurements during the Guam Earthquake of 8 August 1993. Geophys. Res. Lett. 23 (3), 241-244. doi:10.1029/95GL02863

Hayakawa, M., Molchanov, O. A., Ondoh, T., and Kawai, E. (1997). "On the Precursory Signature of Kobe Earthquake on VLF Subionospheric Signals," in IEEE International Symposium on Electromagnetic Compatibility, Beijing, 72-75. doi:10.1109/elmagc.1997.617080

Hayakawa, M. (1994). Terrestrial Electromagnetic Noises. Radiophys Quan. Electron 37 (6), 464-467. doi:10.1007/BF01088657

Hayakawa, M., Yoshino, T., and Morgounov, V. A. (1993). On the Possible Influence of Seismic Activity on the Propagation of Magnetospheric Whistlers at Low Latitudes. Phys. Earth Planet. Interiors 77 (1-2), 97-108. doi:10.1016/0031-9201(93)90036-9

He, C., Dong, S., Santosh, M., and Chen, X. (2014). Seismic Structure of The Longmenshan Area in SW China Inferred From Receiver Function Analysis: Implications for Future Large Earthquakes. J. Asian Earth Sci. 96, 226- 236. doi:10.1016/j.jseaes.2014.09.026

He, L., and Heki, K. (2017). Ionospheric Anomalies Immediately before M W 7.08.0 Earthquakes. J. Geophys. Res. Space Phys. 122 (8), 8659-8678. doi:10.1002/ 2017JA024012

Heaton, T. H. (1975). Tidal Triggering of Earthquakes. Geophys. J. Int. 43 (2), 307-326. doi:10.1111/j.1365-246X.1975.tb00637.x

Heinicke, J., Koch, U., and Martinelli, G. (1995). CO2and Radon Measurements in the Vogtland Area (Germany) - A Contribution to Earthquake Prediction Research. Geophys. Res. Lett. 22 (7), 771-774. doi:10.1029/94GL03074

Heki, K. (2011). Ionospheric Electron Enhancement Preceding the 2011 TohokuOki Earthquake. Geophys. Res. Lett. 38 (17), a-n. doi:10.1029/2011GL047908

Helliwell, R. A. (1965). Whistlers and Related Ionospheric Phenomena, Vol. 50. Calif: Stanford University Press Stanford.

Heraud, J. A., and Lira, J. A. (2011). Co-seismic Luminescence in Lima, $150 \mathrm{Km}$ from the Epicenter of the Pisco, Peru Earthquake of 15 August 2007. Nat. Hazards Earth Syst. Sci. 11 (4), 1025-1036. doi:10.5194/nhess-11-1025-2011
Hitchcock, R. T., and Patterson, R. M. (1995). Radio-frequency and ELF Electromagnetic Energies: A Handbook for Health Professionals. New York: John Wiley \& Sons.

Hobara, Y., and Parrot, M. (2005). Ionospheric Perturbations Linked to a Very Powerful Seismic Event. J. Atmos. Solar-Terrestrial Phys. 67 (7), 677-685. doi:10.1016/j.jastp.2005.02.006

Holub, R. F., and Brady, B. T. (1981). The Effect of Stress on Radon Emanation from Rock. J. Geophys. Res. 86 (B3), 1776-1784. doi:10.1029/JB086iB03p01776

Hong, T.-K., Lee, J., Park, S., and Kim, W. (2018). Time-advanced Occurrence of Moderate-Size Earthquakes in a Stable Intraplate Region after a Megathrust Earthquake and Their Seismic Properties. Sci. Rep. 8 (1), 13331. doi:10.1038/ s41598-018-31600-5

Hough, S. E. (2016). Predicting the Unpredictable: The Tumultuous Science of Earthquake Prediction. Princeton: Princeton University Press. doi:10.1515/ 9781400883547

Hough, S. (2020). The Great Quake Debate: The Crusader, the Skeptic, and the Rise of Modern Seismology. Hough: University of Washington Press.

Hristopulos, D. T., and Mouslopoulou, V. (2013). Strength Statistics and The Distribution of Earthquake Interevent Times. Phys. A: Stat. Mech. Appl. 392, 485-496. doi:10.1016/j.physa.2012.09.011

Huixin, S., and Zuhuang, C. (1986). Geochemical Characteristics of Underground Fluids in Some Active Fault Zones in China. J. Geophys. Res. 91 (B12), 12282-12290. doi:10.1029/jb091ib12p12282

Igarashi, G., Saeki, S., Takahata, N., Sumikawa, K., Tasaka, S., Sasaki, Y., et al. (1995). Ground-water Radon Anomaly before the Kobe Earthquake in Japan. Science 269 (5220), 60-61. doi:10.1126/science.269.5220.60

Igarashi, G., Wakita, H., and Sato, T. (1992). Precursory and Coseismic Anomalies in Well Water Levels Observed for the February 2, 1992 Tokyo Bay Earthquake. Geophys. Res. Lett. 19 (15), 1583-1586. doi:10.1029/92GL01422

Ihmlé, P. F., and Jordan, T. H. (1994). Teleseismic Search for Slow Precursors to Large Earthquakes. Science 266 (5190), 1547-1551. doi:10.1126/ science.266.5190.1547

Ikeya, M. (2004). Earthquakes and Animals. Singapore: World Scientific. doi:10.1142/5382 Earthquakes and Animals

Ikeya, M., Furuta, H., Kajiwara, N., and Anzai, H. (1996). Ground Electric Field Effects on Rats and Sparrows: Seismic Anomalous Animal Behaviors (SAABs). Jpn. J. Appl. Phys. 35 (8), 4587-4594. doi:10.1143/jjap.35.4587

Ikeya, N., and Woodward, J. R. (2021). Cellular Autofluorescence Is Magnetic Field Sensitive. Proc. Natl. Acad. Sci. USA 118 (3), e2018043118. doi:10.1073/ pnas. 2018043118

Inan, S., Akgül, T., Seyis, C., Saatçilar, R., Baykut, S., Ergintav, S., et al. (2008). Geochemical Monitoring in the Marmara Region (NW Turkey): A Search for Precursors of Seismic Activity. J. Geophys. Res. Solid Earth 113 (3), 3401. doi:10.1029/2007JB005206

Inan, S., Ertekin, K., Seyis, C., Şimşek, Ş., Kulak, F., Dikbaş, A., et al. (2010). Multidisciplinary Earthquake Researches in Western Turkey: Hints to Select Sites to Study Geochemical Transients Associated to Seismicity. Acta Geophysica 58 (5), 767-813. doi:10.2478/s11600-010-0016-7

Isaev, N. V., Sorokin, V. M., Chmyrev, V. M., Serebryakova, O. N., and Ovcharenko, O. Y. (2002). "Electric Field Enhancement in the Ionosphere above Tropical Storm Region," in Seismo Electromagnetics: LithosphereAtmosphere-Ionosphere Coupling. Editors M. Hayakawa and O. A. Molchanov, (Tokyo: TERRAPUB), 313-315.

Jacobs, J. A., Kato, Y., Matsushita, S., and Troitskaya, V. A. (1964). Classification of Geomagnetic Micropulsations. J. Geophys., 8 (3), 341-342. doi:10.1111/j.1365246X.1964.tb06301.x

Jhuang, H.-K., Ho, Y.-Y., Kakinami, Y., Liu, J.-Y., Oyama, K.-I., Parrot, M., et al. (2010). Seismo-ionospheric Anomalies of the GPS-TEC Appear before the 12 May 2008 Magnitude 8.0 Wenchuan Earthquake. Int. J. Remote Sensing 31 (13), 3579-3587. doi:10.1080/01431161003727796

Jianguo, H., Tianming, T., and Derui, L. (2000). Progress in the Research on Atmospheric Electric Field Anomaly as an index for Short-Impending Prediction of Earthquakes. J. Earthquake Prediction Res. 8 (3), 241-255.

Jing, F., Shen, X. H., Kang, C. L., and Xiong, P. (2013). Natural Hazards and Earth System Sciences Variations of Multi-Parameter Observations in Atmosphere Related to Earthquake. Hazards Earth Syst. Sci. 13, 27- 33. doi:10.5194/nhess$13-27-2013$ 
Johnson, P. A., Rouet-Leduc, B., Pyrak-Nolte, L. J., Beroza, G. C., Marone, C. J., Hulbert, C., Howard, A., Singer, P., Gordeev, D., Karaflos, D., Levinson, C. J., Pfeiffer, P., Puk, K. M., and Reade, W. (2021). "Laboratory Earthquake Forecasting: A Machine Learning Competition," in Proceedings of the National Academy of Sciences of the United States of America (National Academy of Sciences), 118 Issue 5, e2011362118. doi:10.1073/pnas.2011362118

Johnston, A. C. (1991). Light from Seismic Waves. Nature 354, 361, 1991 . Nature Publishing Group. doi:10.1038/354361a0

Johnston, M. J. S. (1997). Review of Electric and Magnetic fields Accompanying Seismic and Volcanic Activity. Surveys in Geophysics, Netherlands: Springer. 18. Issue 5, 441-476. doi:10.1023/a:1006500408086

Jones, L., and Molnar, P. (1976). Frequency of Foreshocks. Nature 262 (5570), 677-679. doi:10.1038/262677a0

Jones, R. H., and Stewart, R. C. (1997). A Method for Determining Significant Structures in a Cloud of Earthquakes. J. Geophys. Res. 102 (B4), 8245-8254. doi:10.1029/96jb03739

Jordan, T. H. (2006). Earthquake Predictability, Brick by Brick. Seismological Res. Lett. 77 (1), 3-6. doi:10.1785/gssrl.77.1.3

Kafatos, M., Ouzounov, D., Pullinets, S., Cervone, G., and Singh, R. P. (2007). "Energies Associated with the Sumatra Earthquakes of December 26, 2004 and March 28, 2005," in AGU Fall Meeting Abstracts, San Francisco, S42B-S04.2007

Kandalyan, R. A., and AlQuran, M. K. (2010). Ionosphere Scintillation and Earthquakes. Jordan J. Phys. 3 (2), 69-76.

Kappler, K. N., Schneider, D. D., MacLean, L. S., and Bleier, T. E. (2017). Identification and Classification Of Transient Pulses Observed in Magnetometer Array Data by Time-Domain Principal Component Analysis Filtering. Earthquake Sci. 30, 193-207. doi:10.1007/s11589-017-0191-6

Kato, M., Mitsui, Y., and Yanagidani, T. (2010). Photographic Evidence of Luminescence during Faulting in Granite. Earth Planet. Sp 62 (5), 489-493. doi:10.5047/eps.2010.02.004

Kawabe, I. (1985). Anomalous Changes of CH4/Ar Ratio in Subsurface Gas Bubbles as Seismogeochemical Precursors at Matsuyama, Japan. Pageoph 122 (2-4), 194-214. doi:10.1007/BF00874593

Khilyuk, L. F., Robertson, J. O., Jr, Endres, B., and Chilingarian, G. V. (2000). Gas Migration: Events Preceding Earthquakes. Huston: Elsevier.

Kilston, S., and Knopoff, L. (1983). Lunar-solar Periodicities of Large Earthquakes in Southern California. Nature 304 (5921), 21-25. doi:10.1038/304021a0

King, C.-Y. (1986). Gas Geochemistry Applied to Earthquake Prediction: An Overview. J. Geophys. Res. 91 (B12), 12269-12281. doi:10.1029/ jb091ib12p12269

Kirschvink, J. L. (2000). Earthquake Prediction by Animals: Evolution and Sensory Perception. Bull. Seismological Soc. America 90 (2), 312-323. doi:10.1785/ 0119980114

Kirschvink, J. L., Winklhofer, M., and Walker, M. M. (2010). Biophysics of Magnetic Orientation: Strengthening the Interface between Theory and Experimental Design. Journal of the Royal Society Interface, 7 Suppl. 2. doi:10.1098/rsif.2009.0491.focus

Kissin, I. G., and Grinevsky, A. O. (1990). Main Features of Hydrogeodynamic Earthquake Precursors. Tectonophy. 178, 277- 286. doi:10.1016/0040-1951(90) 90154-Z

Klimenko, M. V., Klimenko, V. V., Zakharenkova, I. E., and Pulinets, S. A. (2012). Variations of Equatorial Electrojet as Possible Seismo-Ionospheric Precursor at the Occurrence of TEC Anomalies before strong Earthquake. Adv. Space Res. 49 (3), 509-517. doi:10.1016/j.asr.2011.10.017

Koizumi, N., Kitagawa, Y., Matsumoto, N., Takahashi, M., Sato, T., Kamigaichi, O., et al. (2004). Preseismic Groundwater Level Changes Induced by Crustal Deformations Related to Earthquake Swarms off the East Coast of Izu Peninsula, Japan. Geophys. Res. Lett. 31 (10), a-n. doi:10.1029/2004GL019557

Koizumi, N., Tsukuda, E., Kamigaichi, O., Matsumoto, N., Takahashi, M., and Sato, T. (1999). Preseismic Changes in Groundwater Level and Volumetric Strain Associated with Earthquake Swarms off the East Coast of the Izu Peninsula, Japan. Geophys. Res. Lett. 26 (23), 3509-3512. doi:10.1029/ 1999GL005381

Kon, S., Nishihashi, M., and Hattori, K. (2011). Ionospheric Anomalies Possibly Associated with $M \geqslant 6.0$ Earthquakes in the Japan Area during 1998-2010: Case Studies and Statistical Study. J. Asian Earth Sci. 41 (4-5), 410-420. doi:10.1016/ j.jseaes.2010.10.005
Kondo, G. (1968). The Variation of The Atmospheric Electric Field at The Time of Earthquake. Mem. Kakioka Magnet. Observ. 12, 11-23.

Kopytenko, Y. A., Matiashvili, T. G., Voronov, P. M., Kopytenko, E. A., and Molchanov, O. A. (1993). Detection of Ultra-low-frequency Emissions Connected with the Spitak Earthquake and its Aftershock Activity, Based on Geomagnetic Pulsations Data at Dusheti and Vardzia Observatories. Phys. Earth Planet. Interiors 77 (1-2), 85-95. doi:10.1016/0031-9201(93)90035-8

Korepanov, V., Hayakawa, M., Yampolski, Y., and Lizunov, G. (2009). AGW as a Seismo-Ionospheric Coupling Responsible Agent. Phy. Chem. Earth 34, 485-495. doi:10.1016/j.pce.2008.07.014

Korsunova, L. P., and Khegai, V. V. (2008). Analysis of Seismoionospheric Disturbances at the Chain of Japanese Stations for Vertical Sounding of the Ionosphere. Geomagn. Aeron. 48 (3), 392-399. doi:10.1134/ S0016793208030134

Korsunova, L. P., and Khegai, V. V. (2006). Medium-term Ionospheric Precursors to strong Earthquakes. Int. J. Geomagn. Aeron. 6, 3005. doi:10.1029/ 2005GI000122

Kotsarenko, A., Molchanov, O., Hayakawa, M., Koshevaya, S., Grimalsky, V., Pérez Enríquez, R., et al. (2005). Investigation of ULF Magnetic Anomaly during Izu Earthquake Swarm and Miyakejima Volcano Eruption at Summer 2000, Japan. Nat. Hazards Earth Syst. Sci. 5 (1), 63-69. doi:10.5194/nhess-5-63-2005

Kovach, R. L., Nur, A., Wesson, R. L., and Robinson, R. (1975). Water-level Fluctuations and Earthquakes on the San Andreas Fault Zone. Geol 3 (8), 437. doi:10.1130/0091-7613(1975)3<437:wfaeot>2.0.co;2

Kraus, J. D. (1988). Antennas. McGraw-Hill.

Kuo, C. L., Huba, J. D., Joyce, C. L., and Lee, L. C. (2011). Ionosphere Plasma Bubbles and Density Variations Induced by Pre-Earthquake Rock Currents and Associated Surface Charges. J. Geophys. Res. Space Phys. 116, 10317. doi:10.1029/2011JA016628

Kuznetsov, V. D., Bodnar, L., Garipov, G. K., Danilkin, V. A., Degtyar, V. G., Dokukin, V. S., et al. (2011). Orbital Monitoring of the Ionosphere and Abnormal Phenomena by the Small Vulkan-Compass-2 Satellite. Geomagn. Aeron. 51 (3), 329-341. doi:10.1134/S001679321103011X

Lachenbruch, A. H., and Sass, J. H. (1992). Heat Flow from Cajon Pass, Fault Strength, and Tectonic Implications. J. Geophys. Res. 97 (B4), 4995-5015. doi:10.1029/91JB01506

Lambert, N., Chen, Y.-N., Cheng, Y.-C., Li, C.-M., Chen, G.-Y., and Nori, F. (2013). Quantum Biology. Nat. Phys 9 (1), 10-18. doi:10.1038/nphys2474

Langbein, J., Borcherdt, R., Dreger, D., Fletcher, J., Hardebeck, J. L., Hellweg, M., et al. (2005). Preliminary Report on the 28 September 2004, M 6.0 Parkfield, California Earthquake. Seismological Res. Lett. 76 (1), 10-26. doi:10.1785/ gssrl.76.1.10

Langbein, J. (2015). Borehole Strainmeter Measurements Spanning the $2014 \mathrm{M} \mathrm{W}$ 6.0 South Napa Earthquake, California: The Effect from Instrument Calibration. J. Geophys. Res. Solid Earth 120 (10), 7190-7202. doi:10.1002/ $2015 \mathrm{jb} 012278$

Lanzerotti, L. J., Maclennan, C. G., and Fraser-Smith, A. C. (1990). Background Magnetic Spectra: 10-5to 105Hz. Geophys. Res. Lett. 17 (10), 1593-1596. doi:10.1029/GL017i010p01593

Larkina, V. I., Migulin, V. V., Molchanov, O. A., Kharkov, I. P., Inchin, A. S., and Schvetcova, V. B. (1989). Some Statistical Results on Very Low Frequency Radiowave Emissions in the Upper Ionosphere over Earthquake Zones. Phys. Earth Planet. Interiors 57 (1-2), 100-109. doi:10.1016/0031-9201(89)90219-7

Li, M., Shen, X., Parrot, M., Yu, C., Zhang, X., Yan, R., et al. (2020). Primary Joint Statistical Seismic Influence on Ionospheric Parameters Recorded by the CSES and DEMETER Satellites. doi:10.1002/ESSOAR.10502965.1

Li, X. Q., Xu, Y. B., An, Z. H., Liang, X. H., Wang, P., Zhao, X. Y., et al. (2019). The High-Energy Particle Package Onboard CSES. Radiat. Detect. Technol. Methods 3 (3), 1-11. doi:10.1007/s41605-019-0101-7

Li, Y., Liu, Y., Jiang, Z., Guan, J., Yi, G., Cheng, S., et al. (2009). Behavioral Change Related to Wenchuan Devastating Earthquake in Mice. Bioelectromagnetics 30 (8), 613-620. doi:10.1002/bem.20520

Li, Z., Meier, M.-A., Hauksson, E., Zhan, Z., and Andrews, J. (2018). Machine Learning Seismic Wave Discrimination: Application to Earthquake Early Warning. Geophys. Res. Lett. 45 (10), 4773-4779. doi:10.1029/2018GL077870

Lin, C. Y., Lin, C. C. H., Liu, J. Y., Rajesh, P. K., Matsuo, T., Chou, M. Y., et al. (2020). The Early Results and Validation of FORMOSAT-7/COSMIC-2 Space Weather Products: Global Ionospheric Specification and Ne-Aided Abel 
Electron Density Profile. J. Geophys. Res. Space Phys. 125 (10), e2020JA028028. doi:10.1029/2020JA028028

Lin, J., Shen, X., Hu, L., Wang, L., and Zhu, F. (2018). CSES GNSS Ionospheric Inversion Technique, Validation and Error Analysis. Sci. China Technol. Sci. 61 (5), 669-677. doi:10.1007/s11431-018-9245-6

Liperovsky, V. A., Meister, C.-V., Liperovskaya, E. V., and Bogdanov, V. V. (2008b). On the Generation of Electric Field and Infrared Radiation in Aerosol Clouds Due to Radon Emanation in the Atmosphere before Earthquakes. Nat. Hazards Earth Syst. Sci. 8 (5), 1199-1205. doi:10.5194/ nhess-8-1199-2008

Liperovsky, V. A., Meister, C.-V., Liperovskaya, E. V., Davidov, V. F., and Bogdanov, V. V. (2005). On the Possible Influence of Radon and Aerosol Injection on the Atmosphere and Ionosphere before Earthquakes. Nat. Hazards Earth Syst. Sci. 5 (6), 783-789. doi:10.5194/nhess-5-783-2005

Liperovsky, V. A., Pokhotelov, O. A., Meister, C.-V., and Liperovskaya, E. V. (2008a). Physical Models of Coupling in the Lithosphere-AtmosphereIonosphere System before Earthquakes. Geomagn. Aeron. 48 (6), 795-806. doi:10.1134/s0016793208060133

Lisi, M., Filizzola, C., Genzano, N., Grimaldi, C. S. L., Lacava, T., Marchese, F., et al. (2010). A Study on the Abruzzo 6 April 2009 Earthquake by Applying the RST Approach to 15 Years of AVHRR TIR Observations. Nat. Hazards Earth Syst. Sci. 10 (2), 395-406. doi:10.5194/nhess-10-395-2010

Liu, J. Y., Chen, C. H., Chen, Y. I., Yang, W. H., Oyama, K. I., and Kuo, K. W. (2010). A Statistical Study of Ionospheric Earthquake Precursors Monitored by Using Equatorial Ionization Anomaly of GPS TEC in Taiwan during 20012007. J. Asian Earth Sci. 39 (1-2), 76-80. doi:10.1016/j.jseaes.2010.02.012

Liu, J. Y., Chen, Y. I., Chuo, Y. J., and Chen, C. S. (2006). A Statistical Investigation of Preearthquake Ionospheric Anomaly. J. Geophys. Res. 111 (5), 5304. doi:10.1029/2005JA011333

Liu, J. Y., Chen, Y. I., Chuo, Y. J., and Tsai, H. F. (2001). Variations of Ionospheric Total Electron Content during the Chi-Chi Earthquake. Geophys. Res. Lett. 28 (7), 1383-1386. doi:10.1029/2000GL012511

Liu, J. Y., Chen, Y. I., Pulinets, S. A., Tsai, Y. B., and Chuo, Y. J. (2000). Seismoionospheric Signatures Prior to $\mathrm{M} \geq 6.0$ Taiwan Earthquakes. Geophys. Res. Lett. 27 (19), 3113-3116. doi:10.1029/2000GL011395

Liu, J. Y., Chuo, Y. J., Pulinets, S. A., Tsai, H. F., and Zeng, X. (2002). "A Study on the TEC Perturbations Prior to the Rei-Li, Chi-Chi and Chia-Yi Earthquakes," in Seismo-Electromagnetics: Lithosphere-Atmosphere-Ionosphere Coupling. Editors M. Hayakawa and O. A. Molchanov (Terra Scientific Pub. Comp), 297-301.

Liu, J. Y., Chuo, Y. J., Shan, S. J., Tsai, Y. B., Chen, Y. I., Pulinets, S. A., et al. (2004). Pre-earthquake Ionospheric Anomalies Registered by Continuous GPS TEC Measurements. Ann. Geophys. 22 (5), 1585-1593. doi:10.5194/angeo-22-15852004

Liu, J. Y. (2009). "Earthquake Precursors Observed in the Ionospheric F-Region," in Electromagnetic Phenomena Associated with Earthquakes. Editor M. Hayakawa (Trivandrum: Transworld Research Network), 187-204.

Liu, X., Hattori, K., Han, P., Chen, H., Chie, Y., and Zhao, X. (2020). Possible Anomalous Changes in Solar Quiet Daily Geomagnetic Variation (Sq) Related to the 2011 off the Pacific Coast of Tohoku Earthquake (Mw 9.0). Pure Appl. Geophys. 177 (1), 333-346. doi:10.1007/s00024-018-02086-z

Lizunov, G. V., Skorokhod, T. V., Skorokhod, T. V., and Korepanov, V. Y. (2020). Atmospheric Gravity Waves Among Other Physical Mechanisms of SeismicIonospheric Coupling. Kosm. Nauka Tehnol. 26 (3), 55-80. doi:10.15407/ knit2020.03.055

Lockner, D. A., Johnston, M. J. S., and Byerlee, J. D. (1983). A Mechanism to Explain the Generation of Earthquake Lights. Nature 302 (5903), 28-33. doi:10.1038/302028a0

Lohmann, K. J., and Lohmann, C. M. F. (2019). There and Back Again: Natal Homing by Magnetic Navigation in Sea Turtles and salmon. J. Exp. Biol. 222 (Suppl. 1_1). doi:10.1242/jeb.184077

Lohmann, K. J. (2007). Sea Turtles: Navigating with Magnetism. Curr. Biol. 17 (3), R102-R104. Elsevier. doi:10.1016/j.cub.2007.01.023

Lomnitz, C. (1994). Fundamentals of Earthquake Prediction. Wiley.

LongJohn, T., Morgan, J. K., and Dugan, B. (2018). Microstructural Evolution of Porosity and Stress during the Formation of Brittle Shear Fractures: A Discrete Element Model Study. J. Geophys. Res. Solid Earth 123 (3), 2228-2245. doi:10.1002/2017JB014842
Lorenzetti, E., and Tullis, T. E. (1989). Geodetic Predictions of a Strike-Slip Fault Model: Implications for Intermediate- and Short-Term Earthquake Prediction. J. Geophys. Res. 94 (B9), 12343-12361. doi:10.1029/jb094ib09p12343

Lu, X., Meng, Q. Y., Gu, X. F., Zhang, X. D., Xie, T., and Geng, F. (2016). Thermal Infrared Anomalies Associated with Multi-Year Earthquakes in the Tibet Region Based on China's FY-2E Satellite Data. Adv. Space Res. 58 (6), 989-1001. doi:10.1016/j.asr.2016.05.038

Lyon, G. L. (1974). Geothermal Gases. in Natural Gases in Marine Sediments. Editors I. R. Kaplan. (Boston: Springer US), 141-150. doi:10.1007/978-1-46842757-8_9Geothermal Gases.

Ma, T., and Wu, Z. (2012). Precursor-Like Anomalies Prior to the 2008 Wenchuan Earthquake: A Critical-But-Constructive Review. Int. J. Geophys., 2012, 1-13. doi:10.1155/2012/583097

Ma, W., Kong, X., Kang, C., Zhong, X., Wu, H., Zhan, X., et al. (2015). Research on the Changes of the Tidal Force and the Air Temperature in the Atmosphere of Lushan (China) MS7.0 Earthquake. Therm. Sci. 19, 487-493. doi:10.2298/ TSCI150403148M

Ma, W. Y., Wang, H., Li, F. S., and Ma, W. M. (2012). Relation between the Celestial Tide-Generating Stress and the Temperature Variations of the Abruzzo $\mathrm{M}=6.3$ Earthquake in April 2009. Nat. Hazards Earth Syst. Sci. 12 (3), 819-827. doi:10.5194/nhess-12-819-2012

Ma, Y., Zhao, Y., Liu, S., and Wu, L. (2010). Possible Abnormal Phenomenon of the Atmospheric Water Vapor before Hengchun Earthquake. PIERS Online 6 (1), 21-25. doi:10.2529/PIERS090907094618

Maekawa, S., Horie, T., Yamauchi, T., Sawaya, T., Ishikawa, M., Hayakawa, M., et al. (2006). A Statistical Study on the Effect of Earthquakes on the Ionosphere, Based on the Subionospheric LF Propagation Data in Japan. Ann. Geophys. 24 (8), 2219-2225. doi:10.5194/angeo-24-2219-2006

Mallet, R. (1855). Report of the 24th meeting of the British Association for the Advancement of Science, Liverpool, September 1854. in Third report on the facts of earthquake phenomena, Catalogue of recorded earthquakes from 1606 B.C. to A.D. 1850 (continued from report for 1853), . John Murray, 2-326.

Marchetti, D., De Santis, A., D'Arcangelo, S., Poggio, F., Piscini, A., Campuzano, S. A., et al. (2019). Pre-earthquake Chain Processes Detected from Ground to Satellite Altitude in Preparation of the 2016-2017 Seismic Sequence in Central Italy. Remote Sensing Environ. 229, 93-99. doi:10.1016/j.rse.2019.04.033

Marchetti, D., De Santis, A., Shen, X., Campuzano, S. A., Perrone, L., Piscini, A., et al. (2020). Possible Lithosphere-Atmosphere-Ionosphere Coupling Effects Prior to the $2018 \mathrm{Mw}=7.5$ Indonesia Earthquake from Seismic, Atmospheric and Ionospheric Data. J. Asian Earth Sci. 188, 104097. doi:10.1016/ j.jseaes.2019.104097

Martinelli, G., Facca, G., Genzano, N., Gherardi, F., Lisi, M., Pierotti, L., et al. (2020a). Earthquake-Related Signals in Central Italy Detected by Hydrogeochemical and Satellite Techniques. Front. Earth Sci. 8, 529. doi:10.3389/feart.2020.584716

Martinelli, G., Plescia, P., and Tempesta, E. (2020b). Electromagnetic Emissions from Quartz Subjected to Shear Stress: Spectral Signatures and Geophysical Implications. Geosciences 10 (4), 140. doi:10.3390/geosciences 10040140

Marty, B., Meynier, V., Nicolini, E., Griesshaber, E., and Toutain, J. P. (1993). Geochemistry of Gas Emanations: A Case Study of the Réunion Hot Spot, Indian Ocean. Appl. Geochem. 8 (2), 141-152. doi:10.1016/0883-2927(93) 90030-K

McCartney, B. S., and Bary, B. M. (1965). Echo-sounding on Probable Gas Bubbles from the Bottom of Saanich Inlet, British Columbia. Deep Sea Res. Oceanographic Abstr. 12 (3), 285-294. doi:10.1016/0011-7471(65)90002-1

McNutt, S. R., and Beavan, R. J. (1981). Volcanic Earthquakes at Pavlof Volcano Correlated with the Solid Earth Tide. Nature 294 (5842), 615-618. doi:10.1038/ $294615 \mathrm{a} 0$

Merifield, P. M., and Lamar, D. L. (1981). Anomalous Water-Level Changes and Possible Relation with Earthquakes. Geophys. Res. Lett. 8 (5), 437-440. doi:10.1029/GL008i005p00437

Michael, A. J., and Werner, M. J. (2018). Preface to the Focus Section on the Collaboratory for the Study of Earthquake Predictability (CSEP): New Results and Future Directions. Seismological Research Letters 89 (4), 1226-1228. doi:10.1785/0220180161

Mignan, A. (2008). The Stress Accumulation Model: Accelerating Moment Release and Seismic Hazard. Advances in Geophysics, 49, 67-201. doi:10.1016/S00652687(07)49002-1 
Mizutani, H., Ishido, T., Yokokura, T., and Ohnishi, S. (1976). Electrokinetic Phenomena Associated with Earthquakes. Geophys. Res. Lett. 3 (7), 365-368. doi:10.1029/GL003i007p00365

Molchanov, O. A., and Hayakawa, M. (2008). Seismo-electromagnetics and Related Phenomena: History and Latest Results, Vol. 189. Tokyo: Terrapub.

Molchanov, O. A. (2009). "Lithosphere-atmosphere-ionosphere Coupling Due to Seismicity," in Electromagnetic Phenomena Associated with Earthquakes. Editor M. Hayakawa (Trivandrum: Transworld Research Network), 255-279.

Molchanov, O., Fedorov, E., Schekotov, A., Gordeev, E., Chebrov, V., Surkov, V., et al. (2004). Lithosphere-atmosphere-ionosphere Coupling as Governing Mechanism for Preseismic Short-Term Events in Atmosphere and Ionosphere. Nat. Hazards Earth Syst. Sci. 4 (5-6), 757-767. doi:10.5194/nhess-4-757-2004

Mora, C. V., Davison, M., Martin Wild, J., and Walker, M. M. (2004). Magnetoreception and its Trigeminal Mediation in the Homing pigeon. Nature 432 (7016), 508-511. doi:10.1038/nature03077

Moro, M., Saroli, M., Stramondo, S., Bignami, C., Albano, M., Falcucci, E., et al. (2017). New Insights into Earthquake Precursors from InSAR. Sci. Rep. 7 (1), 1-11. doi:10.1038/s41598-017-12058-3

Morozov, V. N. (2006). The Influence of Convective Current Generator on the Global Current. Nonlin. Process. Geophys. 13 (2), 243-246. doi:10.5194/npg-13243-2006

Mouritsen, H. (2018). Long-distance Navigation and Magnetoreception in Migratory Animals. Nature 558 (7708), 50-59. Nature Publishing Group. doi:10.1038/s41586-018-0176-1

Mulargia, F., and Geller, R. J. (2003). in Earthquake Science and Seismic Risk Reduction. Editors F. Mulargia and R. J. Geller (Dordrecht: Springer Science \& Business Media), Vol. 2.

Musha, K. (1957). Jishin Namazu (Earthquake and Catfish). Tokyo: Toyo Tosho.

Nagamine, K., and Sugisaki, R. (1991). Coseismic Changes of Subsurface Gas Compositions Disclosed by an Improved Seismo-Geochemical System. Geophys. Res. Lett. 18 (12), 2221-2224. doi:10.1029/91GL02710

Nagao, T., Enomoto, Y., Fujinawa, Y., Hata, M., Hayakawa, M., Huang, Q., et al. (2002). Electromagnetic Anomalies Associated with 1995 Kobe Earthquake. J. Geodynamics 33 (4-5), 401-411. doi:10.1016/S0264-3707(02)00004-2

Namgaladze, A. A., Klimenko, M. V., Klimenko, V. V., and Zakharenkova, I. E. (2009). Physical Mechanism and Mathematical Modeling of Earthquake Ionospheric Precursors Registered in Total Electron Content. Geomagn. Aeron. 49 (2), 252-262. doi:10.1134/S0016793209020169

Nanjo, K. Z. (2020). Were Changes in Stress State Responsible for the 2019 Ridgecrest, California, Earthquakes? Nat. Commun. 11 (1), 1-10. doi:10.1038/ s41467-020-16867-5

Natarajan, V., and Philipoff, P. (2018). Observation of Surface and Atmospheric Parameters Using "NOAA 18" Satellite: a Study on Earthquakes of Sumatra and Nicobar Is Regions for the Year 2014 ( $\mathrm{M} \geq 6.0$ ). Nat. Hazards 92 (2), 1097-1112. doi:10.1007/s11069-018-3242-y

Neubert, T., Rycroft, M., Farges, T., Blanc, E., Chanrion, O., Arnone, E., et al. (2008). Recent Results from Studies of Electric Discharges in the Mesosphere. Surveys in Geophysics, 29 Issue 2. Netherlands: Springer, 71-137. doi:10.1007/ s10712-008-9043-1

Nikiforova, N. N., and Michnowski, S. (1995). Atmospheric Electric Field Anomalies Analysis during Great Carpatian Earthquake at Polish Observatory SwiderIUGG XXI General Assembly Abstracts in IUGG XXI General Assembly Abstracts VA11D-16. Boulder, Colorado: IUGG.

Nikolaeva, N. A., Derkachev, A. N., and Obzhirov, A. I. (2009). Characteristic Features of the Occurrence of Gas-Fluid Emanations on the Northeastern Slope of Sakhalin Island, Sea of Okhotsk. Russ. J. Pac. Geol. 3 (3), 234-248. doi:10.1134/S181971400903004X

Nimpf, S., Nordmann, G. C., Kagerbauer, D., Malkemper, E. P., Landler, L., Papadaki-Anastasopoulou, A., et al. (2019). A Putative Mechanism for Magnetoreception by Electromagnetic Induction in the Pigeon Inner Ear. Curr. Biol. 29 (23), 4052-4059. doi:10.1016/j.cub.2019.09.048

Nissen, E., Krishnan, A. K., Arrowsmith, J. R., and Saripalli, S. (2012). Threedimensional Surface Displacements and Rotations from Differencing Pre- and post-earthquake LiDAR point Clouds. Geophys. Res. Lett. 39 (16), a-n. doi:10.1029/2012GL052460

Niu, F., Silver, P. G., Daley, T. M., Cheng, X., and Majer, E. L. (2008). Preseismic Velocity Changes Observed from Active Source Monitoring at the Parkfield SAFOD Drill Site. Nature 454 (7201), 204-208. doi:10.1038/nature07111
Nourbehecht, B. (1936-1963). Irreversible Thermodynamic Effects in Inhomogeneous media and Their Applications in Certain Geoelectric Problems [Massachusetts Institute of Technology]. Available at: https:// dspace.mit.edu/handle/1721.1/11576.

Ogawa, T., Oike, K., and Miura, T. (1985). Electromagnetic Radiations from Rocks. J. Geophys. Res. 90 (D4), 6245-6249. doi:10.1029/jd090id04p06245

Ohayon, M. M. (2000). Prevalence of Hallucinations and Their Pathological Associations in the General Population. Psychiatry Res. 97 (2-3), 153-164. doi:10.1016/S0165-1781(00)00227-4

Okada, Y., Mukai, S., and Singh, R. P. (2004). Changes in Atmospheric Aerosol Parameters after Gujarat Earthquake of January 26, 2001. Adv. Space Res. 33 (3), 254-258. doi:10.1016/S0273-1177(03)00474-5

Omori, Y., Yasuoka, Y., Nagahama, H., Kawada, Y., Ishikawa, T., Tokonami, S., et al. (2007). Anomalous Radon Emanation Linked to Preseismic Electromagnetic Phenomena. Nat. Hazards Earth Syst. Sci. 7 (5), 629-635. doi:10.5194/nhess-7-629-2007

Ondoh, T. (2004). Anomalous Sporadic-E Ionization before a Great Earthquake. Adv. Space Res. 34 (8), 1830-1835. doi:10.1016/j.asr.2003.05.044

Ondoh, T. (2003). Anomalous Sporadic-E Layers Observed before M7.2 HyogoKen Nanbu Earthquake; Terrestrial Gas Emanation Model. Adv. Polar Upper Atmosphere Res. 17, 96-108. doi:10.15094/00006365

Ondoh, T., and Hayakawa, M. (2006). Synthetic Study of Precursory Phenomena of the M7.2 Hyogo-Ken Nanbu Earthquake. Phys. Chem. Earth, Parts A/B/C 31 (4-9), 378-388. doi:10.1016/j.pce.2006.02.017

Ondoh, T. (2009). Investigation of Precursory Phenomena in the Ionosphere, Atmosphere and Groundwater before Large Earthquakes of $\mathrm{M}>6.5$. Adv. Space Res. 43 (2), 214-223. doi:10.1016/j.asr.2008.04.003

O'Neil, J. R., and King, C. Y. (1980). Deuterium Anomalies in Groundwater as Precursors to Seismic Activity in California. Eos, Trans. Am. Geophys. Union 61 (46), 1033, 1980 . Available at: https://eurekamag.com/research/018/717/ 018717545.php.

Orihara, Y., Kamogawa, M., Noda, Y., and Nagao, T. (2019). Is Japanese Folklore Concerning Deep-Sea Fish Appearance a Real Precursor of Earthquakes? Bull. Seismological Soc. America 109 (4), 1556-1562. doi:10.1785/0120190014

Ouzounov, D., Bryant, N., Logan, T., Pulinets, S., and Taylor, P. (2006). Satellite thermal IR Phenomena Associated with Some of the Major Earthquakes in 1999-2003. Phys. Chem. Earth, Parts A/B/C 31 (4-9), 154-163. doi:10.1016/ j.pce.2006.02.036

Ouzounov, D., and Freund, F. (2004). Mid-infrared Emission Prior to strong Earthquakes Analyzed by Remote Sensing Data. Adv. Space Res. 33 (3), 268-273. doi:10.1016/S0273-1177(03)00486-1

Ouzounov, D., Liu, D., Chunli, K., Cervone, G., Kafatos, M., and Taylor, P. (2007). Outgoing Long Wave Radiation Variability from IR Satellite Data Prior to Major Earthquakes. Tectonophysics 431 (1-4), 211-220. doi:10.1016/ j.tecto.2006.05.042

Ouzounov, D., Pulinets, S., Hatori, K., and Taylor, P. (2018). Pre-Earthquake Processes: A Multidisciplinary Approach to Earthquake Prediction Studies. Hoboken: Wiley. John Wiley \& Sons. Available at: https://www.wiley.com/ en-us/Pre+Earthquake+Processes $\%$

$3 \mathrm{~A}+\mathrm{A}+$ Multidisciplinary+Approach + to + Earthquake+Prediction+Studies-p9781119156932.

Panda, S. K., Choudhury, S., Saraf, A. K., and Das, J. D. (2007). MODIS Land Surface Temperature Data Detects thermal Anomaly Preceding 8 October 2005 Kashmir Earthquake. Int. J. Remote Sensing 28 (20), 4587-4596. doi:10.1080/ 01431160701244906

Panza, G. F., Peresan, A., Sansò, F., Crespi, M., Mazzoni, A., and Nascetti, A. (2018). How Geodesy Can Contribute to the Understanding and Prediction of Earthquakes. Rend. Fis. Acc. Lincei 29 (1), 81-93. doi:10.1007/s12210-0170626-y

Papadopoulos, G. A. (1999). "Luminous and Fiery Phenomena Associated with Earthquakes in the East Mediterranean. Atmospheric and Ionospheric Electromagnetic Phenomena Associated with Earthquakes," in Atmospheric and Ionospheric Electromagnetic Phenomena Associated with Earthquakes. Editor M. Hayakawa (Tokyo: Terra Scientific Pub. Comp), 559-575.

Park, S. K., Johnston, M. J. S., Madden, T. R., Morgan, F. D., and Morrison, H. F. (1993). Electromagnetic Precursors to Earthquakes in the Ulf Band: A Review of 
Observations and Mechanisms. Reviews of Geophysics 31 (2), 117-132. doi:10.1029/93RG00820

Parrot, M., Achache, J., Berthelier, J. J., Blanc, E., Deschamps, A., Lefeuvre, F., et al. (1993). High-frequency Seismo-Electromagnetic Effects. Phys. Earth Planet. Interiors 77 (1-2), 65-83. doi:10.1016/0031-9201(93)90034-7

Parrot, M. (1994). Statistical Study of ELF/VLF Emissions Recorded by a LowAltitude Satellite during Seismic Events. J. Geophys. Res. Space Phys. 99 (12), 23339-23347. doi:10.1029/94JA02072

Parrot, M. (2002). The Micro-satellite DEMETER. J. Geodynamics 33 (4-5), 535-541. doi:10.1016/S0264-3707(02)00014-5

Parrot, M. (1995). Use of Satellites to Detect Seismo-Electromagnetic Effects. Adv. Space Res. 15 (11), 27-35. doi:10.1016/0273-1177(95)00072-M

Pergola, N., Marchese, F., and Tramutoli, V. (2004). Automated Detection of thermal Features of Active Volcanoes by Means of Infrared AVHRR Records. Remote Sensing Environ. 93 (3), 311-327. doi:10.1016/j.rse.2004.07.010

Perrone, L., De Santis, A., Abbattista, C., Alfonsi, L., Amoruso, L., Carbone, M., et al. (2018). Ionospheric Anomalies Detected by Ionosonde and Possibly Related to Crustal Earthquakes in Greece. Annales Geophysicae 36 (2), 361-371. doi:10.5194/angeo-36-361-2018

Perrone, L., Korsunova, L. P., and Mikhailov, A. V. (2010). Ionospheric Precursors for Crustal Earthquakes in Italy. Ann. Geophysicae 28 (4), 941-950. doi:10.5194/angeo-28-941-2010

Persenger, M. A., and Derr, J. S. (1984). Geophysical Variables and Human Behavior: XIX. Strong Temporal Relationships between Inclusive Seismic Measures and UFO Reports within Washington State. Perceptual Mot. Skills 59 (2), 551-566. doi:10.2466/pms.1984.59.2.551

Persinger, M. A. (1983). The Tectonic Strain Theory of Luminosities. Pursuit 16 (1), 21-35.

Pfaff, R., Freudenreich, H., Yokoyama, T., Yamamoto, M., Fukao, S., Mori, H., et al. (2005). Electric Field Measurements of DC and Long Wavelength Structures Associated with Sporadic-E Layers and QP Radar Echoes. Ann. Geophysicae 23 (7), 2319-2334. doi:10.5194/angeo-23-2319-2005

Picozza, P., Conti, L., and Sotgiu, A. (2021). Looking for Earthquake Precursors from Space: a Critical Review, In "Geospace Observation of Natural Hazards", Frontiers in Earth Science, Section Geohazards and Georisks. doi:10.3389/feart.2021.676775

Pierce, E. T. (1976). Atmospheric Electricity and Earthquake Prediction. Geophys. Res. Lett. 3 (3), 185-188. doi:10.1029/GL003i003p00185

Piscini, A., De Santis, A., Marchetti, D., and Cianchini, G. (2017). A MultiParametric Climatological Approach to Study the 2016 Amatrice-Norcia (Central Italy) Earthquake Preparatory Phase. Pure Appl. Geophys. 174 (10), 3673-3688. doi:10.1007/s00024-017-1597-8

Plastino, W. (2006). Monitoring Of Geochemical And Geophysical Parameters In The Gran Sasso Aquifer. J. Environ. Radioact., 8, 335-341. doi:10.1016/S15694860(05)08027-7Monitoring of Geochemical and Geophysical Parameters in the Gran Sasso Aquifer.

Plastino, W., and Bella, F. (2001). Radon Groundwater Monitoring at Underground Laboratories of Gran Sasso (Italy). Geophys. Res. Lett. 28 (14), 2675-2677. doi:10.1029/2000GL012430

Plastino, W., Povinec, P. P., De Luca, G., Doglioni, C., Nisi, S., Ioannucci, L., et al. (2010). Uranium Groundwater Anomalies and L'Aquila Earthquake, 6th April 2009 (Italy). J. Environ. Radioactivity 101 (1), 45-50. doi:10.1016/ j.jenvrad.2009.08.009

Polk, C. (1983). Natural and Man-Made Noise in the Earth-Ionosphere Cavity at Extremely Low Frequencies (Schumann Resonances and Man-Made 'interference'). Space Sci. Rev. 35 (1), 83-89. doi:10.1007/BF00173695

Posey, T. B., and Losch, M. E. (1983). Auditory Hallucinations of Hearing Voices in 375 Normal Subjects. Imagination, Cogn. Personal. 3 (2), 99-113. doi:10.2190/ 74v5-hnxn-jey5-dg7w

Press, F., and Siever, R. (1982). Earth. San Francisco: W. H. Freeman. Available at: https://www.abebooks.co.uk/servlet/BookDetailsPL?bi=30754169047andsearchurl=kn \%3DEarth\%2BPress\%252C\%2BFrank\%2Band\%2BSiever\%252C\%2BRaymond \%26sortby\%3D17andcm_sp=snippet-_-srp1-_-title1.

Pulinets, S. A., Alekseev, V. A., Legen'ka, A. D., and Khegai, V. V. (1997). Radon and Metallic Aerosols Emanation before strong Earthquakes and Their Role in Atmosphere and Ionosphere Modification. Adv. Space Res. 20 (11), 2173-2176. doi:10.1016/S0273-1177(97)00666-2

Pulinets, S. A., Legen'ka, A. D., Gaivoronskaya, T. V., and Depuev, V. K. (2003). Main Phenomenological Features of Ionospheric Precursors of strong
Earthquakes. J. Atmos. Solar-Terrestrial Phys. 65 (16-18), 1337-1347. doi:10.1016/j.jastp.2003.07.011

Pulinets, S. A. (2007). Natural Radioactivity, Earthquakes, and the Ionosphere. Eos 88 (20), 217-218. doi:10.1029/2007EO200001

Pulinets, S. A., Ouzounov, D., Karelin, A. V., Boyarchuk, K. A., and Pokhmelnykh, L. A. (2006). The Physical Nature of thermal Anomalies Observed before strong Earthquakes. Phys. Chem. Earth 31 (4-9), 143-153. doi:10.1016/j.pce.2006.02.042

Pulinets, S., and Boyarchuk, K. (2005). Ionospheric Precursors of Earthquakes. Springer Berlin Heidelberg. doi:10.1007/b137616

Pulinets, S., and Ouzounov, D. (2011). Lithosphere-Atmosphere-Ionosphere Coupling (LAIC) Model - an Unified Concept for Earthquake Precursors Validation. J. Asian Earth Sci. 41 (4-5), 371-382. doi:10.1016/j.jseaes.2010.03.005

Pulinets, S. (2011). The Synergy of Earthquake Precursors. Earthquake Sci. 24 (6), 535-548. doi:10.1007/s11589-011-0815-1

Qin, K., Wu, L. X., Zheng, S., Bai, Y., and Lv, X. (2014). Is There an Abnormal Enhancement of Atmospheric Aerosol before the 2008 Wenchuan Earthquake? Adv. Space Res. 54 (6), 1029-1034. doi:10.1016/j.asr.2014.04.025

Qin, K., Wu, L., Zheng, S., and Liu, S. (2013). A Deviation-Time-Space-Thermal (DTS-T) Method for Global Earth Observation System of Systems (GEOSS)based Earthquake Anomaly Recognition: Criterions and Quantify Indices. Remote Sensing 5 (10), 5143-5151. doi:10.3390/rs5105143

Raleigh, C. B., Molnar, P., Hanks, T., Nur, A., Wu, F., Savage, J., et al. (1977). Prediction of the Haicheng Earthquake. Eos, Trans. Am. Geophys. Union 58 (5), 236. doi:10.1029/eo058i005p00236amd

Ramírez-Rojas, A., and Flores-Márquez, E. L. (2013). Order Parameter Analysis of Seismicity of the Mexican Pacific Coast. Physica A: Stat. Mech. Its Appl. 392 (10), 2507-2512. doi:10.1016/j.physa.2013.01.034

Rapoport, Y., Grimalsky, V., Krankowski, A., Pulinets, S., Fedorenko, A., and Petrishchevskii, S. (2020). Algorithm for Modeling Electromagnetic Channel of Seismo-Ionospheric Coupling (SIC) and the Variations in the Electron Concentration. Acta Geophysica 68 (1), 253-278. doi:10.1007/s11600-01900385-0

Reasenberg, P. A. (1999). Foreshock Occurrence before Large Earthquakes. J. Geophys. Res. Solid Earth 104 (B3), 4755-4768. doi:10.1029/1998jb900089

Reimer, G. M. (1990). Geophysical Research Letters, (John Wiley \& Sons) 17 Issue 6, 799. doi:10.1029/GL017i006p00799 The Occurrence and Transport of Radon in the Natural Environment.

Reimer, G. M. (1980). Use of Soil-Gas Helium Concentrations for Earthquake Prediction: Limitations Imposed by Diurnal Variations ( Colorado, Wyoming, California). J. Geophys. Res. 85 (B6), 3107-3114. doi:10.1029/JB085iB06p03107

Revell, L. E., Kremser, S., Hartery, S., Harvey, M., Mulcahy, J. P., Williams, J., et al. (2019). The Sensitivity of Southern Ocean Aerosols and Cloud Microphysics to Sea spray and Sulfate Aerosol Production in the HadGEM3-GA7.1 ChemistryClimate Model. Atmos. Chem. Phys. 19 (24), 15447-15466. doi:10.5194/acp-1915447-2019

Rice, J. R., and Cleary, M. P. (1976). Some Basic Stress Diffusion Solutions for Fluid-saturated Elastic Porous media with Compressible Constituents. Reviews of Geophysics 14 (2), 227-241. doi:10.1029/RG014i002p00227

Richon, P., Sabroux, J. C., Halbwachs, M., Vandemeulebrouck, J., Poussielgue, N., Tabbagh, J., et al. (2003). Radon Anomaly in the Soil of Taal Volcano, the Philippines: A Likely Precursor of the M 7.1 Mindoro Earthquake (1994). Geophys. Res. Lett. 30 (9). doi:10.1029/2003GL016902

Richter, C. F. (1958). Elementary Seismology. San Francisco: W. H. Freeman and Company. Available at: https://www.abebooks.it/Elementary-Seismology1958-Freeman-Company-San/879247410/bd.

Riggio, A., and Santulin, M. (2015). Earthquake Forecasting: a Review of Radon as Seismic Precursor. Bollettino Di Geofisica Teorica e Applicata 56 (2), 95-114. Available at: http://www3.ogs.trieste.it/bgta/provapage.php?id_articolo=650.

Rikitake, T. (1987). Earthquake Precursors in Japan: Precursor Time and Detectability. Tectonophysics 136 (3-4), 265-282. doi:10.1016/0040-1951(87) 90029-1

Rishbeth, H. (2006). Ionoquakes: Earthquake Precursors in the Ionosphere? Eos 87 (32), 316. doi:10.1029/2006eo320008

Rodger, C. J., Clilverd, M. A., and Thomson, N. R. (1999). Modeling of Subionospheric VLF Signal Perturbations Associated with Earthquakes. Radio Sci. 34 (5), 1177-1185. doi:10.1029/1999RS900061

Roeloffs, E. A. (1988). Hydrologic Precursors to Earthquakes: A Review. Pure Appl. Geophys. PAGEOPH 126 (2-4), 177-209. doi:10.1007/bf00878996 
Roeloffs, E., and Quilty, E. (1997). Water Level and Strain Changes Preceding and Following the August 4, 1985 Kettleman Hills, California, Earthquake. Pure Appl. Geophys. 149 (1), 21-60. doi:10.1007/BF00945160

Rouet-Leduc, B., Hulbert, C., Lubbers, N., Barros, K., Humphreys, C. J., and Johnson, P. A. (2017). Machine Learning Predicts Laboratory Earthquakes. Geophys. Res. Lett. 44 (18), 9276-9282. doi:10.1002/2017GL074677

Rozhnoi, A., Solovieva, M., Molchanov, O., Schwingenschuh, K., Boudjada, M., Biagi, P. F., et al. (2009). Anomalies in VLF Radio Signals Prior the Abruzzo Earthquake $(\mathrm{M}=6.3)$ on 6 April 2009. Nat. Hazards Earth Syst. Sci. 9 (5), 1727-1732. doi:10.5194/nhess-9-1727-2009

Rozhnoi, A., Solovieva, M. S., Molchanov, O. A., and Hayakawa, M. (2004). Middle Latitude LF (40 kHz) Phase Variations Associated with Earthquakes for Quiet and Disturbed Geomagnetic Conditions. Phys. Chem. Earth 29 (4-9), 589-598. doi:10.1016/j.pce.2003.08.061

Ruina, A. (1983). Slip Instability and State Variable Friction Laws. J. Geophys. Res. 88 (B12), 10359-10370. doi:10.1029/JB088iB12p10359

Ruzhin, Y. Y., Sorokin, V. M., and Yashchenko, A. K. (2014). Physical Mechanism of Ionospheric Total Electron Content Perturbations over a Seismoactive Region. Geomagnetism and Aeronomy 54 (3), 337-346. doi:10.1134/ S001679321403013X

Sannazzaro, F., Filizzola, C., Marchese, F., Corrado, R., Paciello, R., Mazzeo, G., et al. (2014). Identification Of Dust Outbreaks On Infrared MSG-SEVIRI Data By Using A Robust Satellite Technique (RST). Acta Astronautica 93, 64-70. doi:10.1016/j.actaastro.2013.07.003

Saraf, A. K., and Choudhury, S. (2005). NOAA-AVHRR Detects thermal Anomaly Associated with the 26 January 2001 Bhuj Earthquake, Gujarat, India. International Journal of Remote Sensing 26 (6), 1065-1073. doi:10.1080/ 01431160310001642368

Saraf, A. K., Rawat, V., Choudhury, S., Dasgupta, S., and Das, J. (2009). Advances in Understanding of the Mechanism for Generation of Earthquake thermal Precursors Detected by Satellites. Int. J. Appl. Earth Observation Geoinformation 11 (6), 373-379. doi:10.1016/j.jag.2009.07.003

Sasai, Y. (2001). Tectonomagnetic Modeling Based on the Piezomagnetism: A Review. Ann. Geophys. 44 (2), 361-368. doi:10.4401/ag-3602

Satake, H., Ohashi, M., and Hayashi, Y. (1984). Discharge of H2 from the Atotsugawa and Ushikubi Faults, Japan, and its Relation to Earthquakes. Pure Appl. Geophys. PAGEOPH 122 (2-4), 185-193. doi:10.1007/BF00874592

Sato, M., Sutton, A. J., McGee, K. A., and Russell-Robinson, S. (1986). Monitoring of Hydrogen along the San Andreas and Calaveras Faults in central California in 1980-1984. J. Geophys. Res. Solid Earth 91 (B12), 12315-12326. doi:10.1029/ jb091ib12p12315

Schekotov, A., Molchanov, O., Hattori, K., Fedorov, E., Gladyshev, V. A., Belyaev, G. G., et al. (2006). Seismo-ionospheric Depression of the ULF Geomagnetic Fluctuations at Kamchatka and Japan. Phys. Chem. Earth 31 (4-9), 313-318. doi:10.1016/j.pce.2006.02.043

Scholz, C. H. (2019). The Mechanics of Earthquakes and Faulting. (Cambridge: Cambridge University Press). doi:10.1017/9781316681473 The Mechanics of Earthquakes and Faulting.

Serebryakova, O. N., Bilichenko, S. V., Chmyrev, V. M., Parrot, M., Rauch, J. L., Lefeuvre, F., et al. (1992). Electromagnetic ELF Radiation from Earthquake Regions as Observed by Low-altitude Satellites. Geophys. Res. Lett. 19 (2), 91-94. doi:10.1029/91GL02775

Sgrigna, V., Buzzi, A., Conti, L., Guglielmi, A. V., and Pokhotelov, O. A. (2004). Electromagnetic Signals Produced by Elastic Waves in the Earth's Crust. Nuovo Cimento Della Societa Italiana Di Fisica C 27 (2), 115-132. doi:10.1393/ncc/ i2002-10009-y

Sgrigna, V., Buzzi, A., Conti, L., Picozza, P., Stagni, C., and Zilpimiani, D. (2007). Seismo-induced Effects in the Near-Earth Space: Combined Ground and Space Investigations as a Contribution to Earthquake Prediction. Tectonophysics 431 (1-4), 153-171. doi:10.1016/j.tecto.2006.05.034

Sgrigna, V., Buzzi, A., Conti, L., Picozza, P., Stagni, C., and Zilpimiani, D. (2008a). The ESPERIA Satellite Project for Detecting Seismo-Associated Effects in the Topside Ionosphere. First Instrumental Tests in Space. Earth, Planets and Space 60 (5), 463-475. doi:10.1186/bf03352813

Sgrigna, V., Console, R., Conti, L., Galper, A. M., Malvezzi, V., Parrot, M., et al. (2008b). The ESPERIA Project: a Mission to Investigate the Near-Earth Space. Earth Observation with CHAMP. (Berlin: Springer-Verlag), 407-412. doi:10.1007/3-540-26800-6_65
Sgrigna, V., and Conti, L. (2012). A Deterministic Approach to Earthquake Prediction. Int. J. Geophys. 2012, 1-20. doi:10.1155/2012/406278

Sgrigna, V., and Conti, L. (2010). Earthquake Preparation and Warning: Science, Methods and Technologies. Advances in Environmental Research, (New York: Nova Science Publishers, Inc.) 7, 1-38.

Sgrigna, V., and Malvezzi, V. (2003). Preseismic Creep Strains Revealed by Ground Tilt Measurements in central Italy on the Occasion of the 1997 Umbria-Marche Apennines Earthquake Sequence. Pure Appl. Geophys. 160 (8), 1493-1515. doi:10.1007/s00024-003-2357-5

Shen, X. H., Zhang, X. M., Yuan, S. G., Wang, L. W., Cao, J. Bin., Huang, J. P., et al. (2018). The State-Of-The-Art of the China Seismo-Electromagnetic Satellite mission. Sci. China Technol. Sci. 61 (5), 634-642. doi:10.1007/s11431-0189242-0

Shvets, A., and Hayakawa, M. (2011). Global Lightning Activity on the Basis of Inversions of Natural ELF Electromagnetic Data Observed at Multiple Stations Around the World. Surv. Geophys. 32 (6), 705-732. doi:10.1007/s10712-0119135-1

Sidgwick, H. (1891). A CENSUS OF HALLUCINATIONS. New Rev. 4 (20), 52-59. Sidgwick, H., Johnson, A., Myers, F. W. H., Podmore, F., and Sidgwick, E. M. (1994). "Report on the Census of Hallucinations," in Proceedings of the Society for Psychical Research, 25-422. https://www.scopus.com/ record/display.uri?eid $=2-$ s2.0-0000483685andorigin $=$ inwardandt $x$ Gid $=$ 9d0afbfad00a3800114515bbe534e6cd.10

Silina, A. S., Liperovskaya, E. V., Liperovsky, V. A., and Meister, C. V. (2001). Ionospheric Phenomena before strong Earthquakes. Nat. Hazards Earth Syst. Sci. 1 (3), 113-118. doi:10.5194/nhess-1-113-2001

Silva, A. A., and Claro, L. H. (2005). Surface Air Radon Progeny at São José Dos Campos, Brazil. Atmos. Environ. 39 (26), 4619-4625. doi:10.1016/ j.atmosenv.2005.04.025

Simões, F., Pfaff, R., Berthelier, J. J., and Klenzing, J. (2012). A Review of Low Frequency Electromagnetic Wave Phenomena Related to TroposphericIonospheric Coupling Mechanisms. In Space Science Reviews (Vol. 168, Issues 1-4, pp. 551-593). Springer. doi:10.1007/s11214-011-9854-0

Singh, O. P., Chauhan, V., Singh, V., and Singh, B. (2009). Anomalous Variation in Total Electron Content (TEC) Associated with Earthquakes in India during September 2006-November 2007. Phys. Chem. Earth 34 (6-7), 479-484. doi:10.1016/j.pce.2008.07.012

Sornette, A., and Sornette, D. (1989). Self-organized Criticality and Earthquakes. EPL 9 (3), 197-202. doi:10.1209/0295-5075/9/3/002

Sornette, D., and Sammis, C. G. (1995). Complex Critical Exponents from Renormalization Group Theory of Earthquakes: Implications for Earthquake Predictions. J. de Physique 5 (5), 607-619. doi:10.1051/jp1:1995154

Sorokin, V., and Hayakawa, M. (2014). Plasma and Electromagnetic Effects Caused by the Seismic-Related Disturbances of Electric Current in the Global Circuit. Mod. Appl. Sci. 8 (4), 61-83. doi:10.5539/mas.v8n4p61

Sorokin, V. M., Chmyrev, V. M., and Hayakawa, M. (2020). A Review on Electrodynamic Influence of Atmospheric Processes to the Ionosphere. Open J. Earthquake Res. 09 (02), 113-141. doi:10.4236/ojer.2020.92008

Sorokin, V. M., Chmyrev, V. M., and Isaev, N. V. (1998). A Generation Model of Small-Scale Geomagnetic Field-Aligned Plasma Inhomogeneities in the Ionosphere. J. Atmos. Solar-Terrestrial Phys. 60 (13), 1331-1342. doi:10.1016/S1364-6826(98)00078-9

Sorokin, V. M., Isaev, N. V., Yaschenko, A. K., Chmyrev, V. M., and Hayakawa, M. (2005). Strong DC Electric Field Formation in the Low Latitude Ionosphere over Typhoons. J. Atmos. Solar-Terrestrial Phys. 67 (14), 1269-1279. doi:10.1016/j.jastp.2005.06.014

Sotgiu, A., De Donato, C., Fornaro, C., Tassa, S., Scannavini, M., Iannaccio, D., et al. (2021). Control and Data Acquisition Software of the High-Energy Particle Detector on Board the China Seismo-Electromagnetic Satellite Space mission. Softw. - Pract. Experience 51 (6), 1459-1480. doi:10.1002/spe.2947

St-Laurent, F., Derr, J. S., and Freund, F. T. (2006). Earthquake Lights and the Stress-Activation of Positive Hole Charge Carriers in Rocks. Phys. Chem. Earth 31 (4-9), 305-312. doi:10.1016/j.pce.2006.02.003

St-Laurent, F. (2000). The Saguenay, Québec, Earthquake Lights of November 1988-January 1989: A Comparative Study with Reference to the Geoatmospheric Lights Classification Proposed by Montandon in 1948, and a Description Put Forward by Yasui in 1968. Seismological Research Letters, 71 (2), 160-174. doi:10.1785/gssrl.71.2.160 
Stothers, R. B. (2004). Ancient and Modern Earthquake Lights in Northwestern Turkey. Seismological Res. Lett. 75 (2), 199-204. doi:10.1785/gssrl.75.2.199

Strakhov, V. N., and Liperovsky, V. A. (1999). Short-term Forecast of Catastrophic Earthquakes Using Radiophysical Ground-Based and Space Methods. (Moscow: Inst Earth Phys).

Sugan, M., Kato, A., Miyake, H., Nakagawa, S., and Vuan, A. (2014). The Preparatory Phase of the 2009 Mw 6.3 L'Aquila Earthquake by Improving the Detection Capability of Low-Magnitude Foreshocks. Geophys. Res. Lett. 41 (17), 6137-6144. doi:10.1002/2014GL061199

Sugisaki, R. (1978). Changing He/Ar and N2/Ar Ratios of Fault Air May Be Earthquake Precursors. Nature 275 (5677), 209-211. Nature Publishing Group. doi:10.1038/275209a0

Sugisaki, R., Ito, T., Nagamine, K., and Kawabe, I. (1996). Gas Geochemical Changes at mineral Springs Associated with the 1995 Southern Hyogo Earthquake (M = 7.2), Japan. Earth Planet. Sci. Lett. 139 (1-2), 239-249. doi:10.1016/0012-821x(96)00007-6

Sugisaki, R., and Sugiura, T. (1986). Gas Anomalies at Three mineral Springs and a Fumarole before an Inland Earthquake, central Japan. J. Geophys. Res. Solid Earth 91 (B12), 12296-12304. doi:10.1029/jb091ib12p12296

Sugisaki, R., and Sugiura, T. (1985). Geochemical Indicator of Tectonic Stress Resulting in an Earthquake in central Japan, 1984. Science 229 (4719), 1261-1263. doi:10.1126/science.229.4719.1261

Surkov, V. V. (2015). Pre-seismic Variations of Atmospheric Radon Activity as a Possible Reason for Abnormal Atmospheric Effects. Ann. Geophys. 58 (5), 554. doi:10.4401/ag-6808

Svensmark, H., and Friis-Christensen, E. (1997). Variation of Cosmic ray Flux and Global Cloud Coverage - A Missing Link in Solar-Climate Relationships. J. Atmos. Solar-Terrestrial Phys. 59 (11), 1225-1232. doi:10.1016/S13646826(97)00001-1

Svensmark, H., Pedersen, J. O. P., Marsh, N. D., Enghoff, M. B., and Uggerhøj, U. I. (2007). Experimental Evidence for the Role of Ions in Particle Nucleation under Atmospheric Conditions. Proc. R. Soc. A: Math. Phys. Eng. Sci. 463, 385-396. doi:10.1098/rspa.2006.1773.2078

Tanaka, S., Ohtake, M., and Sato, H. (2002). Spatio-temporal Variation of the Tidal Triggering Effect on Earthquake Occurrence Associated with the 1982 South Tonga Earthquake of Mw 7.5. Geophys. Res. Lett. 29 (16), 3-1-3-4. doi:10.1029/ 2002gl015386

Tanimoto, T., Heki, K., and Artru-Lambin, J. (2015). Interaction of Solid Earth, Atmosphere, and Ionosphere. Treatise on Geophysics 4, 421-443. doi:10.1016/ B978-0-444-53802-4.00083-X

Temmingh, H., Stein, D. J., Seedat, S., and Williams, D. R. (2011). The Prevalence and Correlates of Hallucinations in a General Population Sample: Findings from the South African Stress and Health Study. Afr. J. Psychiatry (South Africa) 14 (3), 211-217. doi:10.4314/ajpsy.v14i3.4

Teng, T. -l., Sun, L. -f., and McRaney, J. K. (1981). Correlation of Groundwater Radon Anomalies with Earthquakes in the Greater Palmdale Bulge Area. Geophys. Res. Lett. 8 (5), 441-444. doi:10.1029/GL008i005p00441

Terada, T. (1930). On Luminous Phenomena Accompanying Earthquakes. Proc. Imperial Acad. 6 (10), 401-404. doi:10.2183/pjab1912.6.401

Thanassoulas, C., and Tselentis, G. (1993). Periodic Variations in the Earth's Electric Field as Earthquake Precursors: Results from Recent Experiments in Greece. Tectonophysics 224 (1-3), 103-111. doi:10.1016/0040-1951(93) 90061-N

Thériault, R., St-Laurent, F., Freund, F. T., and Derr, J. S. (2014). Prevalence of Earthquake Lights Associated with Rift Environments. Seismological Res. Lett. 85 (1), 159-178. doi:10.1785/0220130059

Thomas, D. (1988). Geochemical Precursors to Seismic Activity. Pure Appl. Geophys. PAGEOPH 126 (2-4), 241-266. doi:10.1007/BF00878998

Thomas, J. N., Huard, J., and Masci, F. (2017). A Statistical Study of Global Ionospheric Map Total Electron Content Changes Prior to Occurrences of $\mathrm{M} \geq$ 6.0 Earthquakes during 2000-2014. J. Geophys. Res. Space Phys. 122 (2), 2151-2161. doi:10.1002/2016JA023652

Tichy, H., and Loftus, R. (1996). Hygroreceptors in Insects and a Spider: Humidity Transduction Models. Naturwissenschaften 83 (6), 255-263. doi:10.1007/ BF01149598

Tien, A. Y. (1991). Distribution of Hallucinations in the Population. Soc. Psychiatry Psychiatr. Epidemiol. 26 (6), 287-292. doi:10.1007/BF00789221
Toutain, J. P., and Baubron, J. C. (1999). Gas Geochemistry and Seismotectonics: A Review. Tectonophysics 304 (1-2), 1-27. doi:10.1016/S0040-1951(98) 00295-9

Toutain, J. P., Munoz, M., Poitrasson, F., and Lienard, A. C. (1997). Springwater Chloride Ion Anomaly Prior to a ML $=5.2$ Pyrenean Earthquake. Earth Planet. Sci. Lett. 149 (1-4), 113-119. doi:10.1016/s0012-821x(97)00066-6

Tramutoli, V., Cuomo, V., Filizzola, C., Pergola, N., and Pietrapertosa, C. (2005). Assessing the Potential of thermal Infrared Satellite Surveys for Monitoring Seismically Active Areas: The Case of Kocaeli (İzmit) Earthquake, August 17, 1999. Remote Sensing Environ. 96 (3-4), 409-426. doi:10.1016/j.rse.2005.04.006

Tramutoli, V., Di Bello, G., Pergola, N., and Piscitelli, S. (2001). Robust Satellite Techniques for Remote Sensing of Seismically Active Areas. Ann. Geophys. 44 (2), 295-312. doi:10.4401/ag-3596

Treiber, C. D., Salzer, M., Breuss, M., Ushakova, L., Lauwers, M., Edelman, N., et al. (2013). High Resolution Anatomical Mapping Confirms the Absence of a Magnetic Sense System in the Rostral Upper Beak of Pigeons. Communicative Integr. Biol. 6 (4). doi:10.4161/cib.24859

Treiber, C. D., Salzer, M. C., Riegler, J., Edelman, N., Sugar, C., Breuss, M., et al. (2012). Clusters of Iron-Rich Cells in the Upper Beak of Pigeons Are Macrophages Not Magnetosensitive Neurons. Nature 484 (7394), 367-370. doi:10.1038/nature1 1046

Tributsch, H. (1982). When the Snakes Awake. (Cambridge, Massachusetts: The MIT Press). Available at: https://mitpress.mit.edu/books/when-snakesawake.

Trigunait, A., Parrot, M., Pulinets, S., and Li, F. (2004). Variations of the Ionospheric Electron Density during the Bhuj Seismic Event. Ann. Geophysicae 22 (12), 4123-4131. doi:10.5194/angeo-22-4123-2004

Tronin, A. A. (2002a). "Atmosphere-lithosphere Coupling. Thermal Anomalies on the Earth Surface in Seismic Processes," in Seismo Electromagnetics: Lithosphere-Atmosphere-Ionosphere Coupling. Editors M. Hayakawa and O. A. Molchanov (Tokyo: TERRAPUB), 173-176.

Tronin, A. A., Hayakawa, M., and Molchanov, O. A. (2002b). Thermal IR Satellite Data Application for Earthquake Research in Japan and China. J. Geodynamics 33 (4-5), 519-534. doi:10.1016/S0264-3707(02)00013-3

Tronin, A. A. (1996). Satellite thermal Survey-A New Tool for the Study of Seismoactive Regions. Int. J. Remote Sensing 17 (8), 1439-1455. doi:10.1080/ 01431169608948716

Trugman, D. T., and Ross, Z. E. (2019). Pervasive Foreshock Activity across Southern California. Geophys. Res. Lett. 46 (15), 8772-8781. doi:10.1029/ 2019GL083725

Tsai, Y. Ben., Liu, J. Y., Ma, K. F., Yen, H. Y., Chen, K. S., Chen, Y. I., et al. (2006). Precursory Phenomena Associated with the 1999 Chi-Chi Earthquake in Taiwan as Identified under the iSTEP Program. Phys. Chem. Earth 31 (4-9), 365-377. doi:10.1016/j.pce.2006.02.035

Tse, S. T., and Rice, J. R. (1986). Crustal Earthquake Instability in Relation to the Depth Variation of Frictional Slip Properties. J. Geophys. Res. 91 (B9), 9452. doi:10.1029/jb091ib09p09452

Tsukuda, T. (1997). Sizes and Some Features of Luminous Sources Associated with the 1995 Hyogo-Ken Nanbu Earthquake. J. Phy. Earth 45 (2), 73-82. doi:10.4294/ jpe1952.45.73

Tsunogai, U., and Wakita, H. (1995). Precursory Chemical Changes in Ground Water: Kobe Earthquake, Japan. Science 269 (5220), 61-63. doi:10.1126/ science.269.5220.61

Turcotte, D. L. (1991). Earthquake Prediction. Annu. Rev. Earth Planet. Sci. 19 (1), 263-281. doi:10.1146/annurev.ea.19.050191.001403

Tzanis, A., and Vallianatos, F. (2002). "A Physical Model of Electrical Earthquake Precursors Due to Crack Propagation and the Motion of Charged Edge Dislocations," in Seismo Electromagnetics: Lithosphere-AtmosphereIonosphere Coupling. Editors M. Hayakawa and O. A. Molchanov (Tokyo: TERRAPUB), 117-130.

Uyeda, S., Kamogawa, M., and Tanaka, H. (2009a). Analysis of Electrical Activity and Seismicity in the Natural Time Domain for the Volcanic-Seismic Swarm Activity in 2000 in the Izu Island Region, Japan. J. Geophys. Res. Solid Earth 114 (2). doi:10.1029/2007JB005332

Uyeda, S., Nagao, T., and Kamogawa, M. (2009b). Short-term Earthquake Prediction: Current Status of Seismo-Electromagnetics. Tectonophysics 470 (3-4), 205-213. doi:10.1016/j.tecto.2008.07.019 
Vallianatos, F., Triantis, D., Tzanis, A., Anastasiadis, C., and Stavrakas, I. (2004). Electric Earthquake Precursors: From Laboratory Results to Field Observations. Phys. Chem. Earth 29 (4-9), 339-351. doi:10.1016/j.pce.2003.12.003

Vallianatos, F., and Tzanis, A. (1999). On Possible Scaling Laws between Electric Earthquake Precursors (EEP) and Earthquake Magnitude. Geophys. Res. Lett. 26 (13), 2013-2016. doi:10.1029/1999GL900406

van den Ende, M. P. A., and Ampuero, J. P. (2020). On the Statistical Significance of Foreshock Sequences in Southern California. Geophys. Res. Lett. 47 (3), e2019GL086224. doi:10.1029/2019GL086224

Varotsos, P. A., Sarlis, N. V., and Skordas, E. S. (2003b). Electric fields that "Arrive" before the Time Derivative of the Magnetic Field Prior to Major Earthquakes. Phys. Rev. Lett. 91 (14), 148501. doi:10.1103/PhysRevLett.91.148501

Varotsos, P. A., Sarlis, N. V., Skordas, E. S., and Lazaridou, M. S. (2008). Fluctuations, under Time Reversal, of the Natural Time and the Entropy Distinguish Similar Looking Electric Signals of Different Dynamics. J. Appl. Phys. 103 (1), 014906. doi:10.1063/1.2827363

Varotsos, P. A., Sarlis, N. V., and Skordas, E. S. (2002). Long-range Correlations in the Electric Signals that Precede Rupture. Phys. Rev. E - Stat. Phys. Plasmas Fluids Relat. Interdiscip. Top. 66 (1), 011902. doi:10.1103/PhysRevE.66.011902

Varotsos, P. A., Sarlis, N. V., and Skordas, E. S. (2003a). Long-range Correlations in the Electric Signals that Precede Rupture: Further Investigations. Phys. Rev. E Stat. Phys. Plasmas Fluids Relat. Interdiscip. Top. 67 (2), 13. doi:10.1103/ PhysRevE.67.021109

Varotsos, P. A., Sarlis, N. V., and Skordas, E. S. (2019). Phenomena Preceding Major Earthquakes Interconnected through a Physical Model. Ann. Geophysicae 37 (3), 315-324. doi:10.5194/angeo-37-315-2019

Varotsos, P. (1981). Seismic Electric Currents. Prakt. Akad. Athenon 56, 277-286.

Varshal, G. M., Sobolev, G. A., Barsukov, V. L., Koltsov, A. V., Kostin, B. I., Kudinova, T. F., et al. (1984). Separation of Volatile Components from Rocks under Mechanical Loading as the Source of Hydrogeochemical Anomalies Preceding Earthquakes - Results of a Large-Scale Model experiment. Pure Appl. Geophys. PAGEOPH 122 (2-4), 463-477. doi:10.1007/BF00874612

Vershinin, E. F., Buzevich, A. V., Yumoto, K., Saita, K., and Tanaka, Y. (1999). "Correlations of Seismic Activity with Electromagnetic Emissions and Variations in Kamchatka Region," in Atmospheric and Ionospheric Electromagnetic Phenomena Associated with Earthquakes. Editor M. Hayakawa (Terra Scientific Publishing Company), 513-517.

Virk, H. S., Walia, V., and Kumar, N. (2001). Helium/radon Precursory Anomalies of Chamoli Earthquake, Garhwal Himalaya, India. J. Geodynamics 31 (2), 201-210. doi:10.1016/S0264-3707(00)00022-3

Wakita, H., Nakamura, Y., Notsu, K., Noguchi, M., and Asada, T. (1980). Radon Anomaly: A Possible Precursor of the 1978 Izu-Oshima-Kinkai Earthquake. Science 207 (4433), 882-883. doi:10.1126/science.207.4433.882

Wakita, H., Nakamura, Y., and Sano, Y. (1985). Groundwater Radon Variations Reflecting Changes in Regional Stress Fields. Practical Approaches to Earthquake Prediction and Warning. (Netherlands: Springer), 545-557. doi:10.1007/978-94-017-2738-9_19

Warwick, J. W., Stoker, C., and Meyer, T. R. (1982). Radio Emission Associated with Rock Fracture: Possible Application to the Great Chilean Earthquake of May 22, 1960. J. Geophys. Res. 87 (B4), 2851-2859. doi:10.1029/ JB087iB04p02851

Weiyu, M., Xuedong, Z., Liu, J., Yao, Q., Zhou, B., Yue, C., et al. (2018). Influences of Multiple Layers of Air Temperature Differences on Tidal Forces and Tectonic Stress before, during and after the Jiujiang Earthquake. Remote Sensing Environ. 210, 159-165. doi:10.1016/j.rse.2018.03.003

West, D. J. (1948). A Mass Observation Questionnaire on Hallucinations. J. Soc. Psychical Res. 34 (644-645), 187-195.

Whitehead, N. E., and Ulusoy, Ü. (2015). Origin of Earthquake Light Associated with Earthquakes in Christchurch, New Zealand, 2010-2011. Earth Sci. Res. J. 19 (2), 113-120. doi:10.15446/esrj.v19n2.47000

Wikelski, M., Mueller, U., Scocco, P., Catorci, A., Desinov, L. V., Belyaev, M. Y., et al. (2020). Potential Short-Term Earthquake Forecasting by Farm Animal Monitoring. Ethology 126 (9), 931-941. doi:10.1111/eth.13078

Woith, H., Petersen, G. M., Hainzl, S., and Dahm, T. (2018). Review: Can Animals Predict Earthquakes? Bull. Seismological Soc. America 108 (3A), 1031-1045. doi:10.1785/0120170313

Wright, T. J. (2016). The Earthquake Deformation Cycle. Astron. Geophys. 57 (4), 4.20-4.26. doi:10.1093/astrogeo/atw148
Wu, H. (2007). AGU Fall Meeting Abstracts, S13B-S1302.Jet Stream Converges Prior to 6.8 M Niigata Chuetsu-Oki Earthquake of Japan on 2007/07/162007

Wu, L. Q., and Dickman, J. D. (2012). Neural Correlates of a Magnetic Sense. Science 336 (6084), 1054-1057. doi:10.1126/science.1216567

Wu, L., Zheng, S., De Santis, A., Qin, K., Di Mauro, R., Liu, S., et al. (2016). Geosphere Coupling and Hydrothermal Anomalies before the 2009 Mw 6.3 L'Aquila Earthquake in Italy. Nat. Hazards Earth Syst. Sci. 16 (8), 1859-1880. doi:10.5194/nhess-16-1859-2016

Wyss, M. (1997). Cannot Earthquakes Be Predicted? Science 278 (5337), 487-490. doi:10.1126/science.278.5337.487

Wyss, M., and Dmowska, R. (1997). Earthquake Prediction - State of the Art. Pure and Applied Geophysics, Vol. 149 Issue 1. (Pure and Applied Geophysics (PAGEOPH)).

Xiong, P., Long, C., Zhou, H., Battiston, R., Zhang, X., and Shen, X. (2020). Identification of Electromagnetic Pre-earthquake Perturbations from the Demeter Data by Machine Learning. Remote Sensing 12 (21), 1-27. doi:10.3390/rs12213643

Xiong, P., Tong, L., Zhang, K., Shen, X., Battiston, R., Ouzounov, D., et al. (2021). Towards Advancing the Earthquake Forecasting by Machine Learning of Satellite Data. Sci. Total Environ. 771, 145256. doi:10.1016/j.scitotenv.2021.145256

Xu, G., Han, P., Huang, Q., Hattori, K., Febriani, F., and Yamaguchi, H. (2013). Anomalous Behaviors of Geomagnetic Diurnal Variations Prior to the 2011 off the Pacific Coast of Tohoku Earthquake (Mw9.0). J. Asian Earth Sci. 77, 59-65. doi:10.1016/j.jseaes.2013.08.011

Yamauchi, H., Hayakawa, M., Asano, T., Ohtani, N., and Ohta, M. (2017). Statistical Evaluations of Variations in Dairy Cows' Milk Yields as a Precursor of Earthquakes. Animals 7 (3), 19. doi:10.3390/ani7030019

Yamauchi, H., Uchiyama, H., Ohtani, N., and Ohta, M. (2014). Unusual Animal Behavior Preceding the 2011 Earthquake off the pacific Coast of Tohoku, Japan: A Way to Predict the Approach of Large Earthquakes. Animals 4 (2), 131-145. doi:10.3390/ani4020131

Yan, R., Guan, Y., Shen, X., Huang, J., Zhang, X., Liu, C., et al. (2018). The Langmuir Probe Onboard CSES: Data Inversion Analysis Method and First Results. Earth Planet. Phys. 2 (6), 1-10. doi:10.26464/epp2018046

Yan, R., Parrot, M., and Pinçon, J. L. (2017). Statistical Study on Variations of the Ionospheric Ion Density Observed by DEMETER and Related to Seismic Activities. J. Geophys. Res. Space Phys. 122 (12), 12421-12429. doi:10.1002/ 2017JA024623

Yan, Z., Chunli, K., Weiyu, M., and Qi, Y. (2017). The Change in Outgoing Longwave Radiation before the Ludian Ms6. 5 Earthquake Based on Tidal Force Niche Cycles. Earthquake Res. China 3, 422-430.

Yang, S. S., Asano, T., and Hayakawa, M. (2019). Abnormal Gravity Wave Activity in the Stratosphere Prior to the 2016 Kumamoto Earthquakes. J. Geophys. Res. Space Phys. 124 (2), 1410-1425. doi:10.1029/2018JA026002

Yasui, Y. (1968). A Study on the Luminous Phenomena Accompanied with Earthquake (Part I). Mem. Kakioka Magnet. Observ. 13, 25-61.

Yasuoka, Y., Igarashi, G., Ishikawa, T., Tokonami, S., and Shinogi, M. (2006). Evidence of Precursor Phenomena in the Kobe Earthquake Obtained from Atmospheric Radon Concentration. Appl. Geochem. 21 (6), 1064-1072. doi:10.1016/j.apgeochem.2006.02.019

Yokoi, S., Ikeya, M., Yagi, T., and Nagai, K. (2003). Mouse Circadian Rhythm before the Kobe Earthquake in 1995. Bioelectromagnetics 24 (4), 289-291. doi:10.1002/bem.10108

Yosef, R. (1997). Reactions of Birds to an Earthquake. Bird Study 44 (1), 123-124. doi:10.1080/00063659709461047

Zafrir, H., Ginzburg, B., Hrvoic, I., Shirman, B., Gazit-Yaari, N., Steinitz, G., and Wilson, M. (2003). "Ultra Sensitive Monitoring of the Geomagnetic Field Combined with Radon Emanation as a Tool for Studying Earthquake Related Phenomena," in AGU Fall Meeting Abstracts, San Francisco, T51E-T0206.

Zakharenkova, I. E., Shagimuratov, I. I., Tepenitzina, N. Y., and Krankowski, A. (2008). Anomalous Modification of the Ionospheric Total Electron Content Prior to the 26 September 2005 Peru Earthquake. J. Atmos. Solar-Terrestrial Phys. 70 (15), 1919-1928. doi:10.1016/j.jastp.2008.06.003

Zavarsky, A., Booge, D., Fiehn, A., Krüger, K., Atlas, E., and Marandino, C. (2018). The Influence of Air-Sea Fluxes on Atmospheric Aerosols during the Summer Monsoon over the Tropical Indian Ocean. Geophys. Res. Lett. 45 (1), 418-426. doi:10.1002/2017GL076410 
Zhang, X., Kang, C., Ma, W., Ren, J., and Wang, Y. (2018). Study on thermal Anomalies of Earthquake Process by Using Tidal-Force and Outgoing-LongwaveRadiation. Therm. Sci. 22 (2), 767-776. doi:10.2298/TSCI161229153Z

Zhang, X., Shen, X., Zhao, S., Yao, L., Ouyang, X., and Qian, J. (2014). The Characteristics of Quasistatic Electric Field Perturbations Observed by DEMETER Satellite before Large Earthquakes. J. Asian Earth Sci. 79 (PA), 42-52. doi:10.1016/j.jseaes.2013.08.026

IZhang, X., Zeren, Z., Parrot, M., Battiston, R., Qian, J., and Shen, X. (2011). ULF/ ELF Ionospheric Electric Field and Plasma Perturbations Related to Chile Earthquakes. Adv. Space Res. 47 (6), 991-1000. doi:10.1016/j.asr.2010.11.001

Zhang, X., Zhao, S., Song, R., and Zhai, D. (2019). The Propagation Features of LF Radio Waves at Topside Ionosphere and Their Variations Possibly Related to Wenchuan Earthquake in 2008. Adv. Space Res. 63 (11), 3536-3544. doi:10.1016/j.asr.2019.02.008

Zhang, Y., Feng, W. P., Xu, L. S., Zhou, C. H., and Chen, Y. T. (2009). Spatiotemporal Rupture Process of the 2008 Great Wenchuan Earthquake. Sci. China, Ser. D: Earth Sci. 52 (2), 145-154. doi:10.1007/s11430-008-0148-7

Zhang, Y., and Meng, Q. (2019). A Statistical Analysis of TIR Anomalies Extracted by RSTs in Relation to an Earthquake in the Sichuan Area Using MODIS LST Data. Nat. Hazards Earth Syst. Sci. 19 (3), 535-549. doi:10.5194/nhess-19-5352019

Zhang, Y., Meng, Q., Ouillon, G., Zhang, L., Hu, D., Ma, W., et al. (2021). Longterm Statistical Evidence Proving the Correspondence between Tir Anomalies and Earthquakes Is Still Absent. Eur. Phys. J. Spec. Top. 230 (1), 133-150. doi:10.1140/epjst/e2020-000248-4

Zhang, Y. S., Guo, X., Zhong, M. J., Shen, W. R., Li, W., and He, B. (2010). Wenchuan Earthquake: Brightness Temperature Changes from Satellite
Infrared Information. Chin. Sci. Bull. 55 (18), 1917-1924. doi:10.1007/ s11434-010-3016-8

Zhao, B., Wang, M., Yu, T., Wan, W., Lei, J., Liu, L., et al. (2008). Is an Unusual Large Enhancement of Ionospheric Electron Density Linked with the 2008 Great Wenchuan Earthquake? J. Geophys. Res. Space Phys. 113 (11), 11304. doi:10.1029/2008JA013613

Zheng, S., Qin, K., Wu, L., An, Y., Yin, Q., and Lai, C. (2020). Hydrothermal Anomalies of the Earth's Surface and Crustal Seismicity Related to Ms8.0 Wenchuan EQ. Nat. Hazards 104 (3), 2097-2114. doi:10.1007/s11069-020-04263-7

Zhu, K., Li, K., Fan, M., Chi, C., and Yu, Z. (2019). Precursor Analysis Associated with the Ecuador Earthquake Using Swarm A and C Satellite Magnetic Data Based on PCA. IEEE Access 7, 93927-93936. doi:10.1109/ACCESS.2019.2928015

Zlotnicki, J., and Cornet, F. H. (1986). A Numerical Model of Earthquake-Induced Piezomagnetic Anomalies. J. Geophys. Res. 91 (B1), 709-718. doi:10.1029/ JB091iB01p00709

Conflict of Interest: The authors declare that the research was conducted in the absence of any commercial or financial relationships that could be construed as a potential conflict of interest.

Copyright (c) 2021 Conti, Picozza and Sotgiu. This is an open-access article distributed under the terms of the Creative Commons Attribution License (CC $B Y$ ). The use, distribution or reproduction in other forums is permitted, provided the original author(s) and the copyright owner(s) are credited and that the original publication in this journal is cited, in accordance with accepted academic practice. No use, distribution or reproduction is permitted which does not comply with these terms. 